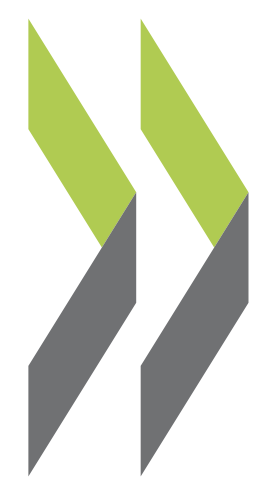

OECD Social, Employment and Migration Working Papers No. 67

The Dynamics of Social Assistance Receipt: Measurement and Modelling Issues, with an Application

\title{
Lorenzo Cappellari,
} to Britain 
The Dynamics of Social Assistance Receipt:

Measurement and Modelling Issues, with an Application to Britain 
Organisation de Coopération et de Développement Économiques

Organisation for Economic Co-operation and Development

01-Oct-2008

DIRECTORATE FOR EMPLOYMENT, LABOUR AND SOCIAL AFFAIRS

English text only EMPLOYMENT, LABOUR AND SOCIAL AFFAIRS COMMITTEE

OECD SOCIAL, EMPLOYMENT AND MIGRATION WORKING PAPERS NO. 67

THE DYNAMICS OF SOCIAL ASSISTANCE RECEIPT:

MEASUREMENT AND MODELLING ISSUES, WITH AN APPLICATION TO BRITAIN

Lorenzo Cappellari and Stephen P. Jenkins

JEL Classification: 138, C33, C35

All Social, Employment and Migration Working papers are now available through OECD's Internet website at http://www.oecd.org/els 


\title{
DIRECTORATE FOR EMPLOYMENT, LABOUR AND SOCIAL AFFAIRS
}

\author{
http://www.oecd.org/els
}

\section{OECD SOCIAL, EMPLOYMENT AND MIGRATION WORKING PAPERS}

\author{
http://www.oecd.org/els/workingpapers
}

This series is designed to make available to a wider readership selected labour market, social policy and migration studies prepared for use within the OECD. Authorship is usually collective, but principal writers are named. The papers are generally available only in their original language - English or French - with a summary in the other.

Comment on the series is welcome, and should be sent to the Directorate for Employment, Labour and Social Affairs, 2, rue André-Pascal, 75775 PARIS CEDEX 16, France.

The opinions expressed and arguments employed here are the responsibility of the author(s) and do not necessarily reflect those of the OECD

\author{
Applications for permission to reproduce or translate \\ all or part of this material should be made to: \\ Head of Publications Service \\ OECD \\ 2, rue André-Pascal \\ 75775 Paris, CEDEX 16 \\ France
}

Copyright OECD 2008 


\begin{abstract}
We model the dynamics of social assistance benefit receipt in Britain using data from the British Household Panel Survey, waves 1-15. First, we discuss definitions of social assistance benefit receipt, and present information about the trends between 1991 and 2005 in the receipt of social assistance benefits, and in annual rates of transition into and out of receipt. Second, we review potential multivariate modelling approaches especially the dynamic random effects probit models that are used in our empirical analysis and, third, discuss sample selection criteria and explanatory variables. Fourth, we present our regression estimation estimates and interpret them. The final section contains a summary of the substantive results, and highlights some lessons concerning application of the analysis for other countries and some methodological issues.
\end{abstract}




\section{ACKNOWLEDGEMENTS}

Research commissioned by the OECD under contract JA00045191. We thank Thomas Andrén, Martin Biewen, Jürgen Hansen, Herwig Immervoll, Chris Orme, Lucinda Platt, and Mark Stewart for helpful comments, and Alfonso Miranda for allowing us to use his Stata programs.

\section{Correspondence}

Cappellari: Istituto di Economia dell'Impresa e del Lavoro, Università Cattolica di Milano, Largo Gemelli 1, 20123 Milano, Italy. Email: Iorenzo.cappellari@unicatt.it

Jenkins: Institute for Social and Economic Research, University of Essex, Colchester, Essex CO4 3SQ, United Kingdom. Email: stephenj dessex.ac.uk. 


\section{EXECUTIVE SUMMARY}

There is interest in learning about the factors associated with the chances of moving into receipt or of moving off receipt of social assistance benefit ('SA'), and in comparing these dynamics across countries. To address this topic, there are a number of definitional issues that need to be resolved, and there are a number of different multivariate statistical modelling approaches that may be employed to summarize the relationship between social assistance receipt and the characteristics of recipients. There are also important data issues. This paper is a form of 'demonstration study'. It not only models the dynamics of social assistance benefit receipt in Britain using data from the British Household Panel Survey, waves 1-15, but also includes extensive discussion of definitional, data, and modelling issues that are relevant for other studies of SA receipt dynamics in different countries.

For Britain, we find that the risk of receiving SA in one year is noticeably higher if SA was also received in the previous year, even after controlling for observed and unobserved differences in characteristics. This might be interpreted as a state dependence or scarring effect of SA receipt, but such an interpretation requires caution particularly because it suggests that there is a single effect for all individuals. By contrast, we show for example that SA persistence rates are higher for lone parents than for other groups.

Compared to previous studies, we give much attention to trends over time in SA transition rates. We show that there was a clear decline in Britain over the last 15 years in the average SA annual entry rate (from above $4 \%$ to below $2 \%$ ), and there was also rise in the average SA annual persistence rate from around $60 \%$ to nearly $75 \%$. According to the model estimates, the key distinction was between the period before 1998 and the period thereafter, which is somewhat of a puzzle since the timing does not closely correspond with the introduction of one of New Labour's major policy reforms to the social security system. We also point out how changes in the characteristics of the populations at risk of entering and of remaining in SA receipt affected the overall SA entry and persistence rates. Factors such as the secular rise in educational qualifications and the decline in local unemployment rates would have reduced the entry rate. The growing concentration of individuals living in social housing among SA recipients was associated with the declining SA exit rates.

Among definitional issues, we consider the definition of SA itself and its component income sources, the unit of SA receipt, and the reference period over which receipt is measured. We stress that the choices that are feasible in the context of empirical analysis will depend on the specific country considered and on the data sources available. We compare panel data derived from household panel surveys with data derived from administrative records. A related point is that the key points of analytical interest concerning SA receipt dynamics may differ across countries. For example, with our long run of panel data we focused on trends over time in Britain in transition probabilities, but note that issues such as differences between nonimmigrant citizens and immigrants - which may be of great interest - could not be addressed using our data source.

With respect to methods, we compare the relative merits of several multivariate regression modelling approaches. We use 'dynamic random effects probit' models in our application, and contribute to a growing econometric literature on the properties of different estimators for such models. We also emphasize caution in interpretation our findings. These are largely descriptive and point to associations that are indicative but not conclusive regarding causation. A full-blown analysis of the impact of particular policies or policy changes requires a different type of study than this one. We also point to potential extensions to the modelling approach, for example to incorporate feedback effects: some factors may not only affect SA receipt chances, but also be affected by them. 


\section{RÉSUMÉ}

Il est intéressant de s'interroger sur les facteurs associés à la probabilité d'accès aux prestations d'aide sociale, ou de sortie des prestations d'aide sociale, et de comparer les dynamiques selon les pays. Dans cette perspective, il y a plusieurs problèmes de définition à résoudre et différentes approches de modélisation statistique multivariée peuvent s'envisager pour synthétiser la relation entre le recours à l'aide sociale et les caractéristiques des bénéficiaires. Se posent aussi des problèmes de données. Cette étude est une sorte de "tentative de démonstration». Non seulement elle modélise la dynamique du recours à l'aide sociale en Grande-Bretagne, en exploitant les données provenant de l'enquête British Household Panel Survey, vagues 1-15, mais elle traite aussi de façon approfondie des problèmes de définition, de données et de modélisation que posent d'autres études de la dynamique du recours à l'aide sociale dans différents pays.

En Grande-Bretagne, nous constatons que le risque de percevoir l'aide sociale au cours d'une année donnée est nettement supérieur si l'intéressé percevait déjà l'aide sociale l'année précédente, même si l'on tient compte des différences observées et non observées dans les caractéristiques. Cela pourrait s'interpréter comme un effet de dépendance d'état ou de stigmatisation du recours à l'aide sociale, mais il faut s'engager avec prudence sur la voie d'une telle interprétation, en particulier parce qu'elle donne à penser qu'il y aurait un effet unique pour tous les individus. Or nous montrons, par exemple, que le recours persistant à l'aide sociale est plus fréquent pour les parents isolés que pour les autres catégories.

Par rapport aux précédentes études, cette étude fait une large place à l'analyse de l'évolution dans le temps des taux de transition au regard de l'aide sociale. Nous mettons en évidence un net recul du taux annuel moyen d'entrée dans l'aide sociale, en Grande-Bretagne, au cours des 15 dernières années (celui-ci passant de plus de $4 \%$ à moins de $2 \%$ ), et une augmentation du taux annuel moyen de persistance dans l'aide sociale, qui passe d'environ $60 \%$ à près de $75 \%$. D'après les estimations du modèle, la ligne de partage serait entre la période antérieure à 1998 et la période postérieure à cette date, ce qui est quelque peu surprenant car cela ne coïncide pas exactement avec l'introduction de l'une des grandes réformes du New Labour dans le système de sécurité sociale. Nous examinons aussi comment les changements dans les caractéristiques des publics risquant d'entrer et de rester dans l'aide sociale affectent les taux globaux d'entrée et de persistance dans l'aide sociale. Des facteurs tels que la hausse tendancielle du niveau d'éducation et le recul des taux de chômage locaux auraient réduit le taux d'entrée. La concentration croissante des personnes vivant dans des logements sociaux parmi les bénéficiaires de l'aide sociale a pu être mise en relation avec le recul des taux de sortie de l'aide sociale.

En ce qui concerne les questions de définition, nous examinons la question de la définition de l'aide sociale proprement dite et des sources de revenu qui la composent, de l'unité de perception de l'aide sociale et de la période de référence sur laquelle le recours à l'aide sociale est mesuré. Nous soulignons que les choix possibles dans le contexte d'une analyse empirique dépendent du pays étudié et des sources de données disponibles. Nous comparons les données de panel provenant d'enquêtes auprès des ménages et les données provenant de registres administratifs. Nous observons aussi que les aspects clés de l'analyse de la dynamique du recours à l'aide sociale peuvent différer selon les pays. Par exemple, nous appuyant sur des séries longues de données de panel, nous avons pu examiner l'évolution dans le temps des probabilités de transition par rapport à l'aide sociale en Grande-Bretagne, mais nous observons que des questions comme les différences entre la population locale et la population immigrée - qui pourraient présenter un grand intérêt — ne peuvent pas être examinées sur la base de notre source de données.

S'agissant de la méthode, nous comparons les avantages relatifs de plusieurs approches de modélisation à l'aide de régressions multivariées. Nous appliquons des modèles Probit dynamiques à effets 
aléatoires et apportons ainsi notre contribution à une littérature économétrique de plus en plus fournie sur les propriétés des différents estimateurs de ces modèles. Nous soulignons aussi qu'il faut être prudent dans l'interprétation des résultats. Ceux-ci sont largement descriptifs et signalent des associations qui ont valeur indicative mais qui ne permettent pas de conclure à une relation causale. Une analyse à part entière de l'impact de telle ou telle mesure ou de telle ou telle modification dans les politiques nécessite un autre type d'étude que celle qui est présentée ici. Nous évoquons aussi des extensions possibles de la modélisation pour, par exemple, intégrer des effets en retour : certains facteurs peuvent affecter la probabilité du recours à l'aide sociale mais peuvent eux-mêmes être impactés. 


\section{TABLE OF CONTENTS}

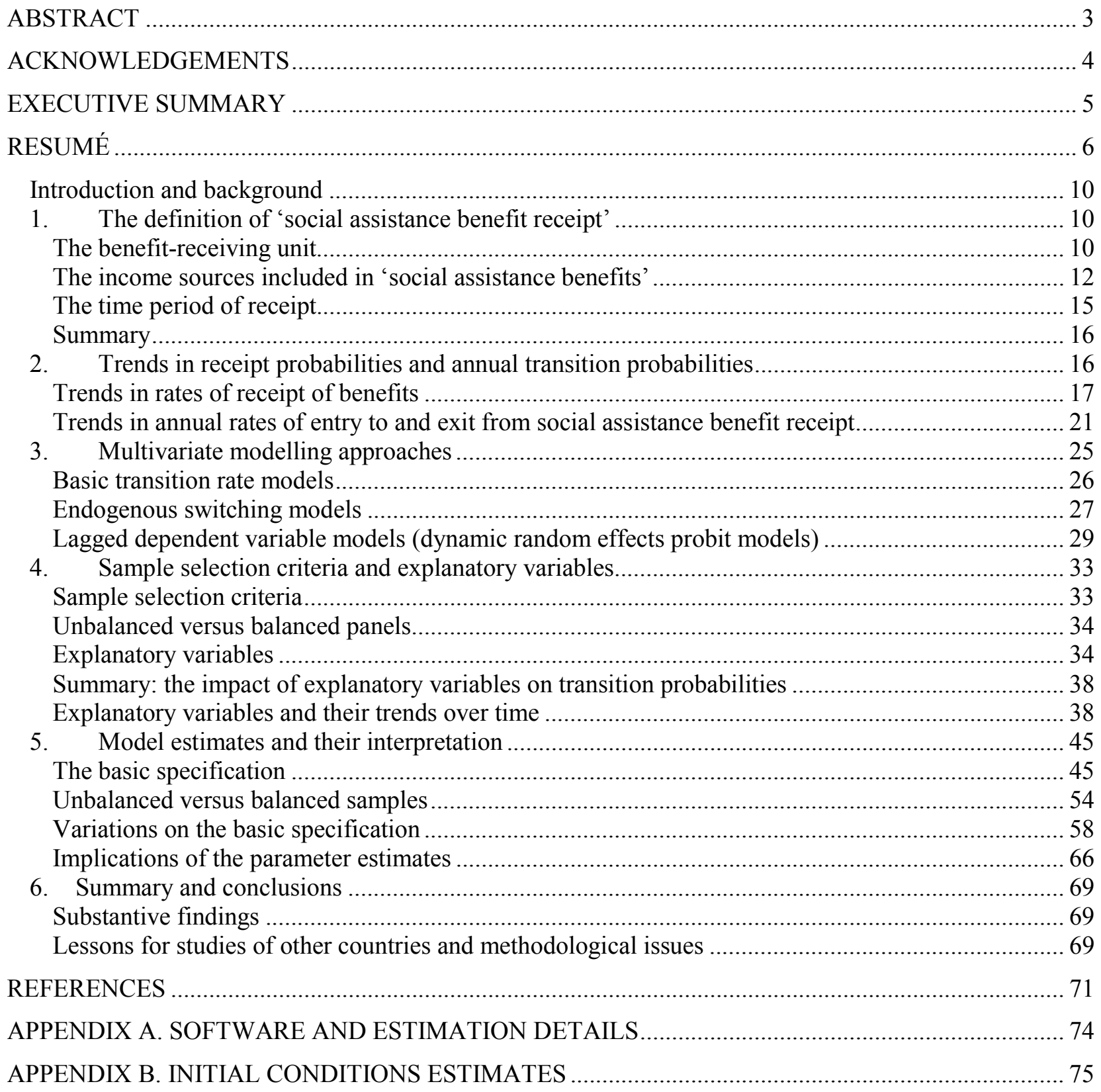




\section{Tables}

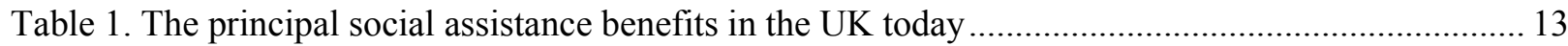

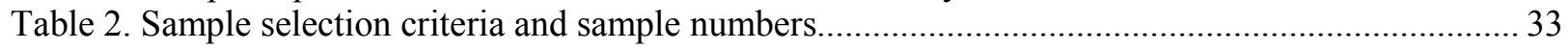

Table 3. Explanatory variables, means by survey year ......................................................................... 41

Table 4. Dynamic effects probit models of the probability of receipt of SA at year $t$ interview .............. 48

Table 5. The probability of SA receipt at $t=1$ (initial conditions) ….................................................. 52

Table 6. Dynamic effects probit models of the probability of receipt of SA at year $t$ survey interview ... 55

Table 7. Dynamic random effects probit models of the probability of receipt of SA at year $t$ survey interview (Heckman estimator), with interactions between lagged benefit receipt status, survey year, and

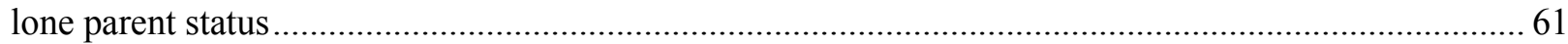

Table 8. Predicted 'Boskin-Nold' steady-state SA transition probabilities and related statistics for

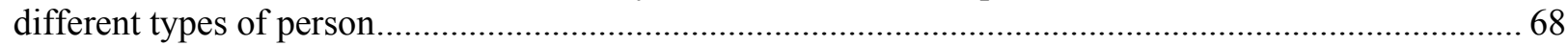

Table B1. The probability of SA receipt at $\mathrm{t}=1$ (initial conditions): basic specification........................ 75

Table B2. The probability of SA receipt at $t=1$ (initial conditions): specifications including with interactions between lagged receipt, survey year, and lone parent status ............................................. 78

\section{Figures}

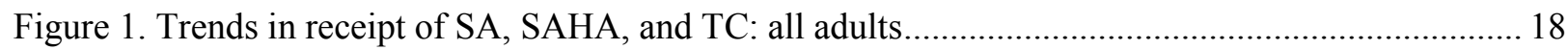

Figure 2. Trends in receipt of SA, SAHA, and TC: couples without children ....................................... 19

Figure 3. Trends in receipt of SA, SAHA, and TC: couples with children .......................................... 19

Figure 4. Trends in receipt of SA, SAHA, and TC: lone parents.......................................................... 20

Figure 5. Trends in receipt of SA, SAHA, and TC: single adults ........................................................... 20

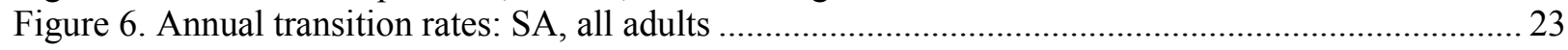

Figure 7. Annual transition rates: SA, couples without children ........................................................ 23

Figure 8. Annual transition rates: SA, couples with children............................................................. 24

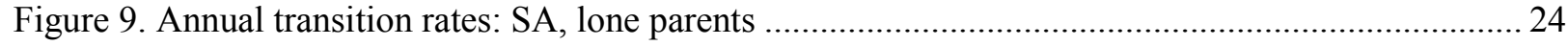

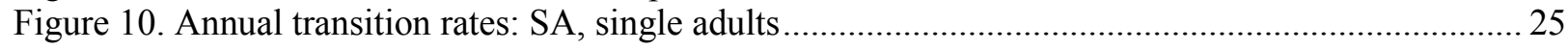




\section{Introduction and background}

1. The Social Policy Division of the OECD has commissioned us "[t]o prepare a paper on the Dynamics of Receipt of Social Assistance Benefits in the United Kingdom. The analysis is to be based on panel data for the UK. One purpose of the paper is to serve as a basis for similar, but independent, studies for other countries. It is expected that this objective will be taken into account in setting out the modelling approach and discussing conceptual and data-related issues."

2. In Section 1, we discuss the definition of 'receipt of social assistance benefits', and explain what is possible to measure using the British Household Panel Survey (BHPS). In Section 2, we report trends between 1991 and 2005 in the receipt of social assistance benefits in Britain, and in annual rates of transition into and out of receipt. We provide an outline of potential approaches to the multivariate modelling of the dynamics of receipt in Section 3, focusing on the dynamic binary random effects probit models that have been employed in similar analysis for Sweden and for Canada. Sample selection criteria and explanatory variables are discussed in Section 4. We also summarize trends in explanatory variables over the period. In Section 5, we present the estimates of a series of multivariate regression models, and interpret them in relation to the evidence about trends. We summarize the implications of the estimates in terms of a series of the transition probabilities and expected spell lengths for individuals with different sets of characteristics. Section 6 contains a summary of the substantive results and highlights some lessons for applications of the analysis to other countries and some methodological issues. Appendix A provides details about the software used and alternatives considered. Appendix B contains additional estimation results, supplementing those reported in the main text.

3. The focus throughout is on individuals of working age. More specifically, we consider only individuals below the age of 60. (The state retirement pension age in Britain is 60 for woman and 65 for men.) To avoid complications associated with education and training we also exclude individuals aged less than 25, or individuals in benefit units in which there are any adults of working age who are full-time students.

\section{The definition of 'social assistance benefit receipt'}

4. Any empirical analysis of the dynamics of social assistance receipt requires definitions for three components:

- The benefit-receiving unit

- The income sources included in 'social assistance benefits'

- The time period over which the benefit(s) are received.

We discuss these in turn.

\section{The benefit-receiving unit}

5. In Britain, the assessment of eligibility for benefits is based on the income of the 'benefit unit'. This unit is essentially the nuclear family, referring to a single person or a couple living together with or without dependent children. A dependent child is aged less than 16 years, or more than 16 years but under 19 years and unmarried, in full-time non-advanced education and living with his/her parents. For brevity, we shall simply refer to children rather than dependent children. The benefit unit differs from the 'household'. A household may contain several benefit units. Examples of this are a non-dependent child 
living with his parents (two benefit units), or three single adults sharing a house (three benefit units). Among persons of working age, there are four main 'client groups' of benefit units: couples with one or more children, couples without children, single adults with one or more children (lone parent families), and single adults.

6. Although only one individual within a benefit unit is the benefit claimant, the family-based means test means that all the individuals within a benefit unit are assumed by the benefit system to gain from the income provided by a social security benefit. That is, there are multiple recipients within each benefit unit (other than within single adult benefit units).

7. Benefit units cannot be followed over time in any consistent manner. Benefit units change composition over time as individuals arrive (e.g. via birth of a child or marriage) or depart (e.g. via a child becoming non-dependent or leaving home, death or divorce). And these types of change are common (see e.g. Jenkins 2000). Thus one can only follow individuals over time, though of course one can characterise individuals in terms of their benefit unit's characteristics including receipt status at a given point in time.

8. There are, however, practical issues for empirical analysis concerning the tracking of recipient and non-recipient individuals over time. When modelling the dynamics of receipt of social assistance, should each benefit unit at a particular point in time be represented in the data set by one individual (and, if so, which one), or should there be as many observations as there are members of the benefit unit?

9. On the one hand, if one is interested in modelling persistence in receipt to learn about changes in the number of claimants over time, this suggests that one should focus on one individual per benefit unit, viz the claimant, in so far as he or she can be identified from the survey data, or another key individual such as the head of benefit unit (defined below). On the other hand, if one is interested in modelling persistence in receipt from a recipient perspective, this suggests that every member of a benefit unit should be represented in the data. The choice is complicated by the fact that a person may become a claimant or stop being a claimant separately from whether or not the person's benefit unit is in receipt. For example, consider a lone mother who is a benefit claimant (and in receipt) in year $t$. At $t+1$, she repartners with a man and it is he who is now the benefit claimant (and benefit unit head). He was also the head of a (separate) benefit unit in year $t$, though his benefit unit was not in receipt. The woman's receipt status has not changed, but her claimant status has. The man's receipt status has changed, but he has remained a benefit unit head and potential claimant. In the example described, a longitudinal data set should track both the woman and the man over time, and count her as remaining in receipt and him as moving into receipt. More generally, we believe that is the changes in receipt status rather than claimant status that are more relevant to analysis of benefit dynamics.

10. In sum, we track working-age adult individuals over time, and characterize each individual's receipt status at each point in time in terms of whether anyone in their benefit unit was receiving social assistance benefits at that time. We do not track dependent children over time as well on the grounds that they are dependent - their benefit receipt status at a particular time depends entirely on their parents. 'Children' are included in the analysis if and when they become non-dependent, i.e. adults in their right. In order to focus on receipt by persons of working age, we did not consider benefit units in which the respondent or spouse if present was aged more than 60 years or less than 25 years. We also excluded all individuals in benefit units in which any adult was a full-time student.

11. Our choice means that we have repeated observations from the same benefit unit at each interview, so introducing a lack of independence between observations. This means that parameter estimates in multivariate models may be subject to bias. Essentially the amount of information provided by the data is not as large as the nominal sample size suggests. However, it is unclear what the magnitude of the bias is likely to be. A similar issue arises in the modelling of individual unemployment dynamics where 
the estimation sample includes both men and women, though we have not seen the issue explicitly discussed. ${ }^{1}$ E.g. Stewart (2007) modelled men's and women's unemployment dynamics using BHPS data, and some of the men and women in his sample lived together in a marital partnership. Like Stewart, we ignore this complication.

12. Following adults over time is the most commonly-used practice in the literature to date, ${ }^{2}$ but there are subtle differences in practice between studies in terms of which adults are followed and in the definition of benefit receipt. Andrén (2007) analyzed social assistance dynamics using the Swedish Income Panel, a register-based panel data set based on a random sample of the Swedish working age population in 1990. He tracked individuals aged 18-50 years over time. Because the sample is of individuals rather than households, his data set does not include all the individuals from a given household in each year. So, although there is a household means-test for social assistance benefits in Sweden, the nature of the data means that Andrén defines receipt in terms of whether the sample person received social assistance at least once during a calendar year (i.e. not whether any person in the individual's household was in receipt). Hansen, Lofstrom, and Zhang (2006) used the Canadian Survey of Labour and Income Dynamics (SLID), a rotating panel to compare social assistance benefit dynamics across Canadian provinces. They state that each household is represented by one person at each point in time: 'the person selected by Statistics Canada as the response person' (p. 8), and a 'household is defined as a welfare participating household, in any given year, if any person belonging to the household received any social assistance at any time during that year' (p. 8). However, throughout their paper they refer to tracking households over time (note the model specification in their Section 5), and it is unclear how they treat the issue of household demographic change and potential changes in who is counted as a household response person (see the earlier discussion). Hansen and Lofstrom (2006) compared social assistance receipt dynamics for Swedish natives and immigrants using the Longitudinal Individual Data, a register-based data set consisting of a large panel of individuals, and their household members, which is representative of the Swedish population from 1960 to 2001. Analysis is of men and women between the ages of 18 and 65, excluding students and retired individuals, tracked between 1991 and 2001. However, it appears that benefit receipt is defined on an individual basis rather than household basis: 'a person as a welfare/UI recipient in a given year if he or she received welfare for at least a month and/or received more than one-half of the so-called "basic amount" ... in unemployment benefits during the year (2006, p. 9). Enberg, Gottschalk and Wolf, (1990) use administrative data from Wisconsin on receipt of Aid for Families with Dependent Children. (See also Boskin and Nold (1975).) Individual adults are followed over time. Receipt is defined on an individual rather than household basis, but this is appropriate because the benefit-recipient unit for AFDC was the individual (the programme targeted lone parents).

\section{The income sources included in 'social assistance benefits'}

13. Social assistance benefits are cash benefits paid to bring incomes up to some minimum income level - they refer to income maintenance. By contrast, social insurance benefits refer to income replacement. They are payments made in response to the occurrence of particular risky events such as sickness or unemployment and for which an appropriate record of social insurance contributions exists. (See e.g. the OECD Glossary of statistical terms used in the National Accounts at http://stats.oecd.org/glossary/detail.asp?ID=2478.)

1. The issue does not arise in the administrative record data sets for which only one individual is sampled per household.

2. One exception is our previous research on poverty dynamics (Cappellari and Jenkins, 2004) also based on analysis of the BHPS. We tracked all individuals (adults and children) over time. Another exception is Biewen's (2004) study of poverty dynamics, in which the fortunes of men aged between 18 and 65 years were tracked. 
14. According to these definitions, the principal social assistance benefits in Britain for people of working age are those shown in Table 1. For an overview of the British system of social security benefits and tax credits see:

http://www.direct.gov.uk/en/MoneyTaxAndBenefits/BenefitsTaxCreditsAndOtherSupport/BeginnersGuide ToBenefits/DG 10021385.

15. Income Support (IS) and income-based Job Seekers Allowance (JSA) differ from Housing Benefit (HB) and Council Tax Benefit (CTB) because receipt depends on employment status. Put differently, receipt of $\mathrm{HB}$ and $\mathrm{CTB}$ depends on income (and some other conditions), but not on employment or job-search status.

Table 1. The principal social assistance benefits in the UK today

\begin{tabular}{l|l}
\hline Benefit & Eligibility conditions (main) \\
\hline Income Support & $\begin{array}{l}\text { Income less than a specified minimum level, and unavailable for } \\
\text { full-time work (e.g. lone parent, registered sick or disabled, caring } \\
\text { for someone who's sick or elderly) }\end{array}$ \\
$\begin{array}{l}\text { Job Seekers Allowance } \\
\text { (income based) } \\
\text { Housing Benefit }\end{array}$ & $\begin{array}{l}\text { Income less than a specified minimum level, and unemployed } \\
\text { Incomancial help to pay all or part of one's housing costs } \\
\text { finand needing } \\
\text { Income less than a specified minimum level, and needing } \\
\text { financial help to pay all or part of one's Council Tax bill }\end{array}$ \\
\hline
\end{tabular}

Notes: Income Support was introduced in 1988 (its predecessor was called Supplementary Benefit). Housing Benefit was introduced in 1983 and Council Tax Benefit in 1993. Job Seekers Allowance was introduced in 1996. See the main text for further discussion.

16. Arguably, according to the definitions above, in-work benefits (notably Working Tax Credit at present) might also be counted as providing social assistance benefits because no national insurance contribution record is required for receipt and one of the principal eligibility conditions relates to having an income below a specified minimum level. ${ }^{3}$ (The other main requirement is to have a family member in fulltime work - at least 16 hours per week.) Against this argument for counting tax credits as social assistance is that one of the key ideas underlying the substantial extension of tax credits by the Labour government since 1998 is that tax credits are not 'welfare benefits' - they are a key plank in Labour's 'welfare to work' programme (note the wording). Reflecting this, tax credits are administered by HM Revenue and Customs, the government department that administers income taxation and national insurance contributions, rather than by the Department for Work and Pensions (which administers IS and JSA). ${ }^{4}$

17. Thus, the current UK government places greater weight on the distinction between benefits available to families with one or more individuals in paid work and benefits available to families without individuals in paid work, than on the classic distinction between social assistance and social insurance

3. The UK has had means-tested in-work benefit programmes for low-income working families with children since 1971, when Family Income Supplement (FIS) was introduced. There have been major increases in generosity and changes to eligibility conditions since then that have led to substantial expansion of receipt. In particular, FIS became Family Credit (FC) in 1988. FC was replaced by Working Families Tax Credit (WFTC) in October 1999 and fully phased in by April 2000. WFTC was replaced by the Working Tax Credit (WTC) and Child Tax Credit programmes from April 2003. WTC extended eligibility to single people and to families without children. See Brewer and Shephard (2004) for a concise overview of the Labour government's welfare to work policies and associated changes in the social security benefit system.

4. Eligibility for Housing Benefit and Council Tax Benefit is assessed by local authorities. 
benefits. ${ }^{5}$ If one follows this line of thought, then, arguably, HB and CTB should be treated differently from IS and income-based JSA, because employment status is not used to assess eligibility.

18. This is not a decisive argument however. There are merits to retaining a definition of social assistance benefits that accords with the classic definition, if only because this may facilitate cross-national comparability of analysis - we note that one of the purposes of our paper is to serve as a basis for similar studies for other countries. (Britain's emphasis on 'welfare to work' is similar to that of the USA, but not to that of most European countries.) For example, although other countries besides Britain may not provide a separate system of housing benefits to help low income people with their housing costs, the levels of social assistance benefits may be set in a fashion that is intended to cover such costs.

19. As it happens, the recipient populations receiving IS and JSA on the one hand, and HB and CTB on the other hand, overlap substantially, and so the choice of whether to include housing benefits in the definition of social assistance benefits may be of little practical importance. ${ }^{6}$

20. There is an additional complication concerning the treatment of JSA and its predecessors. Before 1996, individuals with a satisfactory national insurance contribution record were eligible to claim Unemployment Benefit (UB) when they became unemployed, and the level of benefit paid was a flat-rate that was not means-tested. Unemployed individuals with an incomplete national insurance contribution record and a sufficiently low income were eligible to claim IS (on a means-tested basis). UB recipients were also eligible to claim an IS top-up if their total family income including UB was below the IS minimum. (This was more likely, the greater the number of dependents.) Because UB payments were relatively low, most recipients were also eligible for IS. JSA was introduced from October 1996 as a unified benefit for unemployed jobseekers. Contribution-based JSA is the successor to UB and receipt requires a satisfactory national insurance contributions record. Income-based JSA rather than IS is now the means-tested benefit that is paid to low-income unemployed workers with insufficient national insurance contributions. It remains the case that most JSA recipients receive some income-based benefits. For example, according to administrative record data, at 1 August 2004, there were 737,000 JSA recipients in total, of whom $18 \%(136,000)$ received only contribution-based JSA and $82 \%(601,000)$ received incomebased JSA, including 12,000 with underlying entitlement to contribution-based benefit. ${ }^{7}$

21. In practice, it is difficult to reliably distinguish between receipt of contribution-based JSA and income-based JSA. Since JSA's introduction, the BHPS interview has not asked respondents receiving JSA to distinguish between the two types for precisely this reason (Heather Laurie, BHPS Survey Manager, personal communication). Prior to JSA's introduction, respondents were asked to say whether they were receiving UB or UB combined with IS, though it is unclear how accurately respondents were able to distinguish them.

22. Hence, to produce a consistent longitudinal series for individuals' social assistance benefit receipt from the BHPS, one must combine receipt of UB and UB/IS prior to 1996, and receipt of both types of JSA with receipt of IS after 1996. One cannot define social assistance in terms of IS alone, i.e. excluding

5. There are also benefits for individuals who are ill or injured not discussed here (see the URL cited earlier): Statutory Sick Pay for employees, Incapacity Benefit for those unable to work because of illness or disability and with a suitable national insurance contributions record, Industrial Injuries Disablement Benefit for those ill or disabled because of an accident or event that happened at work or in connection with work.

6. In our estimation sample, $65 \%$ of the recipients of social assistance (defined as including IS or UB/JSA) are also receiving $\mathrm{HB}$ or $\mathrm{CTB}$. Of those receiving $\mathrm{HB}$ or $\mathrm{CTB}, 61 \%$ also received social assistance benefits.

7. See http://www.dwp.gov.uk/asd/asd1/stats_summary/Stats_Summary_dec2004_final.pdf. 
receipt of any type of unemployment benefits, because the shift of unemployed jobseekers from IS to JSA in 1996 was largely administrative. And, whereas one might wish to include only unemployment benefits with a means-tested element in the definition of social assistance benefit, this is not feasible. The only way to distinguish the two types of JSA receipt after 1996 would be to estimate national insurance contribution records, and whether they were satisfactory, using the BHPS between-wave work monthly history data about employment spells and the interview data about earnings. Our view is that such estimates would be time-consuming and subject to error. In any case, the payoff from doing so is relatively small. As stated earlier, the vast majority of JSA recipients receive income-based JSA, just as a substantial fraction of UB recipients also received an IS top-up. We note that Hansen and Lofstrom's (2006) analysis of the dynamics of social assistance receipt in Sweden also included receipt of some unemployment benefits in the definition of social assistance. We also observe that the DWP's Statistical Summary of social security benefits has not broken down JSA recipient numbers by type of JSA since 2005.

\section{The time period of receipt}

23. Individuals receive benefits over periods of time. Spells may start or end on any day of the week, though for spells in progress, payments are made fortnightly. In any given calendar year, an individual may have no receipt, a single spell of receipt, or multiple spells of receipt, and any of these spells may overlap calendar years. Hence the 'dynamics' of receipt are potentially very complicated. Empirical work to date has taken a simpler approach.

24. Previous analysis of social assistance receipt dynamics has mostly defined the time period of receipt in terms of 'a social assistance year'. For example, in Andrén's (2007) analysis, receipt in a given calendar year is based on whether the sample person received social assistance at least once during that year. (His data set provides no information about the sequence of social assistance received during the year, only the number of months.) Hansen and Lofstrom (2006) applied a similar definition to a different Swedish administrative data source: see the quotation from their paper above. And Hansen, Lofstrom, and Zhang's (2006) definition of receipt of Canada's Social Assistance benefit in a given year refers to receipt at any time during that year. In all three cases, it is apparently straightforward to characterise the 'year' over which receipt may occur. This is largely because of the nature of the data sources: the two Swedish studies are based on administrative record data and the SLID, used by Hansen and Lofstrom (2006), also utilizes administrative record linkage as the source for income for many respondents.

25. Interview-based surveys like the BHPS collect benefit receipt information differently, as a consequence of wishing to minimize measurement error and respondent burden. At each BHPS interview, in the Autumn of each year, a lot of information is collected about the various income sources received at the time of the interview, and the corresponding amounts. Information about receipt of each source is also collected for each month back to the September of the year prior to the current survey year using the respondent's retrospective recall. ${ }^{8}$ Since the between-interview interval is not always 12 months, defining the income reference year in this manner ensures that all respondents are asked about all calendar months. But, at the same time, it also means that the retrospective benefit histories from successive interviews provide two reports for each of the months for which the reference years overlap.

26. To create a consistent history of receipt of each individual, and hence to define receipt over succession of 'social assistance years' (as in the studies cited earlier), one has to decide how to handle inconsistencies in reports that arise for the overlap months. It is well known that such retrospective histories often show an implausible number of transitions at the 'seam' where successive histories are spliced together. There is an additional complication because, as we have explained, social assistance

8. The sequence of questions used in the BHPS retrospective histories is: (i) did you receive source X at any time over the reference period; (ii) if yes, was it received in every month; (iii) if no, in which months? 
receipt should be defined in terms of whether any individual in a person's benefit unit is in receipt. To do this for each 'social assistance year' requires information about receipt for every individual who was present in the respondent's benefit unit within each month of the relevant year. However, for adults who left the benefit unit after the last interview and before the current interview, there is no history of receipt over the reference period prior to the current interview. (By definition, they are not interviewed.) Receipt over the year defined in terms of receipt by any person within the individual's benefit unit may therefore be under-reported. Addressing these issues in order to develop a 'social assistance year' measure may well be possible, but would be time-consuming. It is beyond the scope of the current project.

27. Our proposal for this project is to define focus on receipt at the time of the annual interview, so that the dynamics of receipt refers to transitions on and off benefit between successive interviews. This not only avoids the problems of building a consistent 'social assistance year' definition but also exploits the benefit data that are measured most reliably (at the time of the interview). We would also point out that the definition is consistent with many studies of the probability of unemployment, and transitions into and out of unemployment, based on panel surveys: see e.g. Arulampalam, Booth and Taylor (2000) and Stewart (2007).

\section{Summary}

28. The definition of social assistance benefit receipt is not straightforward. The choice depends on country-specific factors - the structure of the social security benefit system and how it has changed over time - and on the data sources available. What is possible with household panel surveys differs from what is possible with data sets built from benefit administration records.

29. We track working age adults over time using BHPS data from survey years 1991 to 2005, using respondents to the original ('Essex') sample only. ${ }^{9}$ An individual defined to be in receipt if any individual in his or her benefit unit is receiving social assistance benefits at the time of the BHPS interview. We define 'social assistance benefits' as including IS and either UB or JSA (of either type).

\section{Trends in receipt probabilities and annual transition probabilities}

30. In this section, we provide information about trends in receipt of social assistance and other related benefits from a cross-sectional perspective and then about trends in transition rates into and out of receipt. This sets the scene for the multivariate analysis to follow. We use the sample of working-age adults defined earlier (and described in more detail later on). Although the main focus of the paper is on social assistance benefit receipt and its trends, it is useful to place these in context with some comparisons with other benefits. For convenience, the following abbreviations and acronyms are used:

- SA: 'social assistance', meaning receipt of IS, with or without receipt of UB or JSA (depending on survey year), or UB/JSA without IS receipt.

- $\quad \mathrm{HA}$ : housing benefits, meaning receipt of $\mathrm{HB}$ or $\mathrm{CTB}$

- SAHA: social assistance including housing benefits, meaning receipt of SA or HA (or both)

9. Thus, observations from the extension samples incorporated at the end of the 1990s for Scotland, Wales and Northern Ireland will not be used. Taking account of the differential sample inclusion probabilities would be a large task, beyond the scope of this project, and the number of observations in the original 1991 sample is relatively large in any case (see below). 
- TC: employment-conditional tax credits of any kind, meaning receipt of Family Credit, Working Families Tax Credit or Working Tax Credit (depending on survey year).

Because HA may received by those receiving employment-conditional tax credits, the memberships of the SAHA and TC recipient groups may overlap.

31. All cross-sectional statistics were computed using the BHPS cross-section respondent weights. Longitudinal statistics such as transition probabilities were computed unweighted, as it is unclear in several cases what the appropriate weight would be (particular when we pool transitions from multiple waves) and, in any case, the BHPS longitudinal weights that are available at wave $s$ for any wave $s=1-15$, exist only for original sample respondents who were interviewed at wave 1 and every wave up to and including wave $s$.

32. Breakdowns are also provided for the four principal client groups defined earlier: couples without children, couples with children, lone parents and singles. In the full person-wave sample, individuals belonging to tax units of couples with children were the most numerous group ( $41 \%$ of the sample). The next largest group of individuals belonged to childless couples (35\%). Single childless tax units formed $19 \%$ of the sample, and lone parents $5 \%$ of the sample. The relatively small number of lone parents in the sample means that all estimates of rates shown below should be treated with caution, especially the annual transition rates (for which the numbers involved are between 80 and 100).

\section{Trends in rates of receipt of benefits}

33. Cross-sectional trends in receipt are summarised in Figures 1-5. Apart from the rise in receipt at the beginning of the 1990s, when Britain was in recession, the percentage of all adults in receipt of SA fell gradually from a peak of around 12\% in 1993 to a low of around 6\% in 2005. The proportion in receipt of SAHA was consistently $2 \%-3 \%$ higher than the proportion in receipt of SA, but followed a similar downward trend. The proportion of all adults in receipt of tax credits was consistently about $2 \%$ to $3 \%$ during the 1990s, until the introduction of WFTC in October 1999, after which the proportion in receipt rose dramatically to about $6.6 \%$ in 2002 . The proportion then rose again significantly with the extension of eligibility provided by the change to WTC in 2003. 
Figure 1. Trends in receipt of SA, SAHA, and TC: all adults

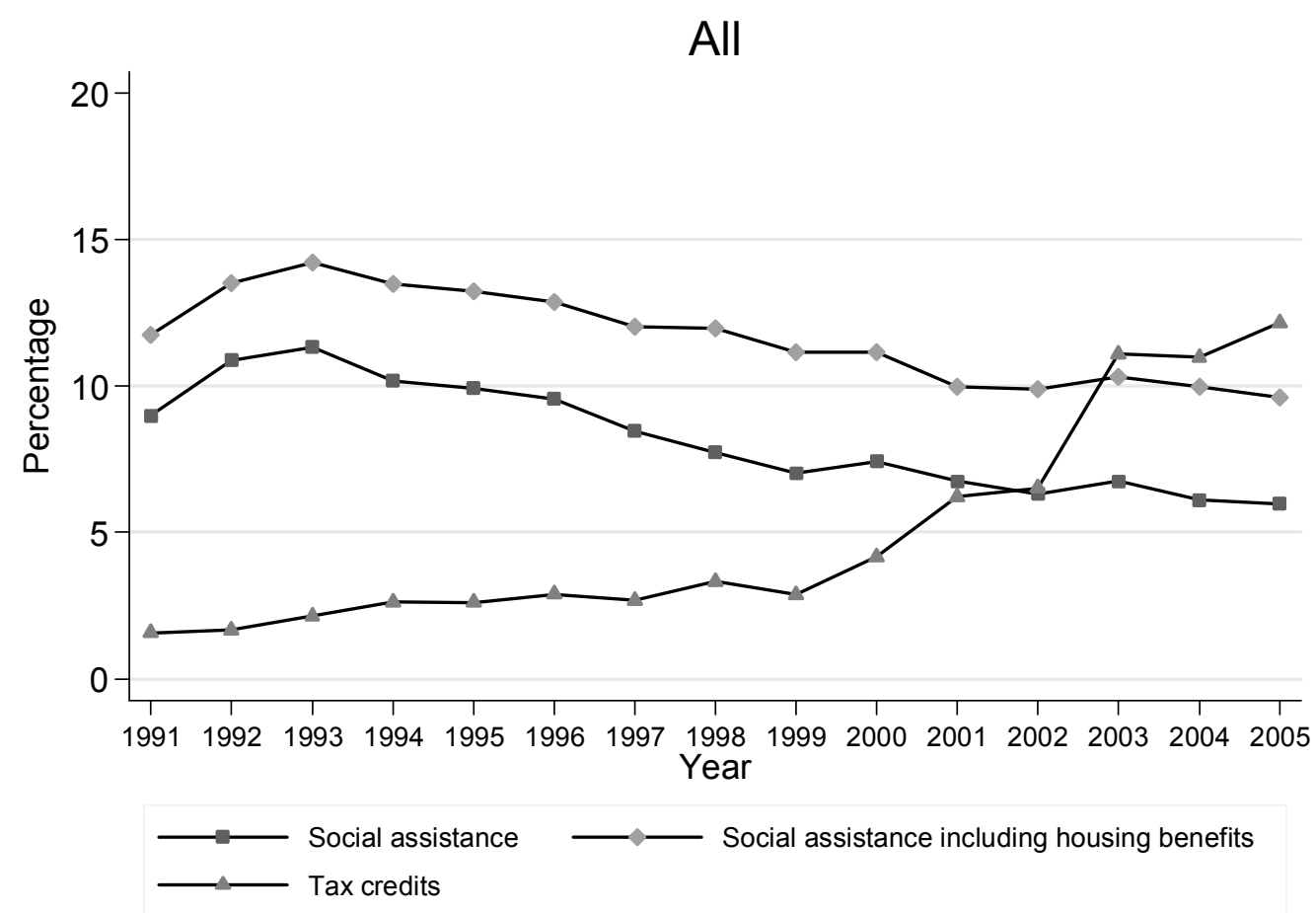

34. Among couples without children (Figure 2), SA receipt rates stayed relatively low, at around 5\%, with little trend. TC receipt rates were zero until eligibility was extended to the group with the introduction of WTC. Among couples with children (Figure 3), the SA receipt rate halved in 15 years from around 10\% in 1992 and 1993 to just below 5\% in 2005. TC receipt rates were about 5\% during the mid-1990s but doubled at the end of the decade after the introduction of WFTC when there was a dramatic increase in receipt (11\% were in receipt by 2001), and there was another increase in 2003 when WTC was introduced (to over $20 \%$ ).

35. Lone parents have the highest SA receipt rates among the four client groups, but the rates for this group have also trended downward since the early 1990s (Figure 4). Almost 55\% of lone parents were in SA receipt 1992-1994 but, in 2005, the rate was 'only' 25\%. The difference between the rate of SA receipt and rate of SAHA receipt is also greater than for other groups (typically more than $10 \%$ ) and appears to have widened slightly between the beginning and end of the period. Lone parents were one of the principal target groups for the welfare-to-work changes in in-work benefits introduced at the end of the 1990s, and hence the sharp increase in TC receipt at that time. At the start of the 1990s, the proportion of lone parents receiving TC was around $10 \%$; it was $35 \%$ by 2001 , and reached $45 \%$ in 2005 .

36. Among single adults, the proportion receiving SA declined sharply from around $15 \%$ in 1992 to about $8 \%$ in 2005 . The proportion receiving SAHA is markedly higher, and the trend downward in receipt was more gradual, from around $20 \%$ in 1992 to around $17 \%$ in 2005 . The TC receipt rate only became non-zero in 2003 with the introduction of WTC, which extended eligibility to this group. 
Figure 2. Trends in receipt of SA, SAHA, and TC: couples without children

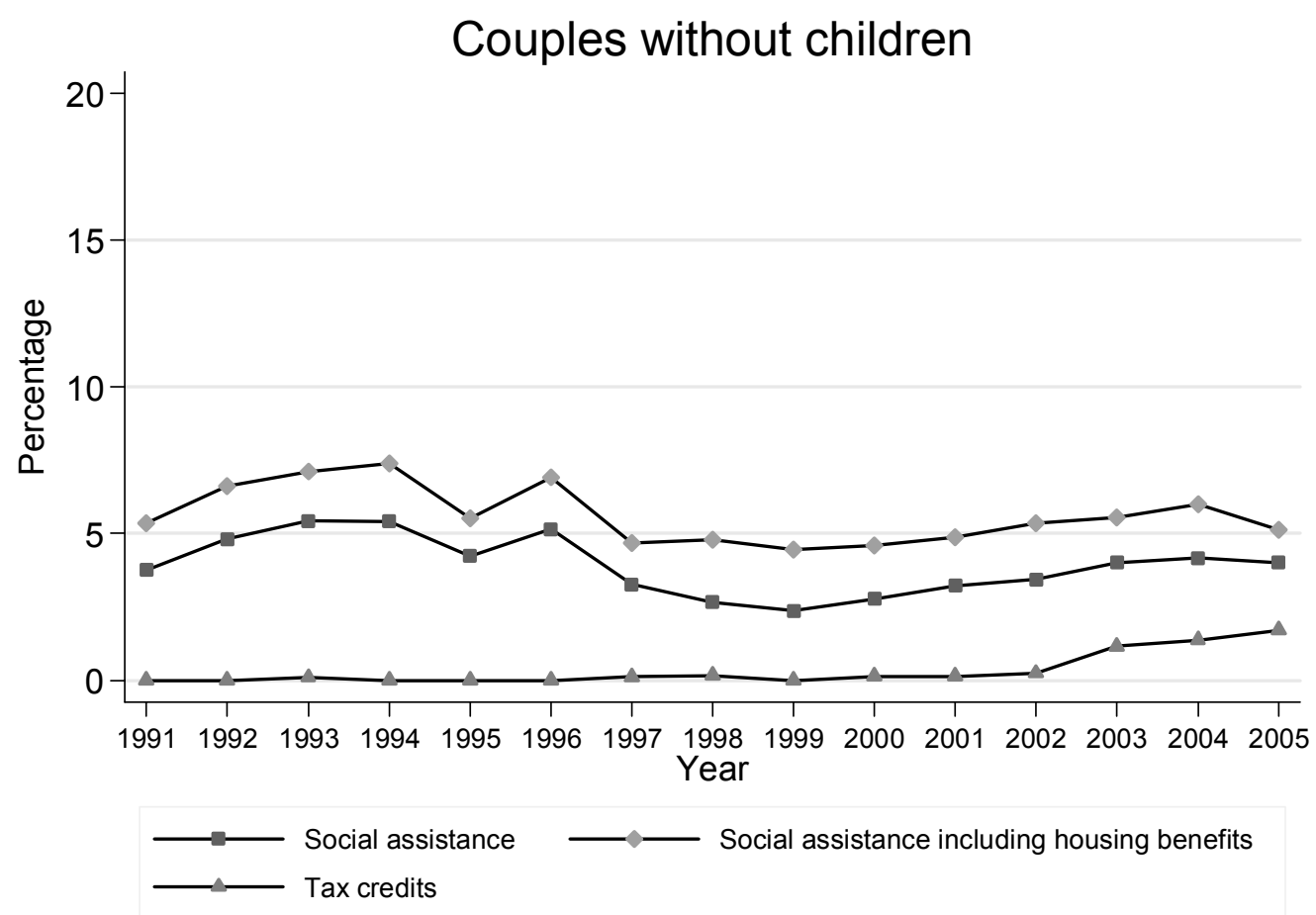

Figure 3. Trends in receipt of SA, SAHA, and TC: couples with children

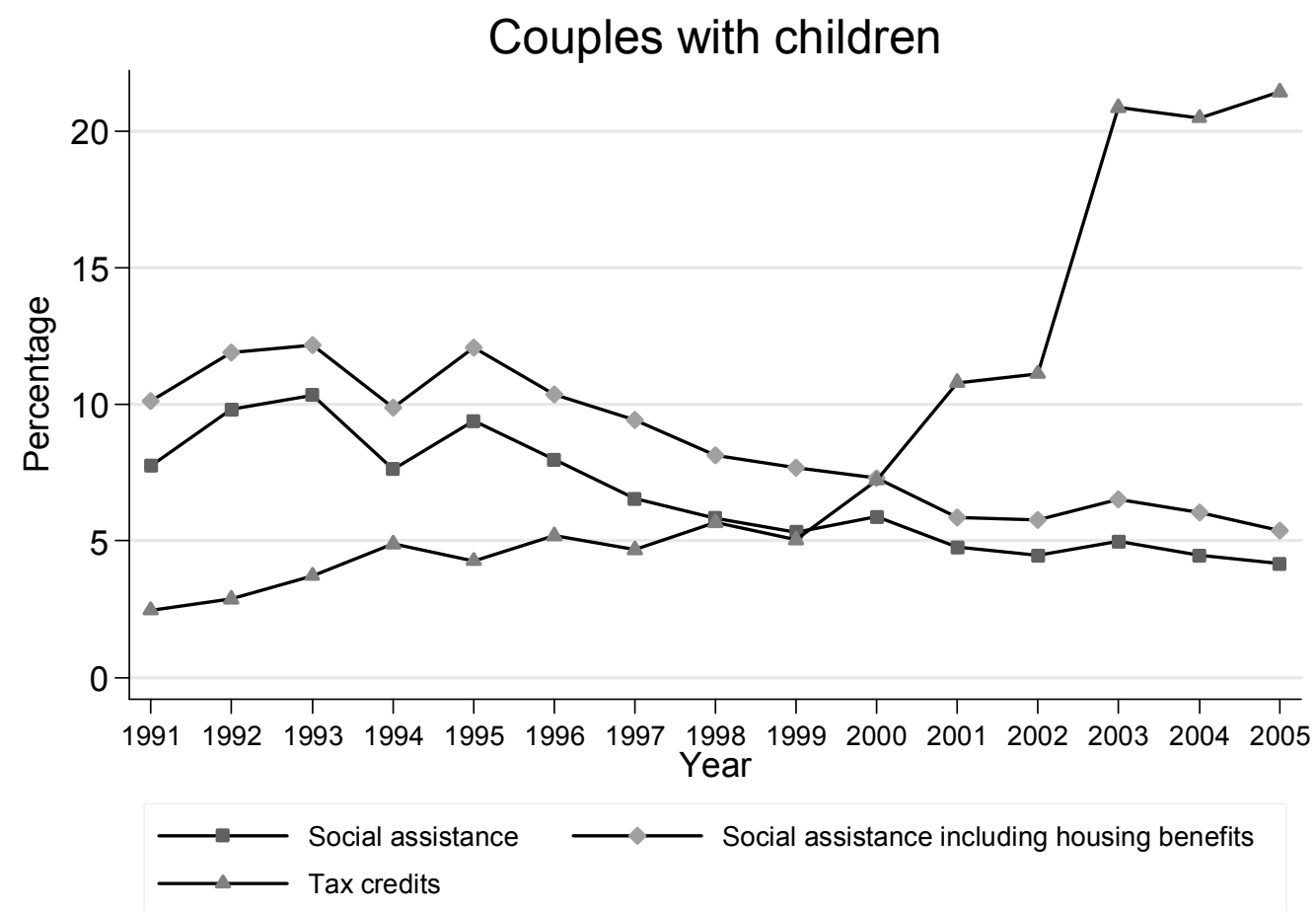


Figure 4. Trends in receipt of SA, SAHA, and TC: lone parents

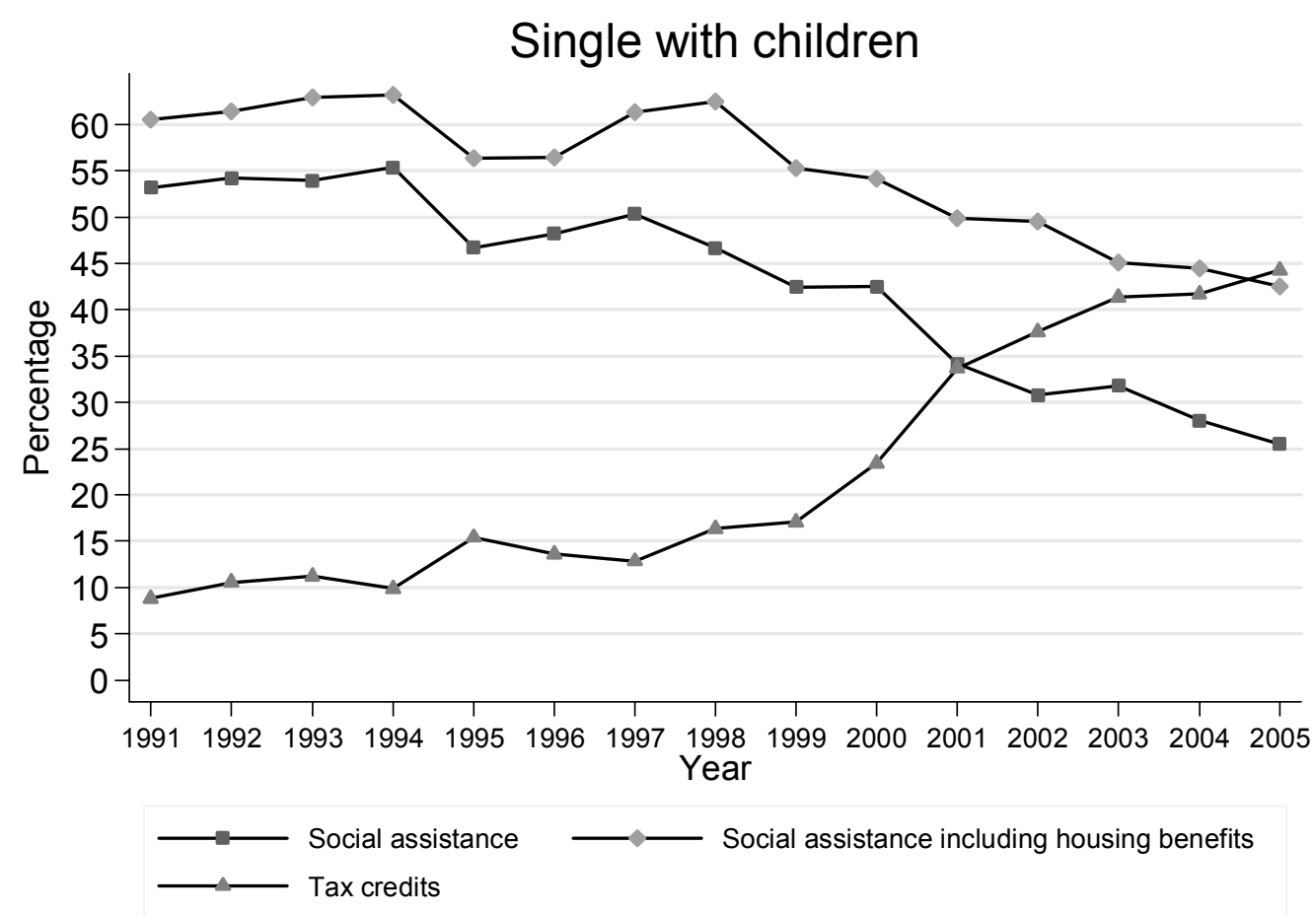

Figure 5. Trends in receipt of SA, SAHA, and TC: single adults

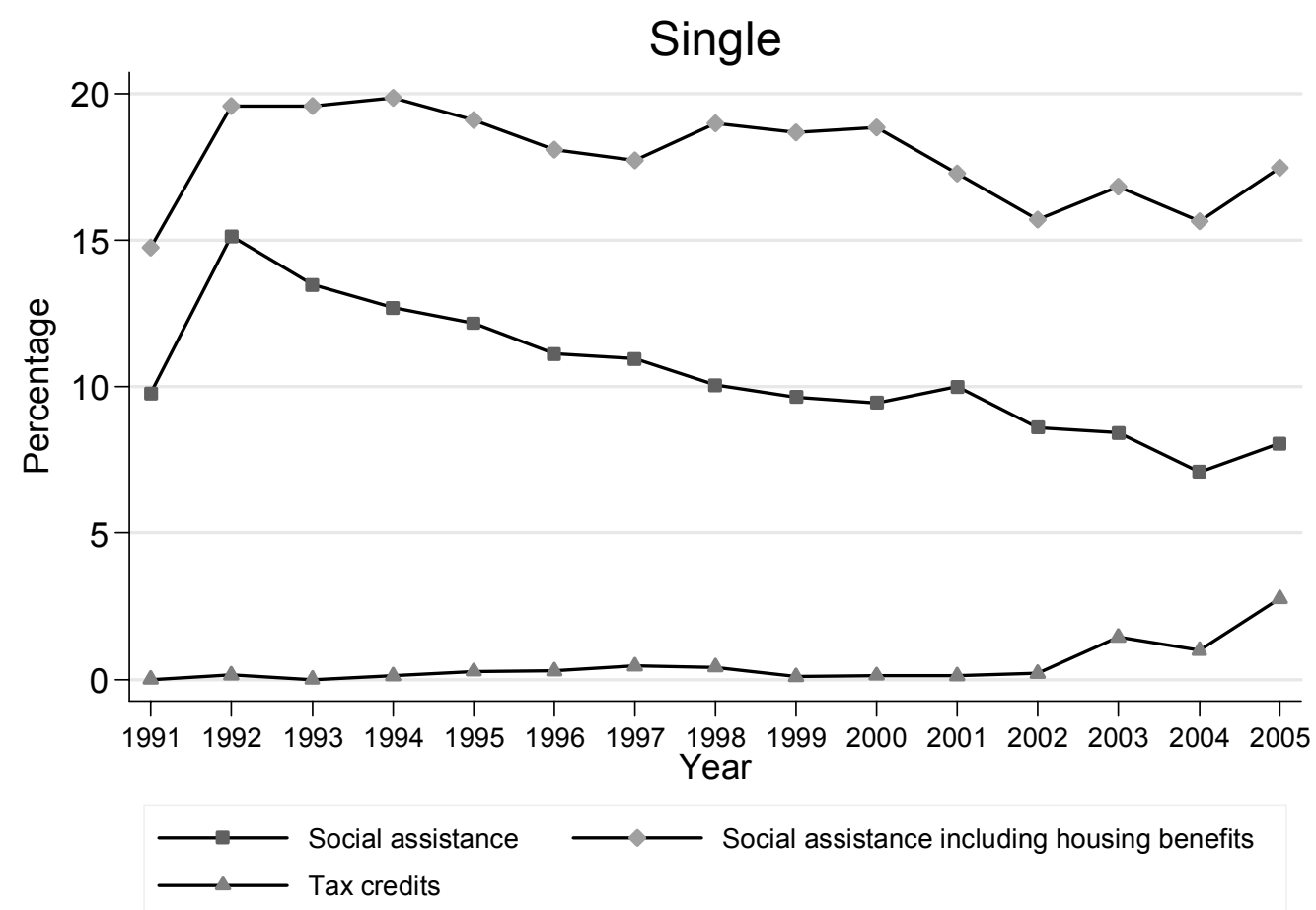




\section{Trends in annual rates of entry to and exit from social assistance benefit receipt}

37. Figures 6-10 show trends in annual transition rates into and out of receipt. The exit rate is the number of individuals in receipt at survey year $t-1$ who are no longer in receipt at $t$, divided by the total number in receipt at $t-1$, and expressed as a percentage. (The persistence rate is one minus the exit rate.) Similarly, the entry rate is the number of individuals not in receipt at survey year $t-1$ who are in receipt at $t$, divided by the total number of individuals not in receipt at $t-1$, expressed as a percentage. The denominator of the entry rate calculation is much larger than the denominator of the exit rate calculation, with the exception of lone parents for whom they are of much the same order. Annual transition rates have been calculated even though small cell sizes mean that estimates are subject to relatively large sampling variability in some cases. Trends remain relatively clear despite this, however.

38. Breakdowns by client group refer to client group membership at year $t$. (Breakdowns by group membership at $t-1$ led to very similar pictures.)

39. Each of the figures that follows shows trends in annual entry and exit rates for SA. A downward trend in the cross-sectional rate of receipt of social assistance - as demonstrated earlier for most groups may reflect an upward trend in the exit rate (decline in the retention rate) or a downward trend in entry rates. We show that it is the latter which appears to be the main influence.

40. Taking all adults together (Figure 6) shows that the decline in cross-sectional receipt rates reflects a downward trend in entry rates: the fall in the entry rate is sufficiently large that it offsets the decline in the exit rate over the same period. However the decline in the entry rate stopped in around 2000, and the rate is relatively constant thereafter. Illustrating these changes, note that the SA annual exit rate is $37 \%$ if transitions from the first nine waves are pooled ( $t-1$ corresponding to waves $1-9)$, and $29 \%$ for transitions pooled from years thereafter. The corresponding entry rates are $3.2 \%$ and $1.6 \%$. For the period as a whole, the exit rate is $34 \%$ and the entry rate $2.4 \%$.

41. For childless couples (Figure 7), and couples with children (Figure 8), much the same story can be told. The decline in the cross-sectional rate of receipt arises from a declining entry rates offsetting declining exit rates, and the trends levelled off from around 2000. (Note the relatively large fluctuations in the exit rate for childless couples, related to small sample numbers.)

42. For lone parents (Figure 9), there is marked sampling variability in both the annual entry and annual exit rates but, notwithstanding this, it is interesting that SA exit rates appear to rise slightly over time, i.e. in the opposite direction to adults in couple benefit units. The SA entry rate appears to decline over the period as a whole, and its impact on the cross-sectional proportion in receipt is reinforced by rising exit rate. For single adults, exit rates were fairly constant between 1991 and 2005, whereas the entry rate declined over time but the rate of decline was slower in the 2000s than in the 1990s.

43. The pattern of trends in SA entry and exit transition probabilities raises interesting questions about what determined them. The change in the entry rate at the end of the 1990s might suggest that the reforms of the benefit system and other New Labour policies introduced at around that time might have been responsible. However there is no sharp correspondence between the dates of the introduction of major reforms like WFTC in 1999 and changes in transition probabilities. Also, changes occurred for childless couples and for single adults as well as for families with children, and it was low income families with children who were the principal targets of the policies. In part, the lack of clear cut correspondences between trends in transition rates and the timing of reforms may simply reflect the combination of a number of reforms with different impacts on different groups. (We offer further cautionary words about the identification of causal explanations below.) 
44. That said, one might expect the introduction of WFTC to reduce SA entry rates on the grounds that, if successful, people who lose their job would be less likely to take up SA benefits because the income from getting a new job was now boosted by WFTC. On similar grounds, one might expect the introduction of WFTC to raise exit rates from SA because WFTC made work more attractive compared to not working. An argument to the contrary is that the changing entry rates also lead to changes in the composition of the SA recipient population. Thus there may be a decline in the exit rate, reflecting a type of 'creaming off'. I.e. it may be that as the fraction of the population receiving SA declined, the people who did receive SA were more likely to have characteristics associated with lower exit rates, other things equal. Indeed we observe the SA exit rate declining for all client groups apart from lone parents, for whom it rose. Petrongolo (2007) discusses the impact of the introduction of JSA in October 1996, including the more stringent job search conditions imposed on claimants relative to the previous system. She suggests that the reforms increased the number of non-employed people who were not claiming benefits but did not clearly increase the job-finding rate. (Some may have moved to other benefits such as incapacity benefits rather than SA.) In Figure 6, an association between the timing of JSA introduction and SA entry rates is hard to discern, however. 
Figure 6. Annual transition rates: SA, all adults

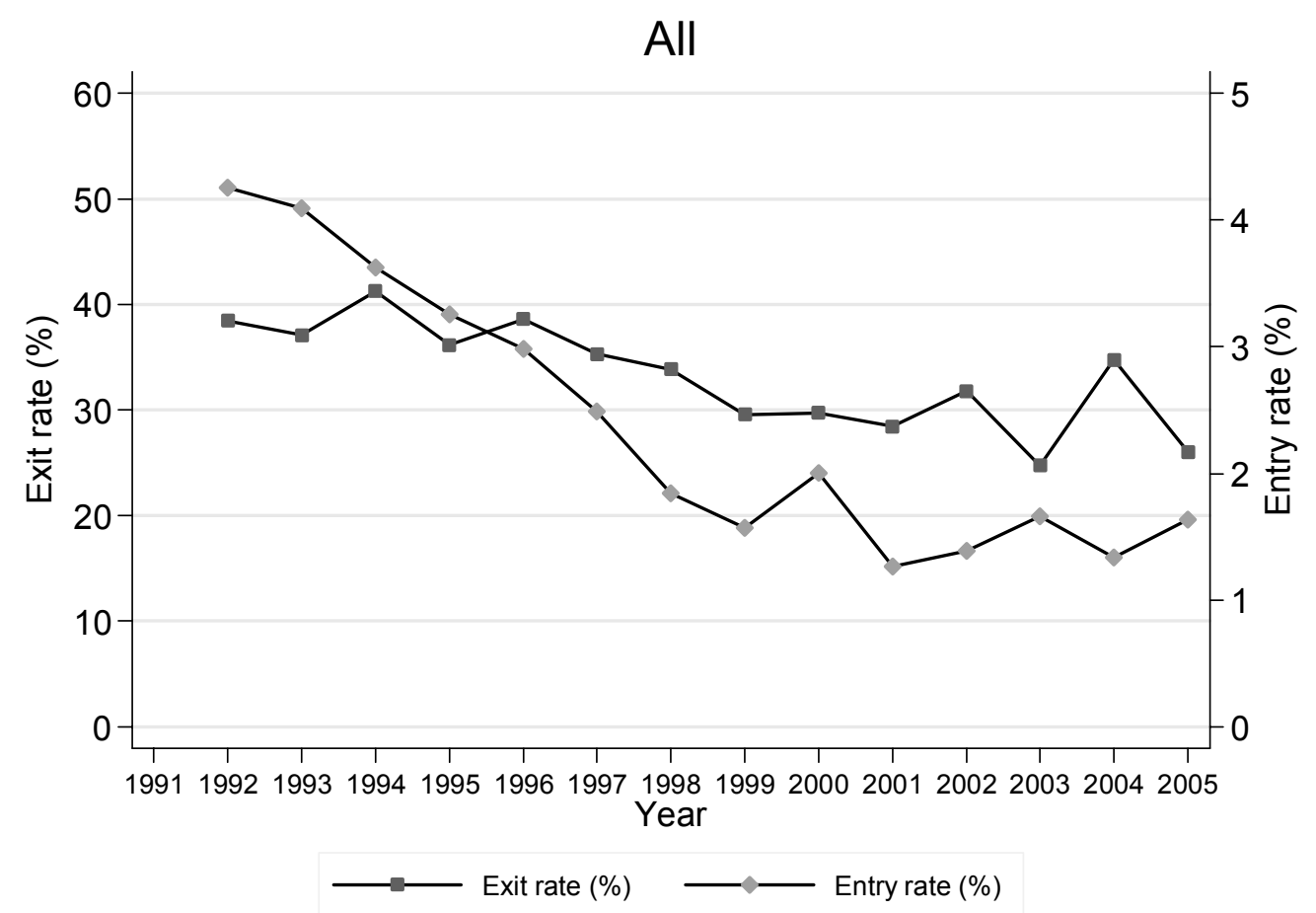

Figure 7. Annual transition rates: SA, couples without children

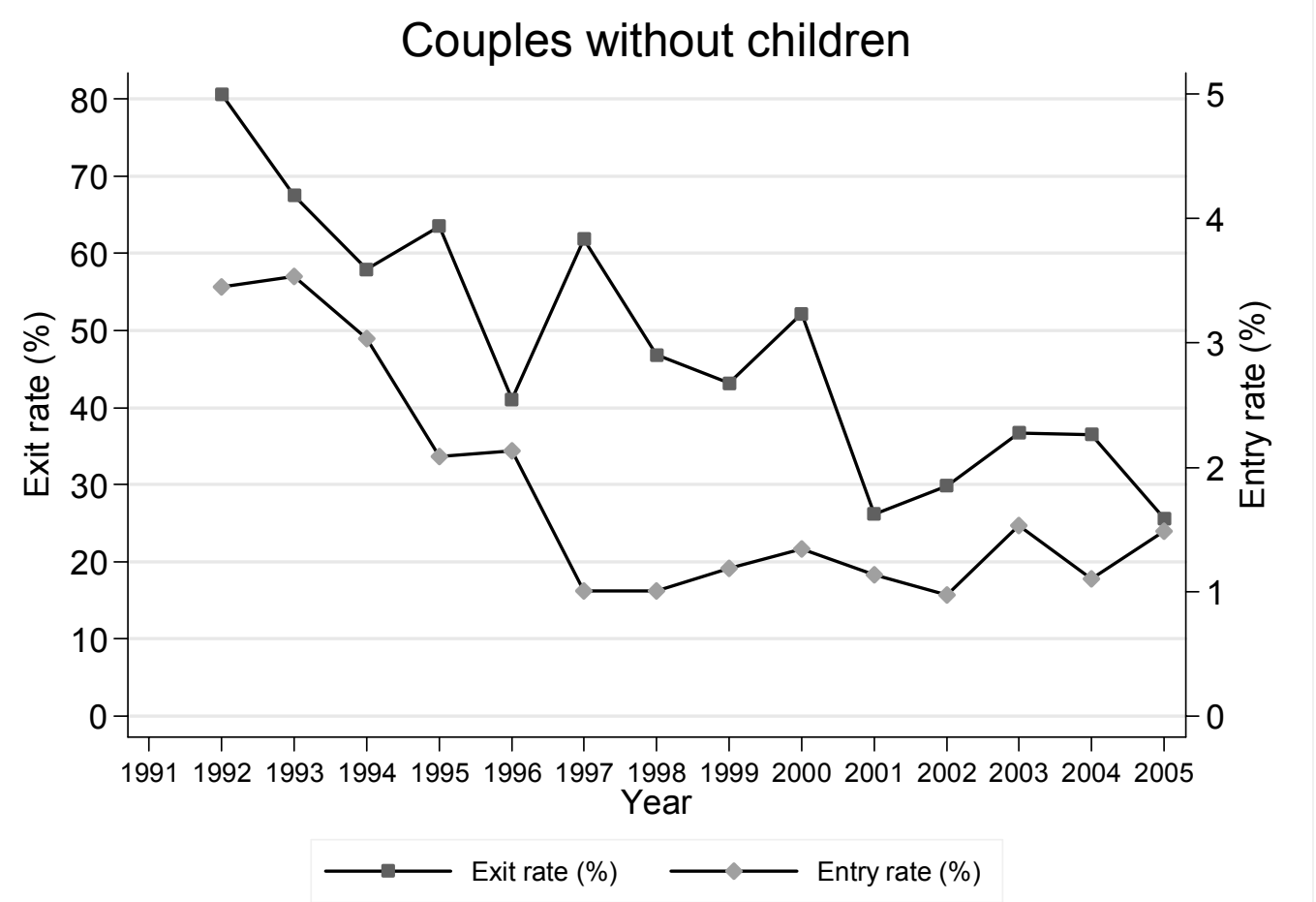


Figure 8. Annual transition rates: SA, couples with children

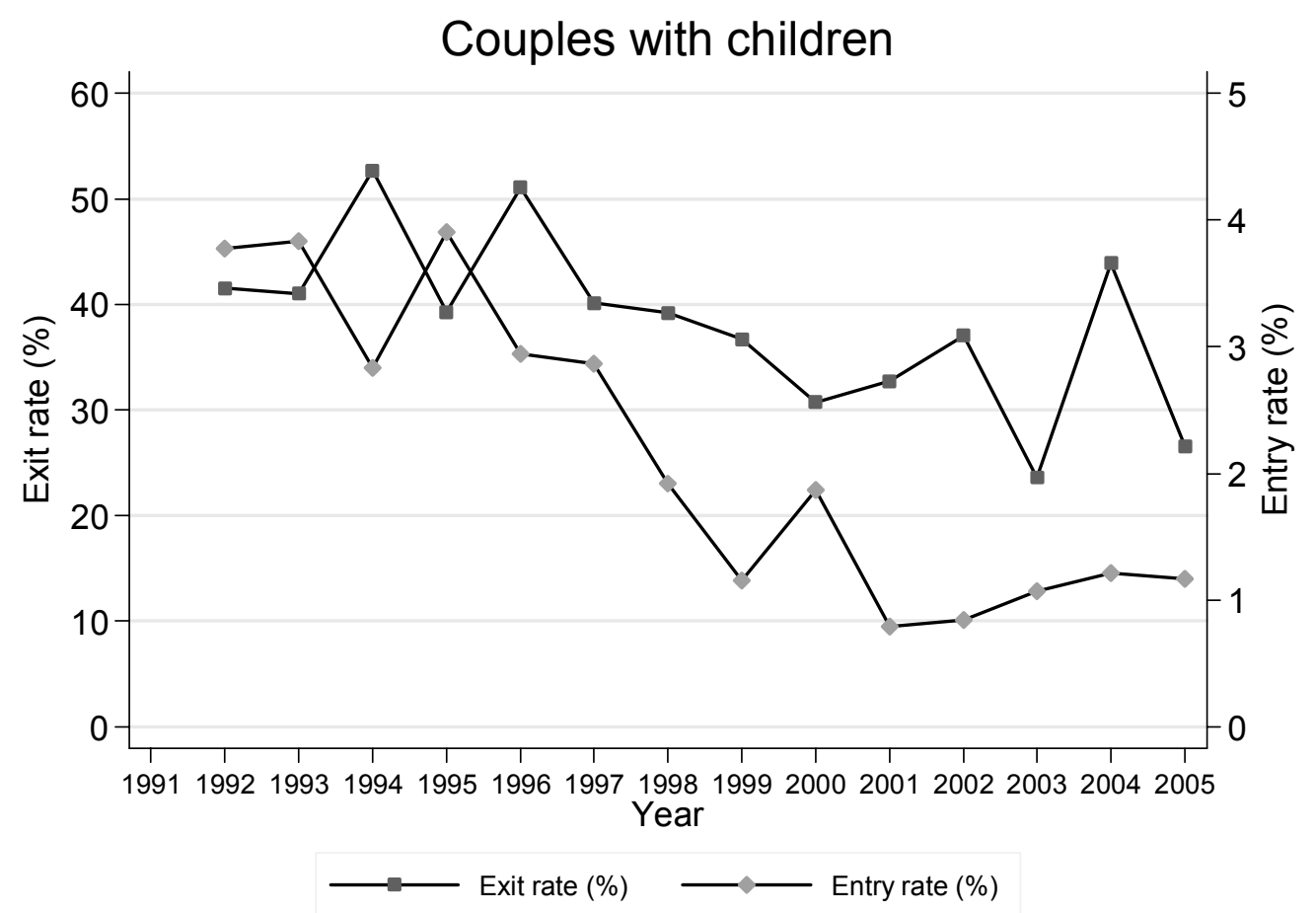

Figure 9. Annual transition rates: SA, lone parents

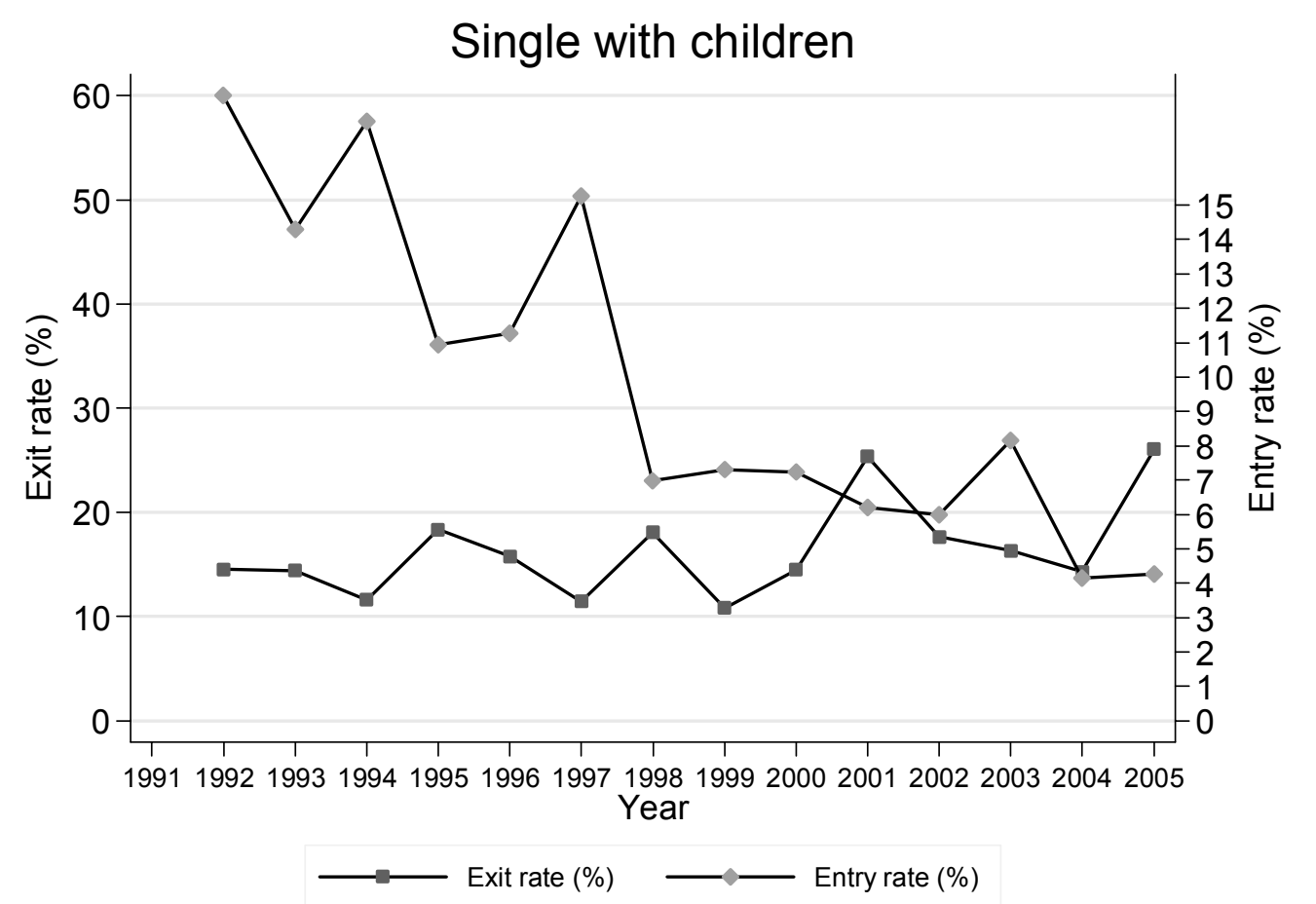


Figure 10. Annual transition rates: SA, single adults

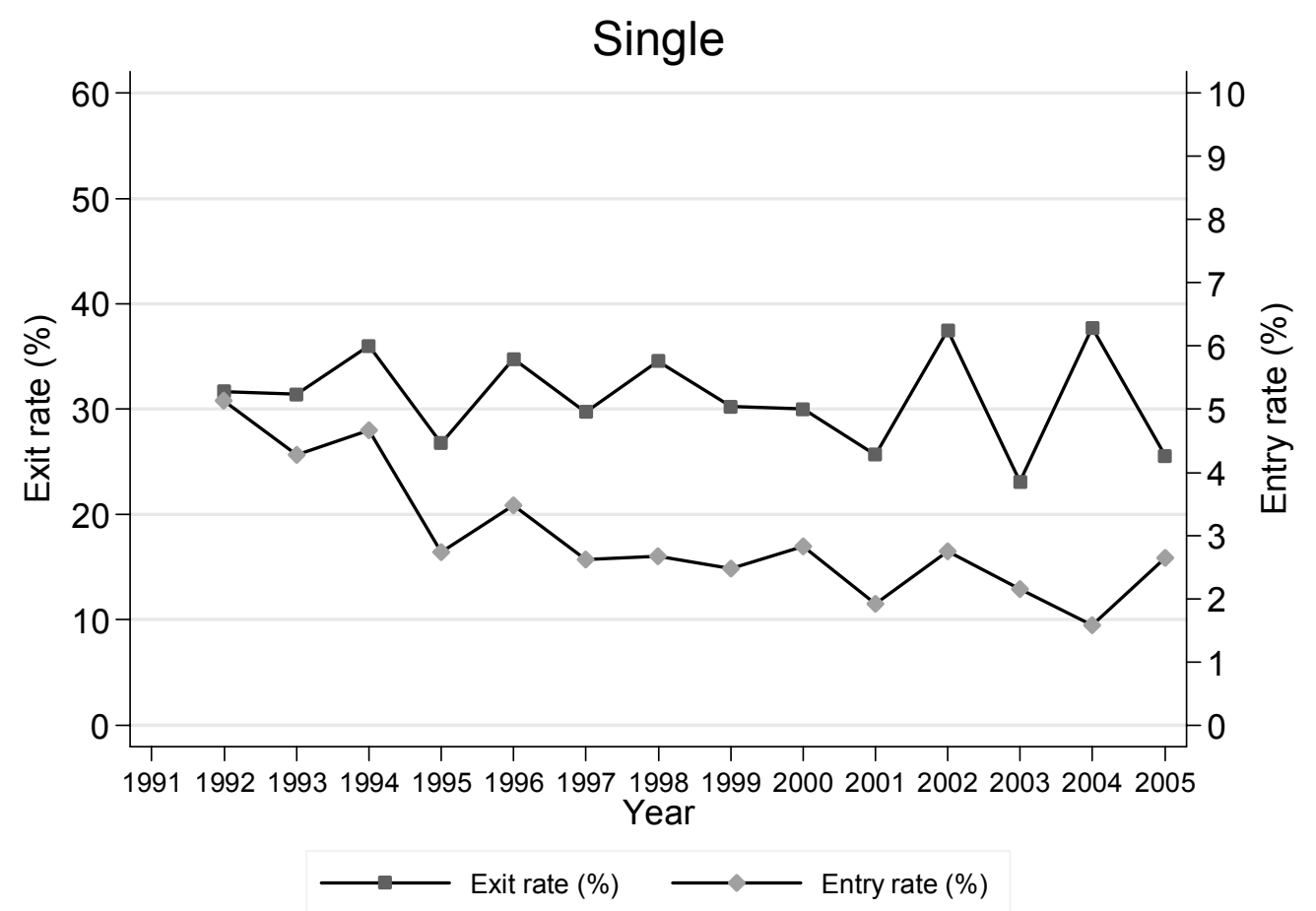

\section{Multivariate modelling approaches}

45. There are two main approaches to modelling benefit dynamics using multivariate methods: hazard or duration models using data about spell lengths, or models of annual probabilities of entry to and exit from receipt ('transition probability' models). As explained earlier, it is not feasible within the scope of the current project to derive satisfactory data about spell lengths of social assistance benefit receipt. We therefore focus on models of annual transition probabilities.

46. A model of whether someone is receiving social assistance benefit at a point in time is an example of a model with a binary dependent variable. Three main types of models have been used in related contexts to examine dynamics in general and transition probabilities in particular:

- Basic models with no allowance for unobserved heterogeneity or state dependence;

- Endogenous switching models with unobserved heterogeneity and state dependence; and

- Lagged dependent variable models with unobserved heterogeneity and state dependence ('dynamic random effects probit models').

We discuss the models in turn.

47. Each of three model types makes particular assumptions about the nature of the dynamic process, and specific distributional assumptions. Another way of incorporating greater flexibility and minimizing distributional assumptions is to use linear probability models of receipt dynamics, estimated using the Generalized Method of Moments estimators proposed by Arellano and Bond (1991) and others. See 
Stewart (2007) for an application to the dynamics of individuals' unemployment status. Because we wish to focus on the types of models most commonly applied to social assistance dynamics in the past, and because of the limited resources available for the current project, we do not discuss linear probability models of dynamics further.

\section{Basic transition rate models}

48. The pioneering application of the basic transition rate models to benefit dynamics was by Boskin and Nold (1975). For an application of their methods to benefit dynamics among British lone mothers, see Böheim, Ermisch, and Jenkins (1999). Although these models are no longer the models of choice, they provide a useful reference point for the more sophisticated types of model.

49. The processes of entry to and exit from receipt are modelled separately. For those that are not in receipt in the base period (call it $t-1$ ), there is a model for the probability that an individual moves from non-receipt at time $t-1$ to receipt at time $t$ (the entry probability). And for those that are in receipt at $t-1$, there is a model for the probability of moving from receipt at $t-1$ to non-receipt at $t$ (the exit probability).

50. Suppose the latent entry probability, $r^{*}{ }_{i t}$, is a linear function of characteristics:

$$
r^{*}{ }_{i t}=\beta^{\prime} X_{i t}+u_{i t}
$$

where subscript $i$ indexes individuals, $X_{i t}$ is a vector of characteristics associated with person $i$, and $u_{i t}$ is a 'white noise' error term, with mean zero and uncorrelated with $X_{i t}$. One can control for secular trends in transition probabilities by incorporating functions of calendar time among the explanatory variables in $X_{i t}$. An entry to receipt is observed if $r^{*}{ }_{i t}>0$ and is zero otherwise.

51. The latent exit probability, $q^{*}{ }_{i t}$ is specified analogously:

$$
q^{*}{ }_{i t}=\alpha^{\prime} Z_{i t}+v_{i t}
$$

where $Z_{i t}$ is a vector of characteristics for individual $i$ (which, again, may include functions of calendar time), and $v_{i t}$ is a white noise error term, with mean zero and uncorrelated with $Z_{i t}$. The $\beta$ and $\alpha$ are vectors of parameters, to be estimated, which capture the relationship between characteristics and transition probabilities. Estimation of each model is straightforward using e.g. either a standard logit estimator (if the errors are assumed to be logistically distributed) or a standard probit estimator (if the errors are assumed to be normally distributed).

52. The major advantages of this modelling approach are that it is easy to estimate and it straightforward to interpret the estimated parameters. In particular, Boskin and Nold (1975) derived a number of expressions that usefully describe the process of benefit dynamics. Suppose that the observed entry and exit rates $r_{i t}$ and $q_{i t}$ are at constant 'steady state' levels $r_{i}$ and $q_{i}$ (the time subscript is no longer relevant). The probability of being in SA receipt in any given year, equivalently the expected proportion of time in which $i$ is in receipt of social assistance, is $r_{i} /\left(r_{i}+q_{i}\right)$. The mean duration of a spell of SA receipt for someone beginning a spell is $1 / q_{i}$ years, and the mean duration of a spell of SA non-receipt for someone leaving receipt is $1 / r_{i}$ years. The corresponding median spell lengths are $-\log (2) / \log \left(1-q_{i}\right)$ years and $\log (2) / \log \left(1-r_{i}\right)$ years. The expected turnover rate is the expected proportion of time spent in SA receipt multiplied by the exit rate. Equivalently it is the number of years in which there is a transition between receipt and non-receipt, expressed as a fraction of total time. The higher the turnover rate, the lower is the regularity of receipt. These expressions are useful for interpretative purposes even if transition rates are not in fact constant over time. They help reveal in numerical terms how the benefit dynamics process differs between individuals with different sets of characteristics. 
53. The basic transition probability model incorporates several important simplifications that ease estimation. The first is that there is no persistent unobserved individual heterogeneity in transition probabilities. ${ }^{10}$ That is, all individual differences are encapsulated by observed characteristics (the elements of $X_{i t}$ and $Z_{i t}$ ). Once observed characteristics have been controlled for, there is no association between unobserved factors determining exit rates and unobserved factors determining exit rates. According to (1), the predicted SA entry probability is simply $\Phi\left(\beta^{\prime} X_{i t}\right)$ in the probit case and, according to (2), the predicted SA exit probability is simply $\Phi\left(\alpha^{\prime} Z_{i t}\right)$. ( $\Phi($.$) is the cumulative density function of the standard normal$ distribution.)

54. Second, receipt probabilities do not depend directly on past receipt. Persistence in receipt over time is assumed to be due to persistence in observed characteristics: the predicted SA persistence probability is $1-\Phi\left(\alpha^{\prime} Z_{i t}\right)$ in the probit case. The alternative hypothesis is that the experience of social assistance receipt may have an independent 'scarring effect' - past recipients may have greater chances of being current recipients, other things being equal. This is the situation known as 'state dependence'. 11

55. Third, and related, no account is taken of 'initial conditions' - whether or not an individual is in receipt or not in the base year is treated as exogenously given. Put differently, among the individuals found to be in receipt in the base year one might expect an over-representation of individuals with unobserved characteristics associated with higher chances of being a recipient. Using this selected sample may yield biased estimates of the transition probabilities among the population.

56. The two types of model discussed next address these issues in different ways. Common to both approaches, however, is that they model the probability of receipt at $t$ rather than the probability of making a transition between times $t-1$ and $t$, and the implications for transition probabilities are derived indirectly.

\section{Endogenous switching models}

57. Following Cappellari and Jenkins (2004, 2008), suppose that the latent probability of receiving social assistance in year $t, p^{*}{ }_{i t}$, is characterised by

$$
p^{*}{ }_{i t}=\left[\left(y_{i t-1}\right) \gamma_{1}{ }^{\prime}+\left(1-y_{i t-1}\right) \gamma_{2}{ }^{\prime}\right] Z_{i t-1}+\varepsilon_{i t} ; \varepsilon_{i t}=\tau_{i}+\zeta_{i t}
$$

where $\gamma_{1}$ and $\gamma_{2}$, are vectors of parameters to be estimated, $Z_{i t-1}$ is a vector of observed characteristics at $t-$ $1,{ }^{12}$ and the composite error term $\varepsilon_{i t}$ is the sum of an individual-specific effect $\left(\tau_{i}\right)$ plus an orthogonal white noise error $\left(\zeta_{i t}\right)$. The $\tau_{i}$ term allows for persistent unobserved heterogeneity. (Because we can only follow individuals, and not benefit units over time, we would emphasise that the individual-specific effect is precisely that - it is not a benefit-unit-specific effect.) An individual is observed to be in receipt at $t$ if $p^{*}{ }_{i t}$ $>0$, in which case $y_{i t}=1$, and a non-recipient otherwise $\left(y_{i t}=0\right)$. Thus the impact of explanatory variables

10. In addition, the unobservable error terms at $t$ for each individual, uit and vit are assumed to be neither correlated with their past values or with each other. Use of cluster-robust standard errors (where the clusters refer to groups of observations for each individual) can help mitigate problems arising if these assumptions do not hold.

11. The most commonly-cited explanations for state dependence refer to the labour market. For example, the experience of social assistance benefit receipt may change individuals' preferences for and attitudes to paid work (cf. the culture of poverty hypothesis extensively discussed particularly in the USA), or employers might treat social assistance receipt as a adverse signal of a potential worker's qualities. See e.g. Arulampulam, Booth, and Taylor (2000) and Arulampalam, Gregg, and Gregory (2001).

12. Cappellari and Jenkins (2004) used lagged values as explanatory variables, but this is not essential. Contemporaneous values, i.e. $Z t$ rather than $Z t-1$ could also be used. 
on current receipt status may differ ('switch') according to whether the individual was in receipt at $t-1$ ( $y_{i t-1}$ $=1)$ or not $\left(y_{i t-1}=0\right)$.

58. There is a second equation for receipt status in the base year. This describes 'initial conditions' using a reduced-form approach, analogous to that proposed by Heckman (1981). The latent receipt propensity at $t-1, p^{*}{ }_{i t-1}$, is characterised by:

$$
p^{*}{ }_{i t-1}=\beta^{\prime} X_{i t-1}+u_{i t-1} ; v_{i t-1}=\mu_{i}+\delta_{i t-1}
$$

where $X_{i t-1}$ is a vector of explanatory variables, $\beta$ is a vector of parameters, and the composite error term $v_{i t-1}$ is the sum of an individual-specific effect $\left(\mu_{i}\right)$ plus an orthogonal white noise error $\left(\delta_{i t-1}\right)$.

59. The model specification is completed by assuming that the composite error terms $\varepsilon_{i t}$ and $v_{i t-1}$ are distributed bivariate standard normal, so that the distribution of unobserved heterogeneity is parameterised by the cross-equation correlation, $\varphi$ (given the necessary normalisations of the variances of the composite error to equal one). This correlation is the covariance between the individual-specific error components: $\varphi$ $\equiv \operatorname{corr}\left(v_{i t-1}, \varepsilon_{i t}\right)=\operatorname{cov}\left(\eta_{i}, \tau_{i}\right)$. If $\varphi=0$, the switching term in (3), $y_{i t-1}$, is exogenous: initial conditions do not matter for the estimation of the current receipt probability. In general, however, with $\varphi \neq 0$, initial conditions do matter: hence the 'endogenous switching' label for the model. If $\varphi=0$, then one is back to the Boskin Nold model of the previous subsection.

60. Transition probabilities can be derived from the model. The exit rate from receipt is one minus the probability of remaining in receipt $\left(s_{i t}\right)$, i.e. one minus the probability of being in receipt at $t$, conditional on being in receipt at $t-1$. The receipt entry rate, $e_{i t}$, is the probability of being in receipt at $t$, conditional on not being in receipt at $t-1$. Expressions for these probabilities are given, respectively, by:

$$
s_{i t} \equiv \operatorname{Pr}\left(y_{i t}=1 \mid y_{i t-1}=1, Z_{i t-1}, X_{i t-1}\right)=\frac{\Phi_{2}\left(\gamma_{1} Z_{i t-1}, \beta^{\prime} X_{i t-1} ; \varphi\right)}{\Phi\left(\beta^{\prime} X_{i t-1}\right)}
$$

and

$$
e_{i t} \equiv \operatorname{Pr}\left(y_{i t}=1 \mid y_{i t-1}=0, Z_{i t-1}, X_{i t-1}\right)=\frac{\Phi_{2}\left(\gamma_{2}{ }^{\prime} Z_{i t-1},-\beta^{\prime} X_{i t-1} ;-\varphi\right)}{\Phi\left(-\beta^{\prime} X_{i t-1}\right)}
$$

where $\Phi_{2}($.$) is the cumulative density functions of the bivariate standard normal distribution. With$ expressions for these probabilities, one can derive the 'Boskin-Nold' expressions describing the process of benefit dynamics that were mentioned earlier in the context of the basic transition rate model (Cappellari and Jenkins 2004).

61. State dependence refers to the extent to which the chances of receiving social assistance at $t$ differ according to whether social assistance was received at $t-1$, while controlling for the effects of heterogeneity, observed and unobserved. The degree of state dependence may be summarised by calculating, for each individual, the difference between the predicted probability of receipt conditional on receipt and the predicted probability of receipt conditional on being a non-recipient poor last period, and then taking the average across all individuals. ${ }^{13}$

13. The calculation of individual-specific probability differences (which are then averaged) ensures that individual heterogeneity is controlled for. 
62. The endogenous switching model addresses the three shortcomings of the basic model and, in principle, it may also be extended to take account of panel attrition and other endogenous selection processes. ${ }^{14}$

63. Estimation of the endogenous switching model requires, at minimum, observations on a large number of individuals for a pair of successive years $(t-1$ and $t)$, as for the basic model. Typically however sample sizes for a single pair of years are relatively small - the advantage of a long run of panel data is that it provides multiple pairs of base and current years. Both this model and the basic model use these multiple year-pairs by pooling them. This raises no additional issues for the basic model because of the strong assumptions incorporated in its specification. Pooling does raise issues for the estimation of the endogenous switching model. The observations in the pooled data set are not independently distributed: because the data set contains repeated observations on the same individual, the common individual-specific unobserved error components induce cross-observation correlations and thence biased estimates of standard errors. Econometricians usually recommend handling this issue by estimating the model in a manner that takes account of this aspect - what is known as 'integrating out' the individual-specific effect. The feasibility of applying this procedure to estimation of endogenous switching models declines rapidly, the greater the number of waves of data used, and the more processes that are modelled. In the light of this, Cappellari and Jenkins $(2004,2008)$ propose that, instead of using a model-based approach, analysts control for the effects of cross-observation correlations using a cluster-robust estimator.

64. A feature of the Cappellari-Jenkins approach of pooling transitions is that the same initial conditions specification is used for every year $t-1$ forming part of every year $t-1$-year $t$ transition pair. The term 'initial conditions' is therefore perhaps a misnomer in this context, and arguably should be reserved for the first year of a complete sequence of observations for a given individual rather than the first year in each transition pair.

65. Labels aside, observe that statistical identification of the parameters of the endogenous switching model - other than by appeal to functional form - requires the availability of variables among the regressors $\left(X_{t-1}\right)$ in the base year receipt probability equation that do not also explain the current year receipt probability. We discuss this general issue of finding 'instruments' below.

\section{Lagged dependent variable models (dynamic random effects probit models)}

66. A 'lagged dependent variable' approach is one employed for the analysis of social assistance dynamics by Andrén (2007), Hansen, Lofstrom (2006), and Hansen, Lofstrom, and Zhang (2006). The approach has also been used to study the dynamics of unemployment by e.g. Arulampalam, Booth, and Taylor (2000) and Stewart (2007). Biewen (2004) also used the approach, and extensions of it, to study poverty dynamics. Econometricians refer to the model as a dynamic random effects probit model.

Let

$$
p^{*}{ }_{i t}=\gamma^{\prime} Z_{i t}+\lambda y_{i t-1}+\tau_{i}+\zeta_{i t} ; \quad t=2, \ldots, T_{i}
$$

describe the latent probability of social assistance receipt in each year of the sequence of $T_{i}$ years for which an individual is observed in the panel, excluding the first year $(t=1)$. An individual is observed to be in receipt, $y_{i t}=1$, in year $t$ if $p^{*}{ }_{i t}>0$ and $y_{i t}=0$ otherwise.

67. By contrast with the endogenous switching model, all the effects of receipt at $t-1$ (state dependence) are characterised through the coefficient on the lagged dependent variable $\left(y_{i t-1}\right)$ - hence our

14. For an application, see Cappellari and Jenkins (2008). 
label for the model. The larger (more positive) the value of $\lambda$, the greater the degree of state dependence in benefit receipt probabilities. As with the endogenous switching model, unobserved individual heterogeneity is characterised by a fixed individual-specific component $\left(\tau_{i}\right)$ and a white noise error component $\left(\zeta_{i t}\right)$, where the error terms are uncorrelated with each other and with the explanatory variables included in $Z_{i t}$. The errors are each assumed to have a mean of zero and be normally distributed (so it is a probit model), with the variance of $\varepsilon_{i t}$ normalised to be one, and variance of $\tau_{i}$ estimated from the data. ${ }^{15}$

68. The standard random effects model assumes that the unobserved individual-specific components are uncorrelated with the observed explanatory variables. We follow Mundlak (1978) and Chamberlain (1984), and a number of authors since, in allowing for correlations between $u_{i}$ and $Z_{i t}$ by supposing that

$$
\tau_{i}=\xi^{\prime} \bar{Z}_{i}+u_{i}
$$

where $u_{i}$ is distributed $N\left(0, \sigma_{u}^{2}\right)$ and is assumed independent of $Z_{i t}$ and $\zeta_{i t}$ for all persons and time periods. The $\bar{Z}_{i}$ may be defined in several ways - we follow the common practice of defining them as the longitudinal average for each individual of each characteristic within the vector $Z_{i t}$ (with the exception of intrinsically time-varying variables like age). ${ }^{16}$ Intuitively, differences in longitudinal averaged characteristics are informative about underlying individual-specific characteristics, so that the individual differences that are left $\left(u_{i}\right)$ may be more plausibly supposed to be independent of observed characteristics. For brevity in notation, we subsume the time-averaged variables into the vector $Z_{i t}$ henceforth.

69. The model assumes that the correlation between the composite errors from any two years $t$ and $s$, $t \neq s$, is the same for any $t, s=2, \ldots, T_{i}$ :

$$
\rho=\operatorname{corr}\left(u_{i}+\zeta_{i t}, u_{i}+\zeta_{i s}\right)=\sigma_{u}^{2} /\left(1+\sigma_{u}^{2}\right) .
$$

70. As with the endogenous switching model, there is an issue for estimation concerning the 'initial conditions' of the sequence of observations for each individual - whether $y_{i 1}$ is independent of $u_{i}$. If receipt in the initial year is correlated with the time-invariant individual-specific effect, a correlation is induced between the error term and the lagged dependent variable in (7), leading to bias in parameter estimates.

71. There are several approaches to handling endogenous initial conditions, of which the most popular is that proposed by Heckman (1981). The receipt equation for the first year is specified using a reduced-form linear approximation as

$$
p^{*}{ }_{i 1}=\pi^{\prime} X_{i 1}+v_{i}
$$

\footnotetext{
15. Although normality is the most commonly used assumption concerning the distribution of the error components, some authors have considered instead discrete mass point distributions: see e.g. Hansen, Lofstrom, and Zhang (2006), and Stewart (2007). Hansen and Lofstrom (2006) used a random effects logit specification rather than a random effects probit one. There have also been extensions of the model that allow for an autocorrelated error structure for the error term Cit (Andrén 2007, Stewart 2007) or unrestricted error structure (Andrén 2007).

16. Neither Andrén (2007) or Hansen, Lofstrom, and Zhang (2006) appear to have used the MundlakChamberlain approach.
} 
where $v_{i}$ is assumed to be distributed as standard normal and correlated with $\tau_{i}$ but not with $\zeta_{i t}$. Such a correlation is typically modelled as an orthogonal projection of $v_{i}$ on $\tau_{i}$ :

$$
v_{i}=\theta \tau_{i}+\zeta_{i 1}
$$

72. The presence of correlated individual specific effects in equations (7) and (8) implies that the initial period equation must be modelled jointly with the dynamic equation in order to obtain consistent maximum likelihood estimators.

73. Estimation of the full model using the Heckman estimator is typically done by 'integrating out' the individual-specific error term from the likelihood function using quadrature methods or by using maximum simulated likelihood methods. We use the latter: see Appendix A for discussion of software issues.

74. There are other estimators of the full model that do not rely on such computationally intensive techniques. Orme $(1997,2001)$ suggested a two-step procedure in the spirit of Heckman's (1979) methods for corrections for sample selection. Orme noted that if the individual-specific random effect is factorised into orthogonal components $u_{i}=\delta \eta_{i}+w_{i}$, so that equation (7) becomes

$$
p^{*}{ }_{i t}=\gamma^{\prime} Z_{i t}+\lambda y_{i t-1}+\delta \eta_{i}+w_{i}+\varepsilon_{i t}
$$

and if one can control for the presence of the $\eta_{i}$ term in the equation, then the initial condition issue no longer applies. Orme suggests accounting for $\eta_{i}$ using a generalised error term derived from the initial condition equation. The generalised error is defined as

$$
\mathrm{E}\left(\eta_{i} \mid y_{i 1}\right)=k_{i} \phi\left(\pi^{\prime} X_{i 1}\right) / \Phi\left(k_{i} \pi^{\prime} X_{i 1}\right)
$$

where $k_{i}=2 y_{i 1}-1$, and $\phi($.$) is the standard normal density function. The derivation relies on an assumption$ that the correlation between $\tau_{i}$ and $y_{i 1}$ is relatively 'small'. Moreover, there is a potential problem because the generalised error is heteroscedastic. However, Orme provided Monte Carlo evidence suggesting that the estimator performed relatively well. So, too does the work of Arulampalam and Stewart (2008).

75. Another approach to accounting for initial conditions that is increasingly used is the conditional maximum likelihood estimator proposed by Wooldridge (2005). Rather than modelling the joint distribution of the sequence of binary receipt indicators from the initial one to the final one conditioning on the set of explanatory variables, Wooldridge suggested modelling the distribution of the binary receipt indicators from $t_{i}=2, \ldots, T_{i}$, and conditioning on the set of explanatory variables and the binary receipt indicator for the initial year. Wooldridge proposed modelling the distribution of $\tau_{i}$ conditional on $y_{i 1}$ and either $Z_{i}=\left(Z_{i 1}, Z_{i 2}, \ldots, Z_{i T}\right)$, or $\bar{Z}_{i}$. His model for the individual-specific component (abstracting from $\bar{Z}_{i}$ already incorporated using the Chamberlain-Mundlak specification) can be written as:

$$
\tau_{i}=a_{0}+a_{1} y_{i 1}+u_{i}+\zeta_{i t}
$$

so that the dynamic equation becomes

$$
p^{*}{ }_{i t}=\gamma^{\prime} Z_{i t}+\lambda y_{i t-1}+\xi^{\prime} \bar{Z}_{i}+a_{0}+a_{1} y_{i 1}+u_{i}+\zeta_{i t} ; \quad t=2, \ldots, T_{i} .
$$


By contrast with the Heckman and Orme approaches, the initial state is not modelled.

76. As Stewart (2007, p. 516) points out, '[t] he estimator can be viewed as simply using a different approximation which has computational advantages'. Those advantages are that the model can be estimated using standard random-effects probit software modules (see Appendix A). There is some evidence that the Heckman, Orme and Wooldridge estimators lead to similar estimates: see Arulampalam and Stewart (2008).

77. The Orme and Wooldridge estimators were developed assuming a balanced panel: the sequence of observations is the length for each individual $\left(T_{i}=T\right.$, all $\left.i\right)$. However, both may be applied to unbalanced panels assuming that sample dropout is ignorable - the unobservable determinants of attrition are not correlated with the unobservables determining SA receipt. This assumption is ubiquitous in this context and we use it too. We also note that even where researchers have found that sample dropout is nonignorable when modelling of labour market dynamics, the impact of attrition is small (see Cappellari and Jenkins 2008 and the references cited therein). To check the robustness of our results, we report estimates derived using the Heckman, Orme, and Wooldridge estimators, and using both balanced and unbalanced panels.

78. The dynamic random effects probit model may be used to provide estimates of transition probabilities for individuals of different types by conditioning on receipt status at $t-1$, since the model implies that the SA persistence rate is:

$$
s_{i t} \equiv \operatorname{Pr}\left(y_{i t}=1 \mid y_{i t-1}=1, Z_{i t}\right)=\Phi\left(\left(\gamma^{\prime} Z_{i t}+\lambda\right) /(1-\rho)^{0.5}\right)
$$

and SA entry rate is

$$
e_{i t} \equiv \operatorname{Pr}\left(y_{i t}=1 \mid y_{i t-1}=0, Z_{i t}\right)=\Phi\left(\left(\gamma^{\prime} Z_{i t}\right) /(1-\rho)^{0.5}\right) .
$$

79. From these expressions, one may also derive 'Boskin-Nold' expressions describing the process of benefit dynamics: see Section 5. Hansen, Lofstrom, and Zhang (2006) estimate models of SA receipt separately for Canadian provinces, and report model-based estimates of transition probabilities for a 'representative' individual in each province. Arulampalam, Booth, and Taylor (2000), and Stewart (2007) also report estimates of 'average' $s_{i t}$ and $e_{i t}$, together with the associated average partial effect (APE) and predicted probability ratio (PPR). Their method involves computing $s_{i t}$ and $e_{i t}$ for each individual in the sample, and then averaging each probability over all individuals. The difference between the averages is the APE; their ratio is the PPR. Since the calculations of $s_{i t}$ and $e_{i t}$ control for observed and unobserved heterogeneity, and are the same except that one assumes SA receipt at $t-1$ and the other assumes nonreceipt, the APE and PPR are natural measures of the magnitude of state dependence.

80. As with the endogenous switching models, identification of the dynamic random effects probit model estimated using the Heckman and Orme estimators is best secured with suitable instruments for initial conditions - explanatory variables that explain receipt probabilities in the initial year but which do not also explain the current year receipt probability. Without these, identification of the model relies on non-linearities in functional form. Interestingly, Andrén (2007) and Hansen, Lofstrom and Zhang (2006) appear to rely on functional form assumptions for identification - instruments for the initial conditions equation are not mentioned. ${ }^{17}$ Arulampalam, Booth and Taylor (2000) and Stewart (2007) use pre-sample information about family background and early labour market experiences as instruments, and so do we.

17. Biewen (2004) and Hansen and Lofstrom (2006) rely on a version of the Wooldridge estimator. Because initial conditions are not modelled, instruments are not required. 
81. Overall, there is little to choose between lagged dependent variable and endogenous switching models taking into account both flexibility of specification and ease of estimation. However, lagged dependent variable models have been the models most commonly used in applications to social assistance benefit dynamics, and also used to study related phenomena such as unemployment and poverty dynamics. So, they are the ones we use in this research.

\section{Sample selection criteria and explanatory variables}

\section{Sample selection criteria}

82. We have access to fifteen waves of BHPS data, ${ }^{18}$ so our analysis data set may contain up to a maximum of 15 observations per individual on social assistance benefit participation and other variables. At least two consecutive waves of data are required to estimate any of the models of dynamics. Individuals may join the panel at wave 1 (survey year 1991) if they are original sample respondents. ${ }^{19}$ They join the panel at later waves if they are the children of original sample members and become respondent adults in their own right, or join (and remain with) a household containing an original sample respondent e.g. through marriage to that respondent. We track individuals from when they are first observed as BHPS respondents until the first wave at which they drop out of the panel, either completely non-responding or with item non-response of sufficient degree that the individual's data cannot be used for estimation. If individuals rejoin the panel at some later wave, leading to gaps in benefit receipt sequences, we exclude them because taking account of intermittent participation complicates modelling substantially (especially initial conditions). Thus, we focus on what is known as the 'absorbing attrition' case.

83. The sample used for the empirical analysis was restricted to individuals of working age and not in full-time education (see earlier), and not missing data on some important explanatory variables. The sample selection criteria, applied sequentially, are summarized in Table 2, together with the numbers of person-year observation excluded by each selection. The basic estimation sample comprises 75,988 person-wave observations for 9,036 adults. The minimum value of $T_{i}$ is 2 and the maximum value is 15 . The majority of the sequences start at wave 1 ( 5,067 out of 9,036 , i.e. $56 \%$ of all adults in the sample), but there are sequences that begin at each subsequent wave as well (roughly 200-300 adults each year).

Table 2. Sample selection criteria and sample numbers

\begin{tabular}{l|rr}
\hline Sample selection criteria (sequential) & \multicolumn{2}{|c}{$\begin{array}{c}\text { Number of person-year observations } \\
\text { Excluded }\end{array}$} \\
\hline $\begin{array}{l}\text { Full BHPS sample (15 waves; all individuals in households } \\
\text { in the original 1991 sample, or in split-off households in } \\
\text { later waves }\end{array}$ & & 187563 \\
Less & & \\
Missing benefit unit type information & 109 & 187454 \\
Dependent children & 43184 & 144270 \\
Respondent aged $<25$ or $>59$ & 53332 & 90938 \\
Spouse (if present) aged $<25$ or $>59$ & 4926 & 86012 \\
Adults in benefit units with at least 1 full-time student & 1322 & 84690 \\
Missing unemployment rate information & 17 & 84673 \\
Gaps in response sequence & 6270 & 78403 \\
Respondent at only one wave & 2415 & 75988 \\
\hline \multicolumn{2}{l}{ The analysis subsample of 75,988 person-wave observations relates to 9,036 adults. }
\end{tabular}

18. See http://www.iser.essex.ac.uk/ulsc/bhps/ for BHPS documentation and information about how to access the data.

19. We do not use observations from the extension samples for Scotland, Wales and Northern Ireland. See n. 9. 


\section{Unbalanced versus balanced panels}

84. There are 9,036 adults in our analysis data set but only $22 \%$ of them - 1,996 adults contributing 29,940 person-wave observations - were respondents at all fifteen waves. Clearly, restricting analysis to a fifteen-wave balanced panel reduces sample numbers substantially, thereby reducing the precision of parameter estimates, other things being equal. Another problem is that a balanced sample may be a nonrandom sub-sample of all respondents (unobserved characteristics associated with retention may be associated with the unobserved characteristics that raise the probability of receiving social assistance). We work with an unbalanced sample for most analysis but check robustness by re-estimating some models using a fifteen-wave balanced panel. With our unbalanced panel we are able to cover a longer period in calendar time, during which there were major changes to the British benefit system and, in respect of attrition, we are less selective. Our practice differs from that of other researchers, however.

85. The social assistance dynamics papers by Andrén (2007), and Hansen, Lofstrom, and Zhang (2006), use balanced panels. Hansen and Lofstrom (2006, p.7) state explicitly that they used a balanced panel to derive the estimates reported, but also say that they estimated the model with an unbalanced panel as a sensitivity check. Our fifteen-year period is longer than in these studies - 10 years in the Swedish studies, and six years for the Canadian one. Stewart's (2007) authoritative study of individual unemployment dynamics used a balanced six-wave panel of 3,060 adults drawn from the BHPS waves 16. Biewen (2004) used a balanced panel of 2,427 men from the German Socio-Economic Panel, survey years 1991-2001. Arulampalam, Booth, and Taylor (2000) used an unbalanced panel from waves 1-5 of the BHPS, but report that using a balanced panel led to 'unaltered' conclusions.

\section{Explanatory variables}

86. Our explanatory variables other than lagged SA receipt status - i.e. the measures of characteristics that comprise $Z_{i t}$ - are of four main types. First, there are individual-level variables, which summarize characteristics of the respondent, plus his or her spouse (if present in the benefit unit). Second, there are benefit unit-level variables that take the same value for each adult within the same benefit unit. Third, there are the longitudinally-averaged variables derived for each individual from the first two types of variable, and used to implement the Mundlak-Chamberlain approach. Fourth and finally, there are variables taking account of variations in receipt probabilities with calendar time that are not captured by other variables.

87. The set of variables used is similar to those used in previous studies of social assistance dynamics. The main differences arise partly as a consequence of our differing samples. Because we have potentially more than one adult per benefit unit in the sample, we take account of spousal characteristics as well as those of respondents. And because our data span a longer time period, we give greater attention to accounting for time trends.

88. The individual-level variables used to summarise the characteristics of a respondent, and of a spouse (if present) are as follows:

- $\quad$ Age (in years) as at $1^{\text {st }}$ December of the year prior to the survey year.

- Sex: whether the respondent is female or not.

- Educational qualifications. We distinguish between four categories: none, low, high, and missing. Low refers to having CSE(s) and/or O-levels; high refers to having A-level(s) or higher qualifications such as a degree. There is a non-negligible fraction of respondents with missing data on educational qualifications (see below). These are mostly respondents for whom only a 
proxy interview was gained - there was sufficient information derived about other characteristics of the individual from the proxy respondent so that the individual could be included in the sample. The missing qualifications indicator is better interpreted as a control for response propensity than as a measure of educational qualifications.

- Health problems (respondent only): whether someone stated that $\mathrm{s} /$ he experiences any health problems. Respondents are asked whether they have any of 13 health problems or disabilities listed on a showcard. ${ }^{20}$ We used this measure rather than any other of the health measures in the BHPS as only this one was available at each interview waves $1-15$.

89. We also considered ethnic minority group membership as an explanatory variable, but have chosen not to, primarily because the large number of such groups meant that there were small cell size problems. Cell size problems cannot be overcome by simply pooling groups. A simple distinction between, UK and foreign born, or between 'white' and 'non-white', say, does not do justice to the large degree of diversity between the many groups in the UK. There is a large number of non-white groups (each with very few representatives in the BHPS sample), and they have diverse experiences. Moreover many members of ethnic minority groups are UK-born and UK citizens. (And a number of 'white' people are not.) Spouse's health was dropped after preliminary analysis indicated it was never statistically significant. For the same reason, we also dropped any differentiation between legally marriages and cohabiting unions. (Assessments of benefit eligibility also make no distinction.) For brevity, we shall refer to both types of partnership as 'married'.

90. The benefit unit-level variables are as follows:

- Presence of dependent children in the benefit unit: binary indicators for whether the number of children present is zero, one, two, or three or more, and whether the age of the youngest child is less than five years.

- Benefit unit type: binary indicators for whether a single adult, couple (legally married or cohabiting), or a lone parent unit. These variables can also be interpreted as characterizing interactions between marital status and presence of children.

- Region: whether the respondent lives in inner or outer London. There are 18 regions that can be distinguished in the BHPS but we focus on differences between London and the rest of the country. This was the key distinction that was apparent from preliminary analyses.

- Housing tenure: whether the respondent lived in owner-occupied housing rather than some other tenure.

- Unemployment rate (\%). Our measure is the ratio of the number of unemployed to the number in the labour force for the respondent's travel-to-work area (TTWA) at the time of the interview,

20. The problems or disabilities refer to: (1) Problems or disability connected with: arms, legs, hands, feet, back, or neck (including arthritis and rheumatism); (2) Difficulty in seeing (other than needing glasses to read normal size print); (3) Difficulty in hearing; (4) Skin conditions/allergies; (5) Chest/breathing problems, asthma, bronchitis; (6) Heart/blood pressure or blood circulation problems; (7) Stomach/liver/kidneys; (8) Diabetes; (9) Anxiety, depression or bad nerves; (10) Alcohol or drug related problems; (11) Epilepsy; (12) Migraine or frequent headaches; (13) Other health problems. 
derived from JUVOS sources. ${ }^{21}$ This is a measure of local labour market tightness. The series is not entirely comparable over time because of changes in definitions during the 1990s (consistent series were used for waves $1-5$ and for waves 6-15) but the changes do not appear to have had an impact on estimates (see also the trends reported in Table 3). Another potential problem is that data could not be matched in for a minority of cases. To address this issue, we used respondentspecific linear interpolations for wave $t$ based on the respondent-specific rates for wave $t-1$ and wave $t+1$. For the cases remaining with missing unemployment rate data, we imputed values using the average rate for the respondent's region for that survey year. Nineteen cases for whom no imputation was possible (data on region was missing) were dropped: see Table 2.

Considered in preliminary analysis but later dropped was an indicator of whether the individual lived in a household containing more than one benefit unit. It was never statistically significant.

91. We also consider whether the impact of SA receipt at $t-1$ differs between groups of respondents, i.e. whether there is heterogeneity in any potential state dependence effect. First, we differentiate between respondents who have been in continuous SA receipt since their previous interview and those in noncontinuous receipt (with a spell of non-receipt after the previous interview and before the current interview). Second, we investigate whether persistence probabilities differ between lone parents and other respondents, on the grounds that lone parents have distinctively long spells of receipt. See Section 5 for more details.

92. The longitudinal time-averaged variables were derived for each respondent from the variables described above (with the exception of age and educational qualifications). The averages were over the $T_{i}$ waves sequence for each individual.

93. Calendar time is a potentially important explanatory variable in its own right as one might expect the various changes made to the British social security system between 1991 and 2005 to be reflected in the coefficients on variables summarizing the passage of time. ${ }^{22}$ Time may also reflect any other calendar time-varying effect such as the business cycle (that is not already picked up by our measure of the local unemployment rate). In the basic models reported first, we simply include indicator variables for each survey year in the receipt probability equation. Thus, equation (7) is modified to

$$
p^{*}{ }_{i t}=w_{3} W_{i 3}+w_{4} W_{i 4}+\ldots+w_{15} W_{i 15}+\gamma^{\prime} Z_{i t}+\lambda y_{i t-1}+\tau_{i}+\zeta_{i t} ; \quad t=2, \ldots, T_{i}
$$

where $W_{i k}, k=2003, \ldots, 2005$, is a survey year indicator variable for person $i$. The reference year is 1992 (wave 2) and its effect is represented by the constant term included within the $Z_{i t}$ vector. In this specification, the survey year variables act as intercept shifters, and fit variations with time that are common to both the probability of SA receipt persistence and of SA entry. In subsequent models, we also allow time to affect SA entry probabilities separately, by introducing interactions between survey year

21. JUVOS: the Joint Unemployment \& Vacancies Operating System Cohort (a 5\% sample of all conputerised claims for unemployment-related benefits selected by reference to a claimants's National Insurance Number).

\section{See e.g. http://www.statistics.gov.uk/STATBASE/Analysis.asp?vlnk=224\&More=Y}

22. We should stress that our ability to conclude that the reforms caused observed changes is constrained. These multivariate models provide informative descriptions of benefit dynamics; they are not structural models nor based on a (quasi-)experimental design. Note also that policy changes may also have an impact over time by changing the composition of the populations at risk of entering or leaving SA receipt (the distributions of the explanatory variables). 
indicators and the lagged SA receipt indicator. (Put another way, the state dependence effect varies with survey year.) In this case, survey year also acts as a slope shifter as well.

$$
\begin{aligned}
p^{*}{ }_{i t}=\quad & w_{3} W_{i 3}+w_{4} W_{i 4}+\ldots+w_{15} W_{i 15}+\gamma^{\prime} Z_{i t} \\
& +\left(\lambda_{2} W_{i 2}+\lambda_{3} W_{i 3}+\lambda_{4} W_{i 4}+\ldots+\lambda_{15} W_{i 15}\right) y_{i t-1} \\
& +\tau_{i}+\zeta_{i t} ; \quad t=2, \ldots, T_{i}
\end{aligned}
$$

94. To anticipate some results, our final specification is a restricted version of equation (17). We find that it is statistically acceptable to distinguish simply between years before and after 1998, for both intercept and slope interactions. See Section 5.

95. In common with previous literature, our explanatory variables do not include measures of events that might trigger moves into or out of receipt such as job loss or job gain, or a marital split or departure or arrival of a new born child. The appeal of including them is that they may help better 'explain' the dynamics of benefits. The problem is that the variables are potentially endogenous, they can only occur to some types of individual (e.g. already-married people cannot get married, unemployed people cannot lose a job) and so there are issues about how to incorporate such variables in a multivariate model and (related) point-in-time characteristics may already incorporate much of the variation encapsulated by these variables. There is also a more general question of whether the assumption of 'strict exogeneity' underlying the lagged dependent variable models holds. For example, is it appropriate to assume that past benefit receipt is not itself a determinant of some of the variables used to explain current benefit receipt, e.g. whether living as a couple or not, or family size? If there are these feedback effects which are not incorporated into the model, then one can derive biased estimates of the impacts of explanatory variables and of the degree of state dependence. As in virtually all the related literature to date we shall assume that feedback effects can be safely ignored. ${ }^{23}$

96. We utilise as instruments for initial conditions variables that have been used in similar contexts, notably the modelling of individual unemployment dynamics using BHPS data by Arulampalam, Booth and Taylor (2000) and Stewart (2007). These are individual-specific variables as follows:

- Whether or not the individual's first labour market spell after leaving full-time education was a spell of employment or self-employment rather than unemployment or inactivity.

- Binary indicators summarizing the socioeconomic group associated with the first job that the respondent had. We distinguished between professional and managerial, non-manual, manual, other (e.g. armed forces or agriculture), and 'missing' (the reference category).

- Measures of the respondent's family background, defined using respondents' responses to questions asking them about their mother and their father when they (the respondents) were aged 14. Specifically these are a set of dummy variables summarising factors such as whether either or both parents were alive at that time and, if so, whether they were employed or not.

23. See Biewen (2004) for further discussion of the strict exogeneity assumption and estimation of a model of poverty dynamics incorporating feedback effects. 


\section{Summary: the impact of explanatory variables on transition probabilities}

97. Consider first transition probabilities at the individual level. Supposing that the estimated coefficient on an variable within the characteristics vector $Z_{i t}$ is positive (negative), then the effect of an increase in the value of the particular characteristic is to increase (decrease) both the SA entry rate $e_{i t}$ and the SA persistence rate $s_{i t}$. For example, thinking about characteristics associated with labour market success (and hence non-receipt of SA), we would expect higher educational qualifications and lower unemployment rates to be associated with lower persistence rates and lower entry rates. Individuals with children, especially young children, and lone parents in particular, would be expected to have higher persistence rates and higher entry rates. So too would those living in rented accommodation, other things being equal, given the positive association between home ownership and affluence. (The idea is not so much that tenancy itself has an effect, but is a marker for having relatively low financial assets and, given the geographical concentration of much social housing, may also pick up adverse area effects that are not otherwise summarized by the local area unemployment rate.) Having controlled for these and other factors, it is not obvious to us what the expected associations are between transition probabilities and characteristics such as age, sex, and living in London relative to other areas of the country.

98. What about aggregate transition probabilities and their trends over time, as shown in Figure 6 in particular? Changes over time in transition probabilities can be accounted for by the model if there are parameters that are allowed to change over time. We allow for survey year intercept shifts (see equation 17) which impose a temporal pattern that is common to both the aggregate SA entry and persistence rates. Specifying the impact of past receipt to vary with survey year is the means by which differences in the temporal patterns of entry and persistence rates are accommodated. Thus, equation (17) implies that the SA persistence rate is:

$s_{i t}=\Phi\left(\left(w_{3} W_{i 3}+\ldots+w_{15} W_{i 15}+\gamma^{\prime} Z_{i t}\right.\right.$

$$
\left.\left.+\lambda_{2} W_{i 2}+\lambda_{3} W_{i 3}+\lambda_{4} W_{i 4}+\ldots+\lambda_{15} W_{i 15}\right) /(1-\rho)^{0.5}\right)
$$

and the SA entry rate is

$$
e_{i t} \equiv=\Phi\left(\left(w_{3} W_{i 3}+\ldots+w_{15} W_{i 15}+\gamma^{\prime} Z_{i t}\right) /(1-\rho)^{0.5}\right) .
$$

99. If estimates of the $w$ parameters are smaller for later survey years, SA entry and persistence rates decline over time. If estimates of the $\lambda$ parameters decline with time, the SA persistence rate declines over time.

100. Changes in the distribution of characteristics over time among the populations at risk of benefit entry and exit may also explain trends in aggregate transition rates. The aggregate SA entry rate rises or falls depending on whether there is an increase or a decrease in the proportion of current SA non-recipients with characteristics making them relatively prone to entry. Similarly the aggregate SA persistence rate rises or falls depending on whether there is an increase or a decrease in the proportion of current SA recipients with characteristics making them relatively prone to remaining in SA receipt. For example, a rise over time in the proportion of people with good educational qualifications among SA recipients and non-recipients would be expected to reduce SA persistence and entry rates over time. So would a secular decline in unemployment rates. Let us therefore investigate the trends over time in characteristics of the SA recipient and non-recipient subsamples.

\section{Explanatory variables and their trends over time}

101. The means of the explanatory variables for each survey year, and for all survey years combined are shown in Table 3. Panel A shows the information for SA non-recipients (those at risk of entry) and panel B shows the information for SA recipients (those at risk of exit). Trends for the sample as a whole 
are very similar to those for SA non-recipients because they comprise the majority of the overall analysis sample.

102. Consider non-recipients first. Panel A, part (a), shows that the average age was 41 years, half were women, and just over one half reported at least one health problem. About thirteen per cent had no educational qualifications and a quarter had only low qualifications (part b). The average age for spouses was around 32 years, a number which reflects the fact that spouse's age is set to zero if there is no spouse present (otherwise the average age is much more similar to that of the respondent). Panel (c) shows that almost a fifth of SA non-recipients had one child and another fifth had two children, and just under a fifth had a child aged less than five years. Four-fifths were part of a couple, some $17 \%$ were single adults and $3 \%$ were lone parents. Just over $80 \%$ lived in owner-occupied accommodation, and one in ten lived in London, and the average local area rate was just over $5 \%$ (panel d).

103. These are averages for the period as a whole and disguise some marked trends over time. ${ }^{24}$ Observe the upward drift in the proportion reporting a health problem (up from around $50 \%$ in 1991 to around $60 \%$ in 2005), and the large changes in the distribution of educational qualifications. The fraction of the sample with no educational qualifications or low qualifications declined from around $53 \%$ in 1991 to $26 \%$ in 2005 , whereas the proportion with high qualifications rose correspondingly. There was a rise too in the proportion with missing data on educational qualifications: this reflects the growing prevalence of proxy interviews to maintain response rates as the BHPS matured. The other main variation over time was in local area unemployment rates, which declined from almost $10 \%$ at the start of the 1990 s to just over $2 \%$ in 2005. In contrast, the means of virtually all the demographic variables (age, number and age of children, benefit unit type) changed very little over time.

104. With respect to the earlier discussion about the relationship between changes in the distribution of characteristics and transition rates, Table 3 suggests that SA entry rates declined over time because of the marked improvement in educational qualifications and the decline in local unemployment rates. (These offset any effects that might have been expected from the increase in the prevalence of health problems.) The levelling off in the rate of decline in the average local unemployment rate around 1997 is consistent with the levelling off in the decline in the SA entry rate around that year.

105. Panel B of Table 3 shows information in the same format as Panel A, but now calculated for the (much smaller) subsample of SA recipients. Compared to non-recipients and for the period as whole, the proportion of women is larger $(60 \%$ rather than $50 \%)$, and the proportion with relatively low educational qualifications is higher ( $40 \%$ rather than $13 \%$ have no qualifications). There are also striking differences in the demography of the samples. In particular, a quarter of the recipients belong to families with three or more children (compared to $8 \%$ of recipients) and the proportion with a child aged under five years is $25 \%$ rather than 18\%. About one quarter of recipients are lone parents but only $3 \%$ of non-recipients. The proportion of SA recipients living in owned accommodation averages one third for the period as a whole compared with $80 \%$ for non-recipients. In addition, recipients tend to live in areas with slightly higher unemployment rates than non-recipients. In sum, and as expected from the earlier discussion, SA receipt is concentrated among individuals with characteristics associated with disadvantage, in the labour market in particular.

106. As far as trends are concerned, there are similarities and differences between SA recipients and non-recipients. For both groups, the prevalence of health problems rose over time, but the increase is larger for recipients (from $53 \%$ to $76 \%$, compared to from $50 \%$ to $59 \%$ ). The proportion with no educational qualifications fell for both groups; so too did local unemployment rates. There are some distinctive

24. Some of these trends may reflect a selective process of sample drop-out: for instance, respondents with low educational qualifications, other things equal, have a high probability of attrition. 
demographic trends: the proportion of recipients in households with children, and with young children in particular, declined over time. There was also a marked decline in the fraction of the sample who were lone parents (from $35 \%$ in 1991 to $18 \%$ in 2005). In part, this might be explained by a shift in low income families with children (and lone parents in particular) from receipt of SA to receipt of in-work benefits, though observe that the decline in the fractions with children and of lone parents is relatively steady over the period, rather than changing sharply at the dates when major policies were introduced. Another marked trend among recipients is the decline in the proportion living in owned accommodation, from $41 \%$ in 1991 to $22 \%$ in 2005 . Put another way, the association between SA receipt and living in social housing has increased (as is relatively well-known).

107. With respect to the earlier discussion about the impact of changes in the distribution of characteristics, Panel B suggests that two trends in particular may help account for the decline in the aggregate SA exit rate over time: the rise in proportion of recipients with health problems, and (especially) the large rise in the proportion in non-owned accommodation. This is consistent with a 'creaming' hypothesis according to which the SA recipient population is increasingly made up of individuals least equipped for work.

108. We now turn from these descriptive statistics to the multivariate modelling to investigate the factors determining SA entry and exit rates in more detail. 
Table 3. Explanatory variables, means by survey year

A. SA non-recipients ( $N=70,235$ person-years $)$

(a) respondent characteristics (SA non-recipients)

\begin{tabular}{c|ccccccc}
\hline Year & $\begin{array}{c}\text { Age } \\
\text { (years) }\end{array}$ & Female & $\begin{array}{c}\text { Health } \\
\text { problems }\end{array}$ & & \multicolumn{3}{c}{ Educational qualifications } \\
& & & & None & $\begin{array}{c}\text { CSE(s), } \\
\text { O-levels }\end{array}$ & $\begin{array}{c}\text { A-level(s) or } \\
\text { higher }\end{array}$ & Missing \\
\hline 1991 & 39.69 & 0.50 & 0.50 & 0.22 & 0.31 & 0.40 & 0.07 \\
1992 & 40.36 & 0.50 & 0.51 & 0.21 & 0.29 & 0.41 & 0.09 \\
1993 & 40.55 & 0.50 & 0.53 & 0.18 & 0.28 & 0.41 & 0.13 \\
1994 & 40.56 & 0.50 & 0.52 & 0.17 & 0.28 & 0.44 & 0.11 \\
1995 & 40.73 & 0.50 & 0.52 & 0.16 & 0.28 & 0.45 & 0.11 \\
1996 & 40.68 & 0.50 & 0.54 & 0.15 & 0.29 & 0.47 & 0.09 \\
1997 & 40.87 & 0.50 & 0.56 & 0.14 & 0.28 & 0.49 & 0.09 \\
1998 & 40.96 & 0.50 & 0.56 & 0.13 & 0.27 & 0.50 & 0.09 \\
1999 & 40.94 & 0.50 & 0.55 & 0.12 & 0.26 & 0.52 & 0.09 \\
2000 & 41.11 & 0.50 & 0.58 & 0.10 & 0.25 & 0.55 & 0.10 \\
2001 & 41.12 & 0.50 & 0.58 & 0.09 & 0.24 & 0.56 & 0.11 \\
2002 & 41.12 & 0.50 & 0.60 & 0.08 & 0.23 & 0.57 & 0.12 \\
2003 & 41.30 & 0.51 & 0.58 & 0.08 & 0.21 & 0.59 & 0.12 \\
2004 & 41.30 & 0.51 & 0.57 & 0.07 & 0.20 & 0.60 & 0.14 \\
2005 & 41.89 & 0.52 & 0.59 & 0.06 & 0.20 & 0.60 & 0.13 \\
All & 40.86 & 0.50 & 0.55 & 0.13 & 0.26 & 0.50 & 0.10 \\
\hline
\end{tabular}

(b) spouse's characteristics (SA non-recipients)

\begin{tabular}{c|ccccc}
\hline Year & $\begin{array}{c}\text { Age } \\
\text { (years) }\end{array}$ & None & $\begin{array}{c}\text { Educational qualifications } \\
\text { CSE(s), O- } \\
\text { levels }\end{array}$ & $\begin{array}{c}\text { A-level(s) } \\
\text { or higher }\end{array}$ & Missing \\
\hline 1991 & 32.51 & 0.18 & 0.25 & 0.32 & 0.03 \\
1992 & 32.90 & 0.18 & 0.24 & 0.32 & 0.03 \\
1993 & 32.92 & 0.15 & 0.23 & 0.32 & 0.05 \\
1994 & 32.89 & 0.14 & 0.23 & 0.35 & 0.04 \\
1995 & 33.02 & 0.13 & 0.23 & 0.35 & 0.05 \\
1996 & 32.88 & 0.12 & 0.23 & 0.38 & 0.04 \\
1997 & 33.05 & 0.12 & 0.23 & 0.38 & 0.04 \\
1998 & 33.16 & 0.11 & 0.23 & 0.40 & 0.04 \\
1999 & 33.22 & 0.10 & 0.21 & 0.41 & 0.04 \\
2000 & 33.10 & 0.09 & 0.20 & 0.43 & 0.05 \\
2001 & 33.14 & 0.08 & 0.19 & 0.45 & 0.05 \\
2002 & 32.97 & 0.07 & 0.18 & 0.45 & 0.05 \\
2003 & 33.29 & 0.06 & 0.17 & 0.47 & 0.05 \\
2004 & 33.03 & 0.05 & 0.16 & 0.48 & 0.05 \\
2005 & 33.67 & 0.05 & 0.16 & 0.48 & 0.06 \\
All & 33.04 & 11.09 & 21.21 & 39.70 & 0.04 \\
\hline Spouse's characteristics set equal to zero if no spouse.
\end{tabular}


(c) characteristics of respondent's benefit unit (SA non-recipients)

\begin{tabular}{c|cccccccc}
\hline Year & \multicolumn{2}{|c}{ No. children in benefit unit } & $\begin{array}{c}\text { Youngest } \\
\text { child }<5\end{array}$ & \multicolumn{2}{c}{ Benefit unit type } & Couple \\
& One & Two & $\begin{array}{c}\text { Three or } \\
\text { more }\end{array}$ & \multicolumn{2}{c}{$\begin{array}{c}\text { Lone } \\
\text { parent }\end{array}$} & Couple & Single & $\begin{array}{c}\text { with } \\
\text { children }\end{array}$ \\
\hline 1991 & 0.17 & 0.23 & 0.10 & 0.19 & 0.03 & 0.81 & 0.17 & 0.47 \\
1992 & 0.17 & 0.20 & 0.08 & 0.18 & 0.02 & 0.80 & 0.17 & 0.43 \\
1993 & 0.18 & 0.20 & 0.08 & 0.18 & 0.03 & 0.80 & 0.17 & 0.43 \\
1994 & 0.19 & 0.19 & 0.08 & 0.18 & 0.03 & 0.80 & 0.17 & 0.44 \\
1995 & 0.19 & 0.19 & 0.08 & 0.18 & 0.03 & 0.80 & 0.17 & 0.43 \\
1996 & 0.18 & 0.20 & 0.08 & 0.17 & 0.03 & 0.80 & 0.17 & 0.43 \\
1997 & 0.18 & 0.19 & 0.08 & 0.17 & 0.03 & 0.80 & 0.18 & 0.42 \\
1998 & 0.19 & 0.18 & 0.08 & 0.18 & 0.03 & 0.80 & 0.17 & 0.42 \\
1999 & 0.18 & 0.19 & 0.08 & 0.17 & 0.03 & 0.80 & 0.17 & 0.42 \\
2000 & 0.19 & 0.19 & 0.08 & 0.17 & 0.03 & 0.79 & 0.18 & 0.43 \\
2001 & 0.20 & 0.19 & 0.07 & 0.17 & 0.03 & 0.80 & 0.17 & 0.43 \\
2002 & 0.19 & 0.20 & 0.07 & 0.18 & 0.03 & 0.79 & 0.18 & 0.43 \\
2003 & 0.18 & 0.21 & 0.07 & 0.17 & 0.03 & 0.79 & 0.17 & 0.43 \\
2004 & 0.19 & 0.21 & 0.07 & 0.18 & 0.03 & 0.79 & 0.18 & 0.43 \\
2005 & 0.20 & 0.22 & 0.07 & 0.18 & 0.04 & 0.80 & 0.17 & 0.45 \\
All & 0.18 & 0.20 & 0.08 & 0.18 & 0.03 & 0.80 & 0.17 & 0.43 \\
\hline
\end{tabular}

(d) other characteristics (SA non-recipients)

\begin{tabular}{c|ccc}
\hline Year & $\begin{array}{c}\text { House } \\
\text { owned }\end{array}$ & $\begin{array}{c}\text { Lives in } \\
\text { London }\end{array}$ & $\begin{array}{c}\text { Unemployment } \\
\text { rate (\%) in } \\
\text { TTWA area }\end{array}$ \\
\hline 1991 & 0.82 & 0.11 & 7.95 \\
1992 & 0.81 & 0.11 & 9.39 \\
1993 & 0.79 & 0.11 & 9.53 \\
1994 & 0.81 & 0.10 & 8.52 \\
1995 & 0.81 & 0.10 & 7.62 \\
1996 & 0.83 & 0.10 & 5.40 \\
1997 & 0.82 & 0.10 & 3.93 \\
1998 & 0.82 & 0.10 & 3.49 \\
1999 & 0.82 & 0.10 & 3.19 \\
2000 & 0.83 & 0.10 & 2.76 \\
2001 & 0.82 & 0.09 & 2.49 \\
2002 & 0.82 & 0.09 & 2.47 \\
2003 & 0.82 & 0.09 & 2.38 \\
2004 & 0.81 & 0.08 & 2.14 \\
2005 & 0.86 & 0.08 & 2.30 \\
All & 0.82 & 0.10 & 5.01 \\
\hline
\end{tabular}


Table 3. Explanatory variables, means by survey year

B. SA recipients ( $N=5,663$ person-years)

(a) respondent characteristics (SA recipients)

\begin{tabular}{c|ccccccc}
\hline Year & $\begin{array}{c}\text { Age } \\
\text { (years) }\end{array}$ & Female & $\begin{array}{c}\text { Health } \\
\text { problems }\end{array}$ & & Educational qualifications & \\
& & & & None & $\begin{array}{c}\text { CSE(s), } \\
\text { O-levels }\end{array}$ & $\begin{array}{c}\text { A-level(s) or } \\
\text { higher }\end{array}$ & Missing \\
\hline 1991 & 36.98 & 0.61 & 0.53 & 0.43 & 0.36 & 0.18 & 0.03 \\
1992 & 37.82 & 0.58 & 0.55 & 0.43 & 0.34 & 0.21 & 0.02 \\
1993 & 38.55 & 0.59 & 0.58 & 0.41 & 0.34 & 0.23 & 0.02 \\
1994 & 39.16 & 0.61 & 0.60 & 0.40 & 0.31 & 0.25 & 0.03 \\
1995 & 38.87 & 0.61 & 0.64 & 0.38 & 0.32 & 0.29 & 0.02 \\
1996 & 39.63 & 0.61 & 0.71 & 0.39 & 0.32 & 0.26 & 0.02 \\
1997 & 39.75 & 0.59 & 0.73 & 0.36 & 0.32 & 0.29 & 0.03 \\
1998 & 39.38 & 0.62 & 0.74 & 0.34 & 0.34 & 0.29 & 0.04 \\
1999 & 39.93 & 0.61 & 0.74 & 0.35 & 0.32 & 0.29 & 0.04 \\
2000 & 39.70 & 0.62 & 0.74 & 0.35 & 0.29 & 0.31 & 0.05 \\
2001 & 40.32 & 0.60 & 0.76 & 0.36 & 0.32 & 0.30 & 0.03 \\
2002 & 41.30 & 0.61 & 0.77 & 0.38 & 0.29 & 0.30 & 0.03 \\
2003 & 41.16 & 0.61 & 0.74 & 0.36 & 0.30 & 0.30 & 0.05 \\
2004 & 40.70 & 0.61 & 0.74 & 0.33 & 0.31 & 0.30 & 0.06 \\
2005 & 41.78 & 0.58 & 0.76 & 0.32 & 0.23 & 0.36 & 0.10 \\
All & 39.35 & 0.60 & 0.67 & 0.38 & 0.32 & 0.27 & 0.03 \\
\hline
\end{tabular}

(b) spouse's characteristics (SA recipients)

\begin{tabular}{c|ccccc}
\hline Year & $\begin{array}{c}\text { Age } \\
\text { (years) }\end{array}$ & None & $\begin{array}{c}\text { Educational qualifications } \\
\text { CSE(s), O- } \\
\text { levels }\end{array}$ & $\begin{array}{c}\text { A-level(s) } \\
\text { or higher }\end{array}$ & Missing \\
\hline 1991 & 20.65 & 0.23 & 0.18 & 0.10 & 0.01 \\
1992 & 21.11 & 0.23 & 0.19 & 0.11 & 0.01 \\
1993 & 22.53 & 0.24 & 0.20 & 0.12 & 0.01 \\
1994 & 21.22 & 0.21 & 0.16 & 0.13 & 0.02 \\
1995 & 22.13 & 0.22 & 0.17 & 0.16 & 0.01 \\
1996 & 22.07 & 0.23 & 0.16 & 0.15 & 0.00 \\
1997 & 20.88 & 0.19 & 0.14 & 0.15 & 0.01 \\
1998 & 20.22 & 0.18 & 0.15 & 0.15 & 0.01 \\
1999 & 20.60 & 0.18 & 0.16 & 0.13 & 0.02 \\
2000 & 20.83 & 0.21 & 0.14 & 0.13 & 0.01 \\
2001 & 22.51 & 0.22 & 0.15 & 0.14 & 0.01 \\
2002 & 23.13 & 0.23 & 0.13 & 0.16 & 0.02 \\
2003 & 22.98 & 0.19 & 0.14 & 0.18 & 0.02 \\
2004 & 24.12 & 0.23 & 0.15 & 0.16 & 0.00 \\
2005 & 25.36 & 0.21 & 0.13 & 0.19 & 0.02 \\
All & 21.80 & 21.60 & 16.26 & 13.97 & 0.01 \\
\hline Spouse's characteristics set equal to zero if no spouse.
\end{tabular}


Table 3. Explanatory variables, means by survey year

B. SA recipients $(N=5,663$ person-years $)$

(c) characteristics of respondent's benefit unit (SA recipients)

\begin{tabular}{c|cccccccc}
\hline Year & \multicolumn{2}{|c}{ No. children in benefit unit } & $\begin{array}{c}\text { Youngest } \\
\text { child }<5\end{array}$ & \multicolumn{2}{c}{ Benefit unit type } & Couple \\
& One & Two & $\begin{array}{c}\text { Three or } \\
\text { more }\end{array}$ & & $\begin{array}{c}\text { Lone } \\
\text { parent }\end{array}$ & Couple & Single & $\begin{array}{c}\text { with } \\
\text { children }\end{array}$ \\
\hline 1991 & 0.24 & 0.26 & 0.21 & 0.35 & 0.29 & 0.55 & 0.16 & 0.41 \\
1992 & 0.24 & 0.19 & 0.19 & 0.29 & 0.23 & 0.55 & 0.22 & 0.39 \\
1993 & 0.23 & 0.20 & 0.20 & 0.28 & 0.23 & 0.58 & 0.20 & 0.40 \\
1994 & 0.22 & 0.20 & 0.19 & 0.24 & 0.26 & 0.53 & 0.21 & 0.35 \\
1995 & 0.22 & 0.21 & 0.22 & 0.29 & 0.23 & 0.56 & 0.21 & 0.42 \\
1996 & 0.24 & 0.18 & 0.18 & 0.25 & 0.24 & 0.56 & 0.21 & 0.37 \\
1997 & 0.24 & 0.22 & 0.20 & 0.30 & 0.27 & 0.51 & 0.22 & 0.39 \\
1998 & 0.23 & 0.22 & 0.20 & 0.27 & 0.27 & 0.51 & 0.22 & 0.38 \\
1999 & 0.21 & 0.20 & 0.20 & 0.22 & 0.26 & 0.50 & 0.23 & 0.35 \\
2000 & 0.21 & 0.23 & 0.19 & 0.24 & 0.26 & 0.51 & 0.23 & 0.36 \\
2001 & 0.15 & 0.22 & 0.18 & 0.17 & 0.21 & 0.54 & 0.25 & 0.35 \\
2002 & 0.17 & 0.19 & 0.15 & 0.13 & 0.21 & 0.54 & 0.25 & 0.31 \\
2003 & 0.24 & 0.18 & 0.14 & 0.16 & 0.23 & 0.54 & 0.23 & 0.32 \\
2004 & 0.23 & 0.19 & 0.16 & 0.19 & 0.22 & 0.58 & 0.20 & 0.36 \\
2005 & 0.19 & 0.18 & 0.16 & 0.17 & 0.18 & 0.59 & 0.23 & 0.36 \\
All & 0.22 & 0.21 & 0.19 & 0.25 & 0.25 & 0.54 & 0.21 & 0.37 \\
\hline
\end{tabular}

Children's variables set equal to zero if no children in benefit unit.

(d) other characteristics (SA recipients)

\begin{tabular}{c|ccc}
\hline Year & $\begin{array}{c}\text { House } \\
\text { owned }\end{array}$ & $\begin{array}{c}\text { Lives in } \\
\text { London }\end{array}$ & $\begin{array}{c}\text { Unemployment } \\
\text { rate (\%) in } \\
\text { TTWA area }\end{array}$ \\
\hline 1991 & 0.41 & 0.13 & 8.55 \\
1992 & 0.38 & 0.15 & 9.98 \\
1993 & 0.41 & 0.14 & 10.23 \\
1994 & 0.37 & 0.13 & 9.26 \\
1995 & 0.36 & 0.13 & 8.19 \\
1996 & 0.30 & 0.12 & 5.58 \\
1997 & 0.32 & 0.11 & 4.22 \\
1998 & 0.31 & 0.09 & 3.85 \\
1999 & 0.25 & 0.13 & 3.59 \\
2000 & 0.32 & 0.09 & 2.96 \\
2001 & 0.27 & 0.08 & 2.85 \\
2002 & 0.29 & 0.07 & 2.67 \\
2003 & 0.26 & 0.06 & 2.67 \\
2004 & 0.20 & 0.09 & 2.31 \\
2005 & 0.23 & 0.08 & 2.54 \\
All & 0.33 & 0.11 & 6.15 \\
\hline
\end{tabular}




\section{Model estimates and their interpretation}

109. In this section we present three main groups of estimates. First, in order to check the robustness of results to the choice of estimator, we report estimates of a basic specification corresponding to equation (7) using five different estimators: a pooled probit model, a dynamic random effects probit model assuming that initial conditions are exogenous, and then three models that assume endogenous initial conditions (the Orme, Wooldridge and Heckman estimators). As it happens, results are insensitive to the choice of estimator, and we focus on estimates derived using the Heckman approach thereafter. The second group of estimates, also based on the equation (7) specification, help assess whether the choice of unbalanced or balanced panel affects the results derived. Third, we present estimates of specifications in which the basic model is augmented with interaction effects that allow the degree of state dependence (and hence entry rates also) to vary over time, and also to vary between different groups within the population. These specifications were characterized in equations (16) and (17).

\section{The basic specification}

110. Estimates of the equation (7) specification are shown in Table 4 (main equation) and in Table 5 (initial conditions equation). Explanatory variables are defined so that the reference categories characterize the situation of a single childless adult with no educational qualifications. (The spousal variables are all equal to zero in this case.) The first row of the table shows the estimate of $\lambda$, the degree of state dependence. The first column provides the estimates from a pooled probit estimator, in which no assumptions are made about the joint distribution of the $\left(y_{i 1}, y_{i 2}, \ldots, y_{i T i}\right)$ for each individual and there is no individual-specific random effect specified. This provides consistent but inefficient estimates (Biewen 2004). Column (2) provides estimates of the dynamic random effects probit model assuming that initial conditions are exogeneous, and the remaining columns show the results derived using the three estimators accounting for endogenous initial conditions.

111. Looking at the Table 4 as a whole, it is striking how similar the estimates are in terms of both magnitude and statistical significance. For example, the estimates of $\lambda-$ the coefficient on lagged SA receipt status - lie in the narrow range between 1.22 and 1.24 according to the three models allowing for endogenous initial conditions (columns $3-5$, row 1 ), and are each strongly statistically different from zero. Observe how the corresponding estimate when initial conditions are ignored provides a substantial overestimate of $\lambda$ : it is around 1.45 in this case (column 2). Because the pooled probit model uses a different normalisation from the random effects models, each coefficient estimate from this model needs to be multiplied by $(1-\rho)^{0.5}$ to make it comparable with its counterpart in columns (3)-(5), i.e. a factor of about 0.79 if one uses the Heckman estimate. Thus the pooled probit coefficient estimate of 1.87 corresponds to a scaled estimate of about 1.47, i.e. of the same order as for the model with exogenous initial conditions.

112. The magnitude of the effect of past SA receipt can be assessed using the concepts of the average partial effect (APE) and predicted probability ratio (PPR) explained earlier. We focus on the results from the Heckman estimator. In this case, the estimates in column (5) imply an average probability of SA receipt at $t$ conditional on receipt at $t-1$ of $19.2 \%$, and the average probability of receipt conditional on non-receipt at $t-1$ is $4.8 \%$. The APE is thus 14.4 percentage points $(=0.192-0.048)$ and the PPR is $4.0(=$ $0.192 / 0.048)$. Thus, on average, and controlling for heterogeneity, past receipt is associated with a difference in receipt probability of almost 15 percentage points or, said differently, the probability is some four times higher than if there was no receipt last period. These estimates are of roughly the same order of magnitude as reported by Stewart (2007, Table III, column 3) in his study of unemployment dynamics using BHPS data. They represent substantially smaller estimates of state dependence than do the 'raw' transition rates of SA persistence and entry which do not control for heterogeneity. For the period as a whole, the former is $65.5 \%$ and the latter is $2.4 \%$, representing a difference of some 63 percentage points, or a ratio of 27 to 1 . 
113. What other factors have statistically significant associations with the probability of SA receipt? All the models point to lower probabilities of receipt for women compared to men. There is a clear pattern associated with educational qualifications: respondents with more qualifications are less likely to be in receipt. Among those with a spouse present, a more qualified spouse also reduces the probability of receipt. Respondents missing educational qualifications information (mostly proxy respondents) are very unlikely to be in receipt, other things equal. Differences in age and health are not associated with statistically significant differences in the probability of receipt however.

114. The presence of a child aged under 5 years is associated with a higher chance of receiving SA but, interestingly, the number of children is not. The point estimates on the three indicator variables suggest that having more children is associated with a higher probability of receipt, but the associations are not statistically significantly different from zero. The exception is the case of a lone parent benefit unit: the combination of a single adult and the presence of dependent children leads to significantly higher probabilities of SA receipt compared to single adults without children who, in turn, have significantly higher probabilities of receipt than those who are married.

115. In addition, SA receipt probabilities are lower for respondents living in owner-occupied accommodation, in a region outside London, or in a travel-to-work-area with a relatively low unemployment rate. (The latter result is unsurprising: individuals living in areas where there are more jobs - and so less unemployment - are more likely to get a job themselves and hence less likely to receive SA.)

116. The coefficients on the survey year indicators become negative in sign from 1998 onwards, which appears consistent with the hypothesis that New Labour's policy reforms had an effect. However, the timing is not entirely as expected (WFTC was introduced in October 1999) and, in any case, none of the estimated coefficients differ significantly from zero. So, there is no strong evidence from these estimates that calendar time effects played a major role in explaining the downward trend in overall SA entry and exit rates shown earlier in Figure 6. We return to this issue later when discussing the model with an extended specification.

117. Observe that the time-averaged variables - representing relatively fixed underlying differences between individuals - play an important role in the basic model. They do help to control for potential correlations between the unobserved individual-specific error and observable characteristics: many of the coefficients on the time-averaged variables are statistically significant. Note also that the sign of the coefficient associated with each of the time-averaged variables is the same as the sign of the coefficient associated with the corresponding year-specific variable reported earlier in the table, albeit with one exception. Living in London (time-averaged) is strongly associated with lower SA receipt probabilities, but, having controlled for this proclivity, living in London in a given survey year is not associated with a higher SA receipt probability. In addition, we observe that, whereas having three or more children in any given year is apparently not associated with receipt probabilities, the time-averaged version of this variable has relatively large and statistically significant coefficient.

118. In Table 5, we report estimates of the initial conditions equation. Column (1) refers to the case in which the equation is estimated by an independent probit estimator. The estimates are used to derive the generalised error term included as a regressor in the Orme model (cf. Table 4, column 3). Column (2) shows the estimates from the initial conditions equation for the Heckman estimator, and which was estimated jointly with the model for which estimates were reported in Table 4, column 5 . Corresponding estimates for the two models are generally similar to each other in magnitude and statistical significance.

119. The results are broadly consistent with those in Table 4, but there are some differences. For example, having lower educational qualifications is associated with higher chances of SA receipt when first observed in the panel as well as with higher chances of receipt at each annual interview thereafter. 
Similarly, owner-occupation and lower local unemployment rates are associated with lower rates of receipt in both cases. On the other hand, whereas lone parenthood is associated with a higher probability of initial period receipt (with a large coefficient), being married is not. Observe too that the estimates of the survey year intercept shifters are now statistically significant, but there is no obvious pattern over time in the point estimates.

120. The final part of Table 5 shows the coefficient estimates of the instruments for initial conditions. Focusing on the results for the Heckman estimator, we find that few of the indicator variables are individually statistically significant at conventional levels. However, a Wald test of the joint hypothesis that each of the coefficients on the instruments is equal to zero cannot be rejected: the test statistic is 10.72 with a $p$-value of 0.065 . So, the initial conditions equation is arguably on the borderline of being identified by the instruments. The implication of this finding is that non-linearities in functional form are important for identification of our model. Nevertheless, we are sanguine about this finding; we are reassured because the coefficient estimates from the Heckman estimator are remarkably similar to the estimates from the Orme and Wooldridge estimators, and the initial conditions problem does not arise in the same way in those cases. 
Table 4. Dynamic effects probit models of the probability of receipt of SA at year $t$ interview

\begin{tabular}{|c|c|c|c|c|c|c|c|c|c|c|}
\hline & Pooled & & $\begin{array}{c}\text { Initial } \\
\text { conditions }\end{array}$ & & & & al conditions & doger & & \\
\hline & (1) & & $\begin{array}{c}\text { exogenous } \\
(2)\end{array}$ & & $\begin{array}{l}\text { Orme } \\
(3)\end{array}$ & & $\begin{array}{c}\text { Wooldridge } \\
(4)\end{array}$ & & $\begin{array}{c}\text { Heckman } \\
(5)\end{array}$ & \\
\hline Received SA at $t-1$ & $\begin{array}{l}1.8694 \\
(0.024)\end{array}$ & $* * *$ & $\begin{array}{l}1.4539 \\
(0.034)\end{array}$ & $* * *$ & $\begin{array}{l}1.2361 \\
(0.036)\end{array}$ & $* * *$ & $\begin{array}{l}1.2195 \\
(0.036)\end{array}$ & $* * *$ & $\begin{array}{l}1.2307 \\
(0.033)\end{array}$ & $* * *$ \\
\hline Age (years) & $\begin{array}{c}-0.0008 \\
(0.002)\end{array}$ & & $\begin{array}{c}-0.0038 \\
(0.002)\end{array}$ & & $\begin{array}{c}-0.0029 \\
(0.002)\end{array}$ & & $\begin{array}{c}-0.0024 \\
(0.002)\end{array}$ & & $\begin{array}{c}-0.0029 \\
(0.002)\end{array}$ & \\
\hline Female & $\begin{array}{c}-0.0609 \\
(0.023)\end{array}$ & $* * *$ & $\begin{array}{c}-0.0943 \\
(0.033)\end{array}$ & $* * *$ & $\begin{array}{c}-0.1050 \\
(0.036)\end{array}$ & $* * *$ & $\begin{array}{c}-0.1055 \\
(0.036)\end{array}$ & $* * *$ & $\begin{array}{c}-0.1051 \\
(0.037)\end{array}$ & $* * *$ \\
\hline Has health problem(s) & $\begin{array}{l}0.0517 \\
(0.032)\end{array}$ & & $\begin{array}{l}0.0580 \\
(0.036)\end{array}$ & & $\begin{array}{l}0.0561 \\
(0.037)\end{array}$ & & $\begin{array}{l}0.0580 \\
(0.037)\end{array}$ & & $\begin{array}{l}0.0561 \\
(0.037)\end{array}$ & \\
\hline Educational qualifications & & & & & & & & & & \\
\hline O-level(s), CSE, etc. & $\begin{array}{c}-0.2056 \\
(0.028)\end{array}$ & $* * *$ & $\begin{array}{c}-0.2698 \\
(0.042)\end{array}$ & $* * *$ & $\begin{array}{c}-0.2972 \\
(0.045)\end{array}$ & $* * *$ & $\begin{array}{c}-0.2487 \\
(0.045)\end{array}$ & $* * *$ & $\begin{array}{c}-0.2994 \\
(0.047)\end{array}$ & $* * *$ \\
\hline A-level(s) or higher & $\begin{array}{c}-0.3368 \\
(0.028)\end{array}$ & $* * *$ & $\begin{array}{c}-0.4640 \\
(0.042)\end{array}$ & $* * *$ & $\begin{array}{c}-0.5098 \\
(0.045)\end{array}$ & $* * *$ & $\begin{array}{c}-0.4332 \\
(0.045)\end{array}$ & $* * *$ & $\begin{array}{c}-0.5204 \\
(0.045)\end{array}$ & $* * *$ \\
\hline Missing & $\begin{array}{c}-0.8152 \\
(0.051)\end{array}$ & $* * *$ & $\begin{array}{c}-1.0989 \\
(0.070)\end{array}$ & $* * *$ & $\begin{array}{c}-1.1942 \\
(0.074)\end{array}$ & $* * *$ & $\begin{array}{c}-1.1138 \\
(0.073)\end{array}$ & $* * *$ & $\begin{array}{c}-1.2154 \\
(0.069)\end{array}$ & $* * *$ \\
\hline Spouse's age (years) & $\begin{array}{l}0.0027 \\
(0.002)\end{array}$ & & $\begin{array}{l}0.0029 \\
(0.003)\end{array}$ & & $\begin{array}{l}0.0032 \\
(0.003)\end{array}$ & & $\begin{array}{l}0.0041 \\
(0.003)\end{array}$ & & $\begin{array}{l}0.0033 \\
(0.003)\end{array}$ & \\
\hline Spouse: no educational qualifications & $\begin{array}{l}0.5590 \\
(0.116)\end{array}$ & $* * *$ & $\begin{array}{l}0.6568 \\
(0.131)\end{array}$ & $* * *$ & $\begin{array}{l}0.6798 \\
(0.133)\end{array}$ & $* * *$ & $\begin{array}{l}0.6925 \\
(0.134)\end{array}$ & $* * *$ & $\begin{array}{l}0.6840 \\
(0.129)\end{array}$ & $* * *$ \\
\hline Spouse has O-level(s), CSE, etc & $\begin{array}{l}0.5224 \\
(0.110)\end{array}$ & $* * *$ & $\begin{array}{l}0.6331 \\
(0.124)\end{array}$ & $* * *$ & $\begin{array}{l}0.6705 \\
(0.127)\end{array}$ & $* * *$ & $\begin{array}{l}0.6777 \\
(0.127)\end{array}$ & $* * *$ & $\begin{array}{l}0.6752 \\
(0.119)\end{array}$ & $* * *$ \\
\hline Spouse has A-level(s) or higher & $\begin{array}{l}0.3928 \\
(0.109)\end{array}$ & $* * *$ & $\begin{array}{l}0.4630 \\
(0.123)\end{array}$ & $* * *$ & $\begin{array}{l}0.4888 \\
(0.125)\end{array}$ & $* * *$ & $\begin{array}{l}0.4976 \\
(0.126)\end{array}$ & $* * *$ & $\begin{array}{l}0.4921 \\
(0.119)\end{array}$ & $* * *$ \\
\hline Spouse's missing educational qualifications & $\begin{array}{l}0.0697 \\
(0.130)\end{array}$ & & $\begin{array}{l}0.0709 \\
(0.146)\end{array}$ & & $\begin{array}{l}0.0648 \\
(0.150)\end{array}$ & & $\begin{array}{l}0.0618 \\
(0.150)\end{array}$ & & $\begin{array}{l}0.0675 \\
(0.153)\end{array}$ & \\
\hline Number of children in $\mathrm{BU}=1$ & $\begin{array}{c}-0.0274 \\
(0.051)\end{array}$ & & $\begin{array}{c}-0.0097 \\
(0.058)\end{array}$ & & $\begin{array}{l}0.0002 \\
(0.060)\end{array}$ & & $\begin{array}{l}0.0003 \\
(0.060)\end{array}$ & & $\begin{array}{l}0.0009 \\
(0.057)\end{array}$ & \\
\hline Number of children in $\mathrm{BU}=2$ & $\begin{array}{l}0.0021 \\
(0.057)\end{array}$ & & $\begin{array}{l}0.0088 \\
(0.065)\end{array}$ & & $\begin{array}{l}0.0295 \\
(0.066)\end{array}$ & & $\begin{array}{l}0.0292 \\
(0.066)\end{array}$ & & $\begin{array}{l}0.0276 \\
(0.064)\end{array}$ & \\
\hline
\end{tabular}


DELSA/ELSA/WD/SEM(2008)4

Table 4. Dynamic effects probit models of the probability of receipt of SA at year $t$ interview

\begin{tabular}{|c|c|c|c|c|c|c|c|c|c|c|}
\hline & Pooled & & $\begin{array}{c}\text { Initial } \\
\text { conditions }\end{array}$ & & & & al conditions & doger & & \\
\hline & (1) & & $\begin{array}{c}\text { exogenous } \\
\text { (2) }\end{array}$ & & $\begin{array}{l}\text { Orme } \\
\text { (3) }\end{array}$ & & $\begin{array}{c}\text { Wooldridge } \\
\text { (4) }\end{array}$ & & $\begin{array}{c}\text { Heckman } \\
\text { (5) }\end{array}$ & \\
\hline Number of children in $\mathrm{BU}=3$ or more & $\begin{array}{l}0.0292 \\
(0.073)\end{array}$ & & $\begin{array}{c}0.0558 \\
(0.082)\end{array}$ & & $\begin{array}{l}0.0893 \\
(0.084)\end{array}$ & & $\begin{array}{l}0.0925 \\
(0.084)\end{array}$ & & $\begin{array}{l}0.0925 \\
(0.082)\end{array}$ & \\
\hline Age of youngest child $<5$ & $\begin{array}{l}0.2405 \\
(0.041)\end{array}$ & $* * *$ & $\begin{array}{l}0.2846 \\
(0.046)\end{array}$ & $* * *$ & $\begin{array}{l}0.2997 \\
(0.047)\end{array}$ & $* * *$ & $\begin{array}{l}0.3061 \\
(0.047)\end{array}$ & $* * *$ & $\begin{array}{l}0.2997 \\
(0.044)\end{array}$ & $* * *$ \\
\hline BU type: lone parent & $\begin{array}{l}0.5451 \\
(0.079)\end{array}$ & $* * *$ & $\begin{array}{l}0.6725 \\
(0.089)\end{array}$ & $* * *$ & $\begin{array}{l}0.7160 \\
(0.091)\end{array}$ & $* * *$ & $\begin{array}{l}0.7427 \\
(0.091)\end{array}$ & $* * *$ & $\begin{array}{l}0.7103 \\
(0.082)\end{array}$ & $* * *$ \\
\hline BU type: couple & $\begin{array}{c}-0.6253 \\
(0.144)\end{array}$ & $* * *$ & $\begin{array}{c}-0.7376 \\
(0.174)\end{array}$ & $* * *$ & $\begin{array}{c}-0.7885 \\
(0.180)\end{array}$ & $* * *$ & $\begin{array}{c}-0.8337 \\
(0.181)\end{array}$ & $* * *$ & $\begin{array}{c}-0.7970 \\
(0.177)\end{array}$ & $* * *$ \\
\hline House tenure: owned & $\begin{array}{c}-0.1018 \\
(0.050)\end{array}$ & $* *$ & $\begin{array}{c}-0.1856 \\
(0.057)\end{array}$ & $* * *$ & $\begin{array}{c}-0.2144 \\
(0.058)\end{array}$ & $* * *$ & $\begin{array}{c}-0.2157 \\
(0.058)\end{array}$ & $* * *$ & $\begin{array}{c}-0.2153 \\
(0.055)\end{array}$ & $* * *$ \\
\hline Lives in London (inner or outer) & $\begin{array}{l}0.2752 \\
(0.145)\end{array}$ & $*$ & $\begin{array}{l}0.3008 \\
(0.164)\end{array}$ & $*$ & $\begin{array}{l}0.3295 \\
(0.169)\end{array}$ & $*$ & $\begin{array}{l}0.3301 \\
(0.169)\end{array}$ & $*$ & $\begin{array}{l}0.3318 \\
(0.137)\end{array}$ & $* *$ \\
\hline Unemployment rate in TTWA (\%) & $\begin{array}{l}0.0288 \\
(0.008)\end{array}$ & $* * *$ & $\begin{array}{l}0.0336 \\
(0.010)\end{array}$ & $* * *$ & $\begin{array}{l}0.0391 \\
(0.011)\end{array}$ & $* * *$ & $\begin{array}{l}0.0329 \\
(0.011)\end{array}$ & $* * *$ & $\begin{array}{l}0.0394 \\
(0.011)\end{array}$ & $* * *$ \\
\hline Survey year & & & & & & & & & & \\
\hline 1993 & $\begin{array}{l}0.0164 \\
(0.045)\end{array}$ & & $\begin{array}{l}0.0014 \\
(0.049)\end{array}$ & & $\begin{array}{l}0.0245 \\
(0.051)\end{array}$ & & $\begin{array}{l}0.0191 \\
(0.051)\end{array}$ & & $\begin{array}{l}0.0264 \\
(0.049)\end{array}$ & \\
\hline 1994 & $\begin{array}{c}-0.0387 \\
(0.046)\end{array}$ & & $\begin{array}{c}-0.0645 \\
(0.051)\end{array}$ & & $\begin{array}{c}-0.0329 \\
(0.052)\end{array}$ & & $\begin{array}{c}-0.0489 \\
(0.052)\end{array}$ & & $\begin{array}{c}-0.0294 \\
(0.053)\end{array}$ & \\
\hline 1995 & $\begin{array}{c}-0.0073 \\
(0.048)\end{array}$ & & $\begin{array}{c}-0.0430 \\
(0.054)\end{array}$ & & $\begin{array}{c}-0.0062 \\
(0.055)\end{array}$ & & $\begin{array}{c}-0.0325 \\
(0.055)\end{array}$ & & $\begin{array}{c}-0.0049 \\
(0.056)\end{array}$ & \\
\hline 1996 & $\begin{array}{l}0.0124 \\
(0.056)\end{array}$ & & $\begin{array}{c}-0.0193 \\
(0.064)\end{array}$ & & $\begin{array}{l}0.0265 \\
(0.067)\end{array}$ & & $\begin{array}{c}-0.0178 \\
(0.067)\end{array}$ & & $\begin{array}{l}0.0297 \\
(0.068)\end{array}$ & \\
\hline 1997 & $\begin{array}{l}0.0097 \\
(0.063)\end{array}$ & & $\begin{array}{c}-0.0273 \\
(0.074)\end{array}$ & & $\begin{array}{l}0.0198 \\
(0.077)\end{array}$ & & $\begin{array}{c}-0.0350 \\
(0.077)\end{array}$ & & $\begin{array}{l}0.0222 \\
(0.080)\end{array}$ & \\
\hline 1998 & $\begin{array}{c}-0.0469 \\
(0.066)\end{array}$ & & $\begin{array}{c}-0.1021 \\
(0.078)\end{array}$ & & $\begin{array}{c}-0.0567 \\
(0.082)\end{array}$ & & $\begin{array}{c}-0.1162 \\
(0.082)\end{array}$ & & $\begin{array}{c}-0.0535 \\
(0.085)\end{array}$ & \\
\hline 1999 & $\begin{array}{c}-0.0484 \\
(0.068)\end{array}$ & & $\begin{array}{c}-0.1183 \\
(0.081)\end{array}$ & & $\begin{array}{c}-0.0715 \\
(0.084)\end{array}$ & & $\begin{array}{c}-0.1348 \\
(0.084)\end{array}$ & & $\begin{array}{c}-0.0718 \\
(0.090)\end{array}$ & \\
\hline
\end{tabular}


Table 4. Dynamic effects probit models of the probability of receipt of SA at year $t$ interview

\begin{tabular}{|c|c|c|c|c|c|c|c|c|c|c|}
\hline & \multirow{2}{*}{$\begin{array}{c}\text { Pooled } \\
\text { (1) }\end{array}$} & & \multirow{2}{*}{$\begin{array}{c}\text { Initial } \\
\text { conditions } \\
\text { exogenous } \\
(2) \\
\end{array}$} & \multicolumn{7}{|c|}{ Initial conditions endogenous } \\
\hline & & & & & $\begin{array}{l}\text { Orme } \\
(3)\end{array}$ & & $\begin{array}{c}\text { Wooldridge } \\
(4)\end{array}$ & & $\begin{array}{c}\text { Heckman } \\
(5)\end{array}$ & \\
\hline 2000 & $\begin{array}{l}0.0414 \\
(0.069)\end{array}$ & & $\begin{array}{c}-0.0228 \\
(0.084)\end{array}$ & & $\begin{array}{l}0.0222 \\
(0.087)\end{array}$ & & $\begin{array}{c}-0.0453 \\
(0.087)\end{array}$ & & $\begin{array}{l}0.0214 \\
(0.091)\end{array}$ & \\
\hline 2001 & $\begin{array}{c}-0.0467 \\
(0.072)\end{array}$ & & $\begin{array}{c}-0.1235 \\
(0.087)\end{array}$ & & $\begin{array}{c}-0.0789 \\
(0.091)\end{array}$ & & $\begin{array}{c}-0.1482 \\
(0.091)\end{array}$ & & $\begin{array}{c}-0.0703 \\
(0.097)\end{array}$ & \\
\hline 2002 & $\begin{array}{c}-0.0422 \\
(0.073)\end{array}$ & & $\begin{array}{c}-0.1267 \\
(0.088)\end{array}$ & & $\begin{array}{c}-0.0932 \\
(0.092)\end{array}$ & & $\begin{array}{c}-0.1640 \\
(0.092)\end{array}$ & * & $\begin{array}{c}-0.0900 \\
(0.097)\end{array}$ & \\
\hline 2003 & $\begin{array}{l}0.0642 \\
(0.072)\end{array}$ & & $\begin{array}{l}0.0006 \\
(0.088)\end{array}$ & & $\begin{array}{l}0.0386 \\
(0.092)\end{array}$ & & $\begin{array}{c}-0.0310 \\
(0.092)\end{array}$ & & $\begin{array}{l}0.0417 \\
(0.097)\end{array}$ & \\
\hline 2004 & $\begin{array}{c}-0.0390 \\
(0.075)\end{array}$ & & $\begin{array}{c}-0.1240 \\
(0.092)\end{array}$ & & $\begin{array}{c}-0.0833 \\
(0.096)\end{array}$ & & $\begin{array}{c}-0.1550 \\
(0.096)\end{array}$ & & $\begin{array}{c}-0.0868 \\
(0.103)\end{array}$ & \\
\hline 2005 & $\begin{array}{l}0.0803 \\
(0.073)\end{array}$ & & $\begin{array}{l}0.0228 \\
(0.089)\end{array}$ & & $\begin{array}{l}0.0623 \\
(0.093)\end{array}$ & & $\begin{array}{c}-0.0091 \\
(0.093)\end{array}$ & & $\begin{array}{l}0.0646 \\
(0.097)\end{array}$ & \\
\hline \multicolumn{11}{|l|}{ Time-averaged characteristics } \\
\hline Has health problem(s) & $\begin{array}{l}0.2321 \\
(0.044)\end{array}$ & $* * *$ & $\begin{array}{l}0.3033 \\
(0.056)\end{array}$ & $* * *$ & $\begin{array}{l}0.3116 \\
(0.059)\end{array}$ & $* * *$ & $\begin{array}{l}0.2744 \\
(0.059)\end{array}$ & $* * *$ & $\begin{array}{l}0.3206 \\
(0.061)\end{array}$ & $* * *$ \\
\hline Spouse: no educational qualifications & $\begin{array}{c}-0.1393 \\
(0.150)\end{array}$ & & $\begin{array}{c}-0.1939 \\
(0.188)\end{array}$ & & $\begin{array}{c}-0.1937 \\
(0.199)\end{array}$ & & $\begin{array}{c}-0.2542 \\
(0.199)\end{array}$ & & $\begin{array}{c}-0.1877 \\
(0.201)\end{array}$ & \\
\hline Spouse has O-level(s), CSE, etc. & $\begin{array}{c}-0.2996 \\
(0.145)\end{array}$ & $* *$ & $\begin{array}{c}-0.4066 \\
(0.183)\end{array}$ & $* *$ & $\begin{array}{c}-0.4516 \\
(0.193)\end{array}$ & $* *$ & $\begin{array}{c}-0.4646 \\
(0.194)\end{array}$ & $* *$ & $\begin{array}{c}-0.4530 \\
(0.195)\end{array}$ & $* *$ \\
\hline Spouse has A-level(s) or higher & $\begin{array}{c}-0.2466 \\
(0.143)\end{array}$ & $*$ & $\begin{array}{c}-0.3309 \\
(0.180)\end{array}$ & $*$ & $\begin{array}{c}-0.3587 \\
(0.190)\end{array}$ & $*$ & $\begin{array}{c}-0.3594 \\
(0.190)\end{array}$ & $*$ & $\begin{array}{c}-0.3629 \\
(0.194)\end{array}$ & $*$ \\
\hline Spouse's missing educational qualifications & $\begin{array}{c}-0.1998 \\
(0.182)\end{array}$ & & $\begin{array}{c}-0.3619 \\
(0.233)\end{array}$ & & $\begin{array}{c}-0.3629 \\
(0.246)\end{array}$ & & $\begin{array}{c}-0.3620 \\
(0.247)\end{array}$ & & $\begin{array}{c}-0.3643 \\
(0.261)\end{array}$ & \\
\hline BU type: couple & $\begin{array}{l}0.0250 \\
(0.148)\end{array}$ & & $\begin{array}{l}0.1200 \\
(0.187)\end{array}$ & & $\begin{array}{l}0.1414 \\
(0.197)\end{array}$ & & $\begin{array}{l}0.1751 \\
(0.197)\end{array}$ & & $\begin{array}{l}0.1273 \\
(0.200)\end{array}$ & \\
\hline BU type: lone parent & $\begin{array}{l}0.0159 \\
(0.104)\end{array}$ & & $\begin{array}{l}0.2966 \\
(0.134)\end{array}$ & $* *$ & $\begin{array}{l}0.4064 \\
(0.141)\end{array}$ & $* * *$ & $\begin{array}{l}0.1137 \\
(0.141)\end{array}$ & & $\begin{array}{l}0.4045 \\
(0.138)\end{array}$ & $* * *$ \\
\hline Number of children in $\mathrm{BU}=1$ & $\begin{array}{l}0.0722 \\
(0.070)\end{array}$ & & $\begin{array}{l}0.0109 \\
(0.091)\end{array}$ & & $\begin{array}{c}-0.0265 \\
(0.096)\end{array}$ & & $\begin{array}{c}-0.0558 \\
(0.096)\end{array}$ & & $\begin{array}{c}-0.0103 \\
(0.096)\end{array}$ & \\
\hline
\end{tabular}


DELSA/ELSA/WD/SEM(2008)4

Table 4. Dynamic effects probit models of the probability of receipt of SA at year $t$ interview

\begin{tabular}{|c|c|c|c|c|c|c|c|c|c|c|}
\hline & Pooled & & $\begin{array}{c}\text { Initial } \\
\text { conditions }\end{array}$ & & & & al conditions & doger & & \\
\hline & $(1)$ & & $\begin{array}{c}\text { exogenous } \\
(2) \\
\end{array}$ & & $\begin{array}{c}\text { Orme } \\
(3)\end{array}$ & & $\begin{array}{c}\text { Wooldridge } \\
(4)\end{array}$ & & $\begin{array}{c}\text { Heckman } \\
(5) \\
\end{array}$ & \\
\hline Number of children in $\mathrm{BU}=2$ & $\begin{array}{l}0.0119 \\
(0.074)\end{array}$ & & $\begin{array}{c}-0.0324 \\
(0.094)\end{array}$ & & $\begin{array}{c}-0.0440 \\
(0.099)\end{array}$ & & $\begin{array}{c}-0.0908 \\
(0.099)\end{array}$ & & $\begin{array}{c}-0.0259 \\
(0.102)\end{array}$ & \\
\hline Number of children in $\mathrm{BU}=3$ or more & $\begin{array}{c}0.3202 \\
(0.090)\end{array}$ & $* * *$ & $\begin{array}{l}0.3748 \\
(0.113)\end{array}$ & $* * *$ & $\begin{array}{l}0.3662 \\
(0.118)\end{array}$ & $* * *$ & $\begin{array}{l}0.2399 \\
(0.119)\end{array}$ & $* *$ & $\begin{array}{l}0.3817 \\
(0.123)\end{array}$ & $* * *$ \\
\hline Age of youngest child $<5$ & $\begin{array}{c}-0.1211 \\
(0.069)\end{array}$ & $*$ & $\begin{array}{c}-0.1037 \\
(0.090)\end{array}$ & & $\begin{array}{c}-0.0932 \\
(0.095)\end{array}$ & & $\begin{array}{c}-0.0764 \\
(0.096)\end{array}$ & & $\begin{array}{c}-0.0996 \\
(0.101)\end{array}$ & \\
\hline House tenure: owned & $\begin{array}{c}-0.5938 \\
(0.057)\end{array}$ & $* * *$ & $\begin{array}{c}-0.7673 \\
(0.070)\end{array}$ & $* * *$ & $\begin{array}{c}-0.7751 \\
(0.072)\end{array}$ & $* * *$ & $\begin{array}{c}-0.6422 \\
(0.073)\end{array}$ & $* * *$ & $\begin{array}{c}-0.8041 \\
(0.070)\end{array}$ & $* * *$ \\
\hline Lives in London (inner or outer) & $\begin{array}{c}-0.3062 \\
(0.149)\end{array}$ & $* *$ & $\begin{array}{c}-0.3189 \\
(0.173)\end{array}$ & * & $\begin{array}{c}-0.3489 \\
(0.179)\end{array}$ & $*$ & $\begin{array}{c}-0.3331 \\
(0.179)\end{array}$ & $*$ & $\begin{array}{c}-0.3511 \\
(0.146)\end{array}$ & $* *$ \\
\hline Unemployment rate in TTWA (\%) & $\begin{array}{l}0.0131 \\
(0.008)\end{array}$ & $*$ & $\begin{array}{l}0.0221 \\
(0.010)\end{array}$ & $* *$ & $\begin{array}{l}0.0229 \\
(0.010)\end{array}$ & $* *$ & $\begin{array}{c}0.0208 \\
(0.010)\end{array}$ & $* *$ & $\begin{array}{l}0.0227 \\
(0.010)\end{array}$ & $* *$ \\
\hline Generalised error from $t=1$ probit & & & & & $\begin{array}{l}0.4192 \\
(0.028)\end{array}$ & $* * *$ & & & & \\
\hline Received SA at $t=1$ & & & & & & & $\begin{array}{l}0.8136 \\
(0.053)\end{array}$ & $* * *$ & & \\
\hline Constant & $\begin{array}{c}-1.4215 \\
(0.102)\end{array}$ & $* * *$ & $\begin{array}{c}-1.3653 \\
(0.137)\end{array}$ & $* * *$ & $\begin{array}{c}-1.4709 \\
(0.146)\end{array}$ & $* * *$ & $\begin{array}{c}-1.5989 \\
(0.147)\end{array}$ & $* * *$ & $\begin{array}{c}-1.4705 \\
(0.147)\end{array}$ & $* * *$ \\
\hline$\sigma_{u}$ & & & $\begin{array}{l}0.6402 \\
(0.028)\end{array}$ & $* * *$ & $\begin{array}{l}0.7176 \\
(0.028)\end{array}$ & $* * *$ & $\begin{array}{l}0.7207 \\
(0.028)\end{array}$ & $* * *$ & $\begin{array}{l}0.7795 \\
(0.030)\end{array}$ & $\begin{array}{l}* * * \\
* * *\end{array}$ \\
\hline$\rho$ & & & $\begin{array}{l}0.2907 \\
(0.018)\end{array}$ & $* * *$ & $\begin{array}{l}0.3399 \\
(0.018)\end{array}$ & $* * *$ & $\begin{array}{l}0.3418 \\
(0.018)\end{array}$ & $* * *$ & $\begin{array}{c}0.3780 \\
(0.018) \\
-\end{array}$ & \\
\hline Log-likelihood & -8887.678 & & -8682.186 & & -8550.674 & & -8539.622 & & 10747.078 & \\
\hline No. person-years & 66952 & & 66952 & & 66952 & & 66952 & & 75988 & \\
\hline No. persons & 9036 & & 9036 & & 9036 & & 9036 & & 9036 & \\
\hline
\end{tabular}

Standard errors shown in parentheses. ${ }^{*} p<0.10,{ }^{* *} p<0.05,{ }^{* * *} p<0.01 .$. Models (1)-(4) estimated using observations for $t>1$ only

Initial conditions equation estimates shown in Table 5 below 
Table 5. The probability of SA receipt at $t=1$ (initial conditions)

\begin{tabular}{|c|c|c|c|c|}
\hline & $\begin{array}{c}\text { Exogenous } \\
\text { (1) }\end{array}$ & & $\begin{array}{c}\text { Heckman } \\
(2)\end{array}$ & \\
\hline Age (years) & $\begin{array}{l}0.0005 \\
(0.003)\end{array}$ & & $\begin{array}{c}-0.0012 \\
(0.004)\end{array}$ & \\
\hline Female & $\begin{array}{c}-0.0190 \\
(0.047)\end{array}$ & & $\begin{array}{c}-0.0310 \\
(0.057)\end{array}$ & \\
\hline Has health problem(s) & $\begin{array}{l}0.2102 \\
(0.044)\end{array}$ & $* * *$ & $\begin{array}{l}0.2546 \\
(0.052)\end{array}$ & $* * *$ \\
\hline \multicolumn{5}{|l|}{ Educational qualifications } \\
\hline O-level(s), CSE, etc & $\begin{array}{c}-0.2239 \\
(0.058)\end{array}$ & $* * *$ & $\begin{array}{c}-0.2604 \\
(0.069)\end{array}$ & $* * *$ \\
\hline A-level(s) or higher & $\begin{array}{c}-0.4974 \\
(0.062)\end{array}$ & $* * *$ & $\begin{array}{c}-0.5989 \\
(0.076)\end{array}$ & $* * *$ \\
\hline Missing & $\begin{array}{c}-0.7647 \\
(0.095)\end{array}$ & $* * *$ & $\begin{array}{c}-0.9503 \\
(0.117)\end{array}$ & $* * *$ \\
\hline Spouse's age (years) & $\begin{array}{c}-0.0044 \\
(0.004)\end{array}$ & & $\begin{array}{c}-0.0043 \\
(0.005)\end{array}$ & \\
\hline Spouse: no educational qualifications & $\begin{array}{l}0.1881 \\
(0.141)\end{array}$ & & $\begin{array}{l}0.2571 \\
(0.175)\end{array}$ & \\
\hline Spouse has O-level(s), CSE, etc. & $\begin{array}{c}-0.0398 \\
(0.140)\end{array}$ & & $\begin{array}{c}-0.0122 \\
(0.173)\end{array}$ & \\
\hline Spouse has A-level(s) or higher & $\begin{array}{c}-0.1612 \\
(0.139)\end{array}$ & & $\begin{array}{c}-0.1493 \\
(0.172)\end{array}$ & \\
\hline Spouse's missing educational qualifications & $\begin{array}{c}-0.4177 \\
(0.209)\end{array}$ & $* *$ & $\begin{array}{c}-0.4538 \\
(0.256)\end{array}$ & * \\
\hline Number of children in $B U=1$ & $\begin{array}{l}0.2260 \\
(0.071)\end{array}$ & $* * *$ & $\begin{array}{l}0.2320 \\
(0.082)\end{array}$ & $* * *$ \\
\hline Number of children in $\mathrm{BU}=2$ & $\begin{array}{l}0.2467 \\
(0.073)\end{array}$ & $* * *$ & $\begin{array}{l}0.2768 \\
(0.085)\end{array}$ & *** \\
\hline Number of children in $\mathrm{BU}=3$ or more & $\begin{array}{l}0.4771 \\
(0.086)\end{array}$ & $* * *$ & $\begin{array}{l}0.5255 \\
(0.109)\end{array}$ & $* * *$ \\
\hline Age of youngest child $<5$ & $\begin{array}{l}0.1974 \\
(0.063)\end{array}$ & $* * *$ & $\begin{array}{l}0.2405 \\
(0.077)\end{array}$ & *** \\
\hline BU type: lone parent & $\begin{array}{l}1.0247 \\
(0.101)\end{array}$ & $* * *$ & $\begin{array}{l}1.2230 \\
(0.126)\end{array}$ & *** \\
\hline BU type: couple & $\begin{array}{c}-0.0682 \\
(0.207)\end{array}$ & & $\begin{array}{c}-0.1143 \\
(0.239)\end{array}$ & \\
\hline House tenure: owned & $\begin{array}{c}-0.6464 \\
(0.044)\end{array}$ & $* * *$ & $\begin{array}{c}-0.7677 \\
(0.056)\end{array}$ & *** \\
\hline Lives in London (inner or outer) & $\begin{array}{c}-0.0740 \\
(0.068)\end{array}$ & & $\begin{array}{c}-0.0902 \\
(0.085)\end{array}$ & \\
\hline Unemployment rate in TTWA (\%) & $\begin{array}{l}0.0585 \\
(0.011)\end{array}$ & $* * *$ & $\begin{array}{l}0.0622 \\
(0.013)\end{array}$ & $* * *$ \\
\hline \multicolumn{5}{|l|}{ Survey year } \\
\hline 1993 & $\begin{array}{l}0.2212 \\
(0.102)\end{array}$ & $* *$ & $\begin{array}{l}0.2535 \\
(0.117)\end{array}$ & $* *$ \\
\hline 1994 & $\begin{array}{l}0.1872 \\
(0.114)\end{array}$ & & $\begin{array}{l}0.1327 \\
(0.130)\end{array}$ & \\
\hline 1995 & $\begin{array}{l}0.2849 \\
(0.115)\end{array}$ & $* *$ & $\begin{array}{l}0.3142 \\
(0.136)\end{array}$ & $* *$ \\
\hline 1996 & $\begin{array}{l}0.2900 \\
(0.118)\end{array}$ & $* *$ & $\begin{array}{l}0.3429 \\
(0.145)\end{array}$ & $* *$ \\
\hline
\end{tabular}


Table 5. The probability of SA receipt at $t=1$ (initial conditions)

\begin{tabular}{|c|c|c|c|c|}
\hline & $\begin{array}{c}\text { Exogenous } \\
(1) \\
\end{array}$ & & $\begin{array}{c}\text { Heckman } \\
(2)\end{array}$ & \\
\hline 1997 & $\begin{array}{l}0.4928 \\
(0.128)\end{array}$ & $* * *$ & $\begin{array}{l}0.4851 \\
(0.161)\end{array}$ & $* * *$ \\
\hline 1998 & $\begin{array}{l}0.2687 \\
(0.141)\end{array}$ & $*$ & $\begin{array}{l}0.2649 \\
(0.171)\end{array}$ & \\
\hline 1999 & $\begin{array}{l}0.3891 \\
(0.138)\end{array}$ & $* * *$ & $\begin{array}{l}0.3622 \\
(0.172)\end{array}$ & $* *$ \\
\hline 2000 & $\begin{array}{l}0.3348 \\
(0.150)\end{array}$ & $* *$ & $\begin{array}{l}0.2826 \\
(0.201)\end{array}$ & \\
\hline 2001 & $\begin{array}{l}0.3298 \\
(0.148)\end{array}$ & $* *$ & $\begin{array}{l}0.3317 \\
(0.179)\end{array}$ & $*$ \\
\hline 2002 & $\begin{array}{l}0.1728 \\
(0.167)\end{array}$ & & $\begin{array}{l}0.1499 \\
(0.194)\end{array}$ & \\
\hline 2003 & $\begin{array}{l}0.3824 \\
(0.163)\end{array}$ & $* *$ & $\begin{array}{l}0.2778 \\
(0.210)\end{array}$ & \\
\hline 2004 or 2005 & $\begin{array}{l}0.4771 \\
(0.151)\end{array}$ & $* * *$ & $\begin{array}{l}0.4727 \\
(0.192)\end{array}$ & $* *$ \\
\hline \multicolumn{5}{|l|}{ Instruments for SA receipt status at $t=1$} \\
\hline Mother's employment status missing & $\begin{array}{l}0.0715 \\
(0.131)\end{array}$ & & $\begin{array}{l}0.0208 \\
(0.162)\end{array}$ & \\
\hline Mother not employed & $\begin{array}{l}0.1303 \\
(0.046)\end{array}$ & $* * *$ & $\begin{array}{l}0.1307 \\
(0.054)\end{array}$ & $* *$ \\
\hline Mother not alive & $\begin{array}{l}0.2730 \\
(0.148)\end{array}$ & $*$ & $\begin{array}{l}0.2804 \\
(0.184)\end{array}$ & \\
\hline Father's employment status missing & $\begin{array}{l}0.2084 \\
(0.102)\end{array}$ & $* *$ & $\begin{array}{l}0.1757 \\
(0.127)\end{array}$ & \\
\hline Father not employed & $\begin{array}{l}0.0503 \\
(0.113)\end{array}$ & & $\begin{array}{c}-0.0315 \\
(0.137)\end{array}$ & \\
\hline Father not alive & $\begin{array}{c}-0.0296 \\
(0.107)\end{array}$ & & $\begin{array}{c}-0.0551 \\
(0.122)\end{array}$ & \\
\hline Had job when first left full-time education & $\begin{array}{c}-0.0795 \\
(0.059)\end{array}$ & & $\begin{array}{c}-0.0559 \\
(0.070)\end{array}$ & \\
\hline SEG $1^{\text {st }}$ job: manager or professional & $\begin{array}{l}0.0165 \\
(0.150)\end{array}$ & & $\begin{array}{l}0.0217 \\
(0.173)\end{array}$ & \\
\hline SEG $1^{\text {st }}$ job: non-manual & $\begin{array}{c}-0.0670 \\
(0.066)\end{array}$ & & $\begin{array}{c}-0.1028 \\
(0.077)\end{array}$ & \\
\hline SEG $1^{\text {st }}$ job: manual & $\begin{array}{l}0.0965 \\
(0.061)\end{array}$ & & $\begin{array}{l}0.0643 \\
(0.071)\end{array}$ & \\
\hline SEG $1^{\text {st }}$ job: other & $\begin{array}{l}0.1559 \\
(0.121)\end{array}$ & & $\begin{array}{l}0.1749 \\
(0.141)\end{array}$ & \\
\hline Constant & $\begin{array}{c}-1.3653 \\
(0.174)\end{array}$ & $* * *$ & $\begin{array}{c}-1.4793 \\
(0.206)\end{array}$ & $* * *$ \\
\hline $\begin{array}{l}\text { Wald test for IC instrument validity } \\
\qquad \begin{array}{l}\chi^{2}(11) \\
p \text {-value }\end{array}\end{array}$ & $\begin{array}{c}27.68 \\
0.0036\end{array}$ & & $\begin{array}{c}18.77 \\
0.0654\end{array}$ & \\
\hline $\begin{array}{l}\text { Log-likelihood } \\
\text { No. cases }\end{array}$ & $\begin{array}{c}-2194.27 \\
9036\end{array}$ & & 9036 & \\
\hline
\end{tabular}

Standard errors in parentheses. ${ }^{*} p<0.10,{ }^{* *} p<0.05,{ }^{* * *} p<0.01 .$. Model (1) estimated assuming initial conditions exogenous, and was used to derive the generalised error used for estimation using the Orme approach: see model (3) in Table 4 above. Model (2) estimated jointly with (5) in Table 4 above. Test for instrument validity is a test that coefficients on all instruments are jointly zero. 


\section{Unbalanced versus balanced samples}

121. In Table 6, we retain the Heckman estimator and the basic specification, but explore sensitivity to the type of sample used. (Initial conditions equations corresponding to each of these estimates are reported in Appendix Table B1.) The estimates reported in column 1 were derived from an unbalanced panel, as above, with the exception that we only use adults whose sequences began in wave 1 . This reduces the sample size substantially, to 5,067 adults contributing 51,509 person-wave observations. The estimates reported in column 2 are from an even smaller sample - the balanced fifteen-wave sample of 1,996 adults contributing 29,940 person-wave observations. (We return to discussion of column 3 shortly.)

122. Reassuringly, the estimates from columns 1 and 2 are broadly consistent with each other, and with those from Table 4, column 5 discussed earlier, in terms of the point estimates and their statistical significance. ${ }^{25}$ The state dependence effect is similar. For example, the APE corresponding to the column 1 estimates is 13.0 percentage points and the PPR, 5.1; for the column 2 estimates, the APE and PPR are 19.1 percentage points and 4.4. (The earlier estimates were 14.4 percentage points and 4.0.)

123. The most obvious differences across the columns concern the estimates for the local unemployment rate and for the survey year indicators. The local unemployment rate loses statistical significance (absolute $t$-ratios, not shown, are smaller) but, on the other hand, the survey year dummies are now jointly statistically significant and their coefficients tend to be larger (more negative) towards the end of the period compared to the beginning - which is consistent with the downward trend in unemployment rates over the period (and the declining SA exit and entry shown in Figure 6). This raises the question whether it is more difficult to identify separate effects of time and unemployment rates for these samples - there may be less independent variation in the series, and the sample sizes are smaller.

124. The other noticeable difference from the results discussed earlier concerns the initial conditions estimates for the unbalanced sample with all sequences starting at wave 3 . According to the Wald test, instrument validity is now not rejected at the $1 \%$ level of significance (the $p$-value is $0.020)$. On the other hand, for the fifteen wave balanced panel the $p$-value for the test is 0.94 .

125. Notwithstanding these results, the coefficient estimates are close to those derived using the Wooldridge and Orme estimators (not shown). So, our overall conclusion is that the choice of sample does not have a major impact on the conclusions drawn. We therefore proceed to investigate variations on the basic specification using the complete unbalanced panel.

25. We also applied the Orme and Wooldridge estimators to these two samples, and the estimates were similar to their Heckman estimator counterparts. The estimates are not reported for brevity. 
Table 6. Dynamic effects probit models of the probability of receipt of SA at year $t$ survey interview (Heckman estimator), by type of estimation sample

\begin{tabular}{|c|c|c|c|c|c|c|}
\hline \multirow[b]{3}{*}{ Received SA at $t-1$} & \multirow{2}{*}{\multicolumn{2}{|c|}{$\begin{array}{l}\text { Unbalanced } \\
\text { panel, all } \\
\text { sequences start at } \\
\text { wave } 1 \\
\qquad(1)\end{array}$}} & \multirow{2}{*}{\multicolumn{2}{|c|}{$\begin{array}{l}\text { Fifteen-wave } \\
\text { balanced panel }\end{array}$}} & \multirow{2}{*}{\multicolumn{2}{|c|}{$\begin{array}{l}\text { Unbalanced } \\
\text { panel, excluding } \\
\text { sequences with } \\
\text { continuous } \\
\text { receipt } \\
\text { (3) }\end{array}$}} \\
\hline & & & & & & \\
\hline & $\begin{array}{l}1.2542 \\
(0.042)\end{array}$ & $* * *$ & $\begin{array}{l}1.3553 \\
(0.058)\end{array}$ & $* * *$ & $\begin{array}{l}0.5025 \\
(0.055)\end{array}$ & $* * *$ \\
\hline Age (years) & $\begin{array}{c}-0.0045 \\
(0.004)\end{array}$ & & $\begin{array}{l}0.0006 \\
(0.007)\end{array}$ & & $\begin{array}{c}-0.0064 \\
(0.002)\end{array}$ & $* * *$ \\
\hline Female & $\begin{array}{c}-0.0837 \\
(0.045)\end{array}$ & * & $\begin{array}{c}-0.0285 \\
(0.066)\end{array}$ & & $\begin{array}{c}-0.0871 \\
(0.032)\end{array}$ & $* * *$ \\
\hline Has health problem(s) & $\begin{array}{l}0.0567 \\
(0.044)\end{array}$ & & $\begin{array}{l}0.0368 \\
(0.062)\end{array}$ & & $\begin{array}{l}0.0539 \\
(0.043)\end{array}$ & \\
\hline \multicolumn{7}{|l|}{ Educational qualifications } \\
\hline O-level(s), CSE, etc. & $\begin{array}{c}-0.2530 \\
(0.055)\end{array}$ & $* * *$ & $\begin{array}{c}-0.2653 \\
(0.083)\end{array}$ & $* * *$ & $\begin{array}{c}-0.1642 \\
(0.044)\end{array}$ & $* * *$ \\
\hline A-level(s) or higher & $\begin{array}{c}-0.4325 \\
(0.054)\end{array}$ & $* * *$ & $\begin{array}{c}-0.4334 \\
(0.081)\end{array}$ & $* * *$ & $\begin{array}{c}-0.2756 \\
(0.044)\end{array}$ & $* * *$ \\
\hline Missing & $\begin{array}{c}-1.2007 \\
(0.089)\end{array}$ & $* * *$ & $\begin{array}{c}-0.9469 \\
(0.152)\end{array}$ & $* * *$ & $\begin{array}{c}-0.7906 \\
(0.077)\end{array}$ & $* * *$ \\
\hline Spouse's age (years) & $\begin{array}{l}0.0045 \\
(0.004)\end{array}$ & & $\begin{array}{l}0.0094 \\
(0.006)\end{array}$ & & $\begin{array}{l}0.0012 \\
(0.003)\end{array}$ & \\
\hline Spouse: no educational qualifications & $\begin{array}{l}0.8555 \\
(0.148)\end{array}$ & $* * *$ & $\begin{array}{l}0.7362 \\
(0.217)\end{array}$ & $* * *$ & $\begin{array}{l}0.3742 \\
(0.159)\end{array}$ & $* *$ \\
\hline Spouse has O-level(s), CSE, etc. & $\begin{array}{l}0.9399 \\
(0.143)\end{array}$ & $* * *$ & $\begin{array}{l}0.8745 \\
(0.200)\end{array}$ & $* * *$ & $\begin{array}{l}0.3377 \\
(0.150)\end{array}$ & $* *$ \\
\hline Spouse has A-level(s) or higher & $\begin{array}{l}0.7161 \\
(0.143)\end{array}$ & $* * *$ & $\begin{array}{l}0.5776 \\
(0.200)\end{array}$ & $* * *$ & $\begin{array}{l}0.2864 \\
(0.148)\end{array}$ & $*$ \\
\hline Spouse's missing educational qualifications & $\begin{array}{l}0.2544 \\
(0.182)\end{array}$ & & $\begin{array}{l}0.1351 \\
(0.249)\end{array}$ & & $\begin{array}{c}-0.0747 \\
(0.178)\end{array}$ & \\
\hline Number of children in $\mathrm{BU}=1$ & $\begin{array}{l}0.0018 \\
(0.065)\end{array}$ & & $\begin{array}{c}-0.0941 \\
(0.080)\end{array}$ & & $\begin{array}{c}-0.0159 \\
(0.066)\end{array}$ & \\
\hline Number of children in $\mathrm{BU}=2$ & $\begin{array}{l}0.0215 \\
(0.075)\end{array}$ & & $\begin{array}{c}-0.1218 \\
(0.095)\end{array}$ & & $\begin{array}{c}-0.0466 \\
(0.073)\end{array}$ & \\
\hline Number of children in $\mathrm{BU}=3$ or more & $\begin{array}{l}0.1013 \\
(0.097)\end{array}$ & & $\begin{array}{c}-0.0077 \\
(0.119)\end{array}$ & & $\begin{array}{l}0.0477 \\
(0.097)\end{array}$ & \\
\hline Age of youngest child $<5$ & $\begin{array}{l}0.3051 \\
(0.056)\end{array}$ & $* * *$ & $\begin{array}{l}0.2297 \\
(0.067)\end{array}$ & $* * *$ & $\begin{array}{l}0.2564 \\
(0.055)\end{array}$ & $* * *$ \\
\hline BU type: lone parent & $\begin{array}{c}0.5723 \\
(0.100)\end{array}$ & $* * *$ & $\begin{array}{c}0.7557 \\
(0.129)\end{array}$ & $* * *$ & $\begin{array}{c}0.6276 \\
(0.105)\end{array}$ & $* * *$ \\
\hline BU type: couple & $\begin{array}{c}-1.1259 \\
(0.226)\end{array}$ & $* * *$ & $\begin{array}{c}-1.0232 \\
(0.334)\end{array}$ & $* * *$ & $\begin{array}{c}-0.3429 \\
(0.196)\end{array}$ & $*$ \\
\hline House tenure: owned & $\begin{array}{c}-0.2836 \\
(0.073)\end{array}$ & $* * *$ & $\begin{array}{c}-0.2796 \\
(0.096)\end{array}$ & $* * *$ & $\begin{array}{c}-0.1306 \\
(0.063)\end{array}$ & $* *$ \\
\hline Lives in London (inner or outer) & $\begin{array}{l}0.2288 \\
(0.177)\end{array}$ & & $\begin{array}{l}0.2148 \\
(0.237)\end{array}$ & & $\begin{array}{l}0.2797 \\
(0.133)\end{array}$ & $* *$ \\
\hline Unemployment rate in TTWA (\%) & $\begin{array}{l}0.0212 \\
(0.013)\end{array}$ & $*$ & $\begin{array}{c}0.0153 \\
(0.021)\end{array}$ & & $\begin{array}{l}0.0376 \\
(0.011)\end{array}$ & $* * *$ \\
\hline
\end{tabular}

Survey year 
Table 6. Dynamic effects probit models of the probability of receipt of SA at year $t$ survey interview (Heckman estimator), by type of estimation sample

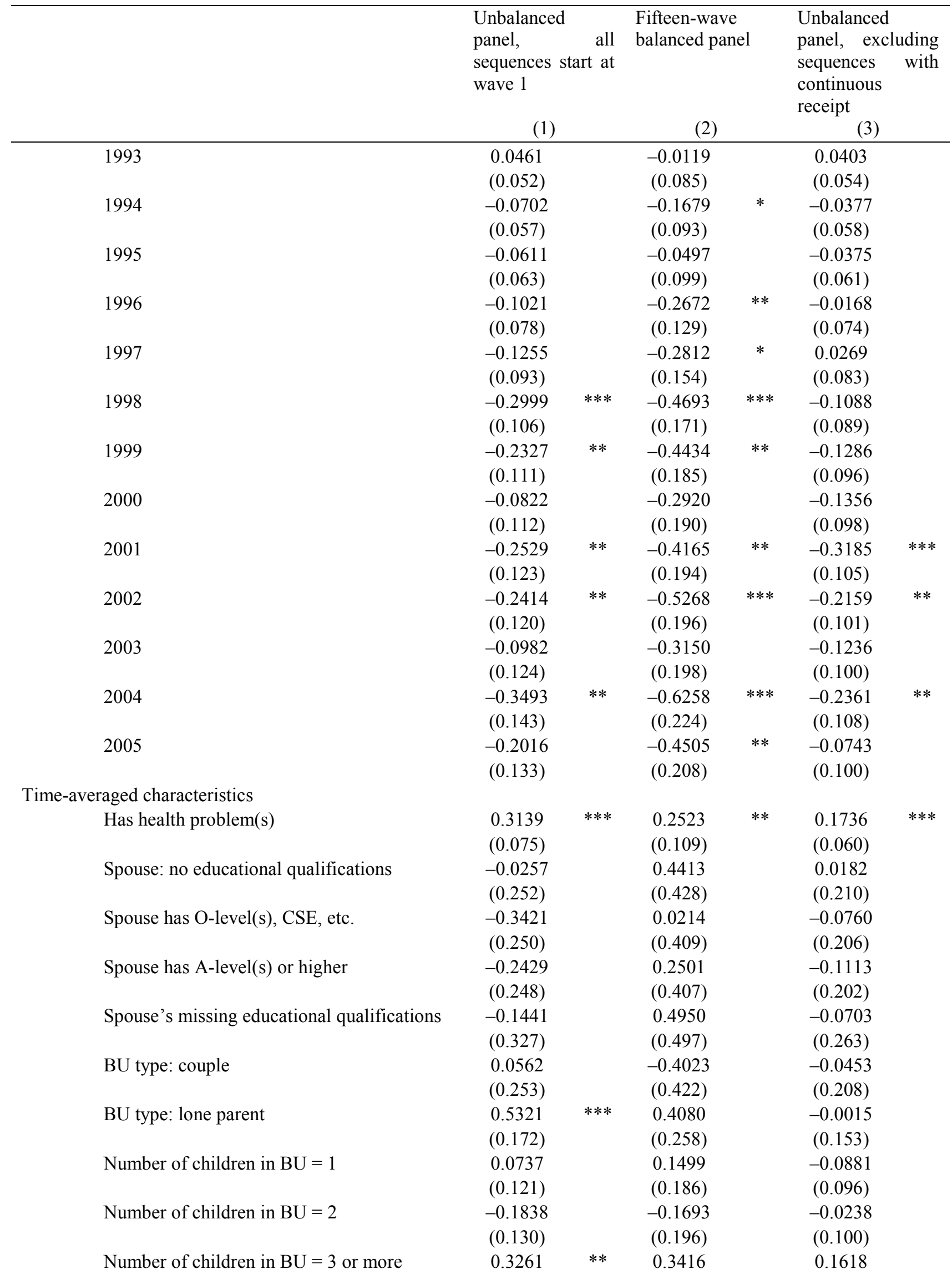


DELSA/ELSA/WD/SEM(2008)4

Table 6. Dynamic effects probit models of the probability of receipt of SA at year $t$ survey interview (Heckman estimator), by type of estimation sample

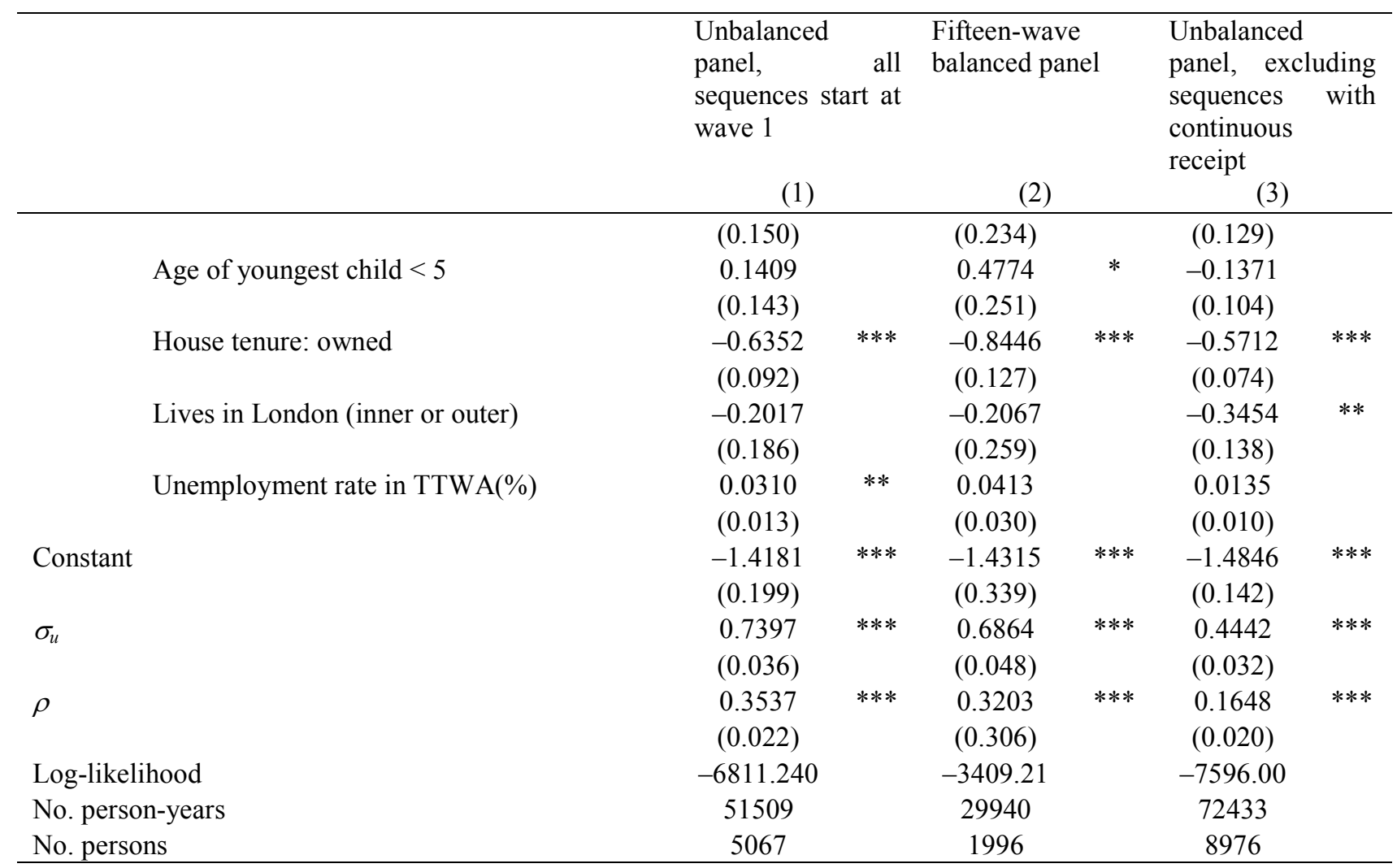

Standard errors in parentheses. $* p<0.10, * * p<0.05, * * * p<0.01$. See Appendix Table B1 for the estimates of the jointly-estimated initial conditions equation. 


\section{Variations on the basic specification}

126. We turn first to the issue of heterogeneity in state dependence effects and the interpretation of estimates of the coefficient on the lagged SA receipt variable $(\lambda)$. One dimension of this issue concerns the prevalence of 'continuing' spells of benefit receipt.

127. Among those in receipt of SA at the time of an annual interview, a substantial proportion $(63 \%)$ were also in receipt at the previous interview without any intervening months of non-receipt. Put another way, for this group, the association between receipt at interview and receipt during year simply reflects the length of the spell. The existence of these 'continuing' spells raises questions about whether $\lambda$ can be interpreted as an indicator of genuine state dependence in this case. (See e.g. Arulampalam, Booth, and Taylor (2000) and Stewart (2007) for further discussion.) Another way of stating the issue is to say that the prevalence of 'continuing' spells draws attention to heterogeneity in state dependence, and so any overall measure derived from a sample that pools individuals with and without continuing spells will be a misleading combination of the measures for the separate groups.

128. There are several ways to address this issue. ${ }^{26}$ The first and most common practice, which we also follow, is simply to re-estimate the model excluding the continuous spell observations and to compare the estimates with those from the original full sample model. The problem with this approach is that the subsample selection may be endogenous, and this motivates the second method, using a bivariate probit random effects model to control for such selection. Stewart (2007) estimated such a model though, interestingly, he reports that he could not reject independence (2007, p. 522). A third method, also implemented by Stewart (2007), is to allow for heterogeneity in state dependence issue directly, rather than by distinguishing between continuing and non-continuing spells. He estimated a model with unobserved differences in $\lambda$ characterised by a discrete distribution with two mass points representing relatively high and relative low state dependence. (As it happens, the model turned out not to fit his unemployment data particularly well.) A fourth method is to allow slopes to vary with differences in observed rather than unobserved characteristics. We note that just under $30 \%$ of the SA recipients with continuing spells are lone parents, a substantial over-representation relative to the group's sample numbers, and therefore introduce interactions between lagged SA receipt and the lone parent indicator. ${ }^{27}$

129. The estimates derived when we excluded adults with continuing SA receipt are shown in column (3) of Table 6. The principal effect of the sample selection is to reduce the estimate of the coefficient on lagged SA receipt from well above unity to 0.503 , a reduction of more than one half. There is also a sharp fall in the APE, to 3.7 percentage points, and in the PPR to 2.4, compared to 14.4 percentage points and 4.0 for the full sample. This is evidence consistent with the concept of heterogeneity in state dependence. The estimates for the other coefficients are broadly in line with those estimated with the Heckman estimator applied to the whole sample (Table 5, column 5).

130. In Table 7 we report estimates from specifications that introduce interactions between explanatory variables and lagged SA receipt in order whether effects differ with calendar time or across groups. (See Appendix Table B2 for estimates of the initial conditions equations that were estimated jointly with the equation reported in Table 7. The $p$-value for the test of instrument validity

26. The three social assistance dynamics papers cited earlier do not acknowledge this issue. It has received most attention in the unemployment dynamics literature: see Arulampalam, Booth, and Taylor (2000) and Stewart (2007).

27. Arulampalam, Booth and Taylor (2000) considered differences between those aged less than 25 years versus those aged more than 25 years. (All our sample members are aged 25 or more.) Andrén (2007) also allowed for heterogeneity in $\lambda$ using interactions with a number of observed variables. By contrast, Hansen, Lofstrom, and Zhang (2006), and Hansen and Lofstrom (2006) allowed state dependence to differ by fitting separate models for different groups (those living in different Canadian provinces, and immigrant versus native Swedes, respectively). 
was 0.06 or 0.07 in each case.) Apart from the interactions, the sets of explanatory variables are identical to those used for the basic specification discussed earlier. The sample is also the full sample of 75,988 person-wave observations used earlier. Because the estimates for explanatory variables other than the interactions are very similar, we do not discuss them. ${ }^{28}$

131. Specification (1) introduces interactions between survey year and lagged SA receipt, and the variables are defined so that the reference category refers to 1992 for year $t$ (and hence 1991 for year $t-1)$. The table shows that none of the survey year interactions for years prior to 1998 are statistically different from zero, whereas all the interactions for the subsequent years are. The interaction point estimates for the late 1990s onwards follow no clear monotonic pattern, but all are clearly larger than the ones for the earlier years. For instance, the estimate of $\lambda$ for 1992 is 1.065 whereas, for 2005, it is $1.065+0.440=1.505$. The coefficient estimates imply a larger SA persistence rate or, equivalently, a smaller SA exit rate, in the later period, other things being equal. This is consistent with the downward trend in the raw SA exit rate pictured in Figure 6.

132. Specification (2) is the same as specification (1) except that the estimate of $\lambda$ is now free to differ between lone parents and adults in other groups, and this differential is itself free to change before and after 1998. Specification (2) is strongly preferred by the data to specification (1): a likelihood ratio test that these additional lone parent interactions are jointly equal to zero is rejected with $\chi^{2}(2)$ test statistic 25.07 with a $p$-value of 0.000 . In the augmented model, the estimates of $\lambda$ for non-lone parents are slightly smaller than those implied by specification (1). For example, the estimate for 1992 is 0.995 and for 2005 it is 1.379 . The additional interaction variables indicate that the estimate of $\lambda$ for lone parents was 1.479 in $1992(0.995+0.484)$ but 1.586 in $2005(0.995+$ $0.481+0.484-0.374)$. So, the increase in $\lambda$ across the period was more moderate for lone parents than for other groups (SA exit rates did not fall as much, other things being equal, which is broadly consistent with the trends shown in Figures 6 and 9).

133. To focus on differences before and after 1998, we estimated specification (3) in which the individual survey year slope shifters used in (2) were combined into just two variables that distinguished between the earlier and later period. According to a likelihood ratio test, we cannot reject (3) in favour of (2): the $\chi^{2}(12)$ test statistic is 13.23 with a $p$-value of 0.353 . The estimate of $\lambda$ for non-lone parents is now 0.990 for years before 1998, and 1.484 for 1998-2005. For lone parents, the corresponding estimates are 1.478 and 1.598, thereby implying a decline in the SA exit rate, other things being equal.

134. The final specification, (4), is the same as (3) except that is also combines the survey year intercept shifter variables so that they distinguished only between years before 1998, and 1998 and afterwards. The pooling was suggested by the pattern of the coefficient estimates in (3): they become negative and statistically significant from 1998 onwards. According to a likelihood ratio test, we cannot reject (4) in favour of (3): the $\chi^{2}(12)$ test statistic is 14.84 with a $p$-value of 0.250 . And the coefficients on the other variables in (4) are very similar to their counterparts in (3). According to (4), there was a clear fall in both SA entry rates and SA persistence rates in the period from 1998 onwards, relative to 1991-1997, other things being equal.

135. The change in slope and intercept interaction effects in 1998 almost lines up with the timing of the introduction of major welfare-to-work policies such as WFTC by the Labour government (in 1999), and the different trend over time in the SA exit rate for lone parents relative to other groups is consistent with the intended targeting of these policies on low income families with children, a large number of whom were headed by lone parents. Thus, there is some suggestion that the introduction of these policies did have a causal impact on SA receipt via exit rates. However we would be cautious in

28. The most obvious difference from the basic specification estimates is that some of the survey year intercept shifters are now statistically different from zero. But there remains no clear temporal pattern to the point estimates. 
drawing such a conclusion, and not only because the timing of the change in coefficients does not exactly match the timing of the policy changes. Drawing more substantive conclusions about policy effects requires substantially more research directed at this specific question, and is beyond the scope of the current project. $^{29}$

136. Instead, we turn now to interpret the estimates further with reference to the steady state SA entry and persistence rates, and associated statistics, implied by them.

29. An identification strategy based on a difference-in-differences approach would more explicitly compare the SA receipt experience of lone mothers with that of comparison groups (married mothers with children and childless women) before and after the reforms. For studies of the causal effect of WFTC introduction on lone mothers' labour supply, see e.g. Brewer et al. (2006), Francesconi and van der Klaauw (2007), and Gregg, Harkness and Smith (2007). For a differences-in-differences approach to the impact of the introduction of JSA, see Petrongolo (2007). 
DELSA/ELSA/WD/SEM(2008)4

Table 7. Dynamic random effects probit models of the probability of receipt of SA at year $t$ survey interview (Heckman estimator), with interactions between lagged benefit receipt status, survey year, and lone parent status

\begin{tabular}{|c|c|c|c|c|c|c|c|c|}
\hline & \multirow{2}{*}{$\begin{array}{c}\text { Survey year } \\
\text { interactions } \\
\text { (1) }\end{array}$} & \multicolumn{7}{|c|}{ Survey year and lone parent interactions } \\
\hline & & & $(2)$ & & (3) & & $(4)$ & \\
\hline Received SA at $t-1$ & $\begin{array}{l}1.0650 \\
(0.099)\end{array}$ & $* * *$ & $\begin{array}{l}0.9950 \\
(0.100)\end{array}$ & $* * *$ & $\begin{array}{l}0.9901 \\
(0.044)\end{array}$ & $* * *$ & $\begin{array}{l}0.9922 \\
(0.044)\end{array}$ & $* * *$ \\
\hline \multicolumn{9}{|c|}{ Received SA at $t-1$ and survey year is } \\
\hline 1993 & $\begin{array}{c}-0.0139 \\
(0.128)\end{array}$ & & $\begin{array}{c}-0.0130 \\
(0.127)\end{array}$ & & & & & \\
\hline 1994 & $\begin{array}{c}-0.1423 \\
(0.131)\end{array}$ & & $\begin{array}{c}-0.1448 \\
(0.131)\end{array}$ & & & & & \\
\hline 1995 & $\begin{array}{l}0.0287 \\
(0.132)\end{array}$ & & $\begin{array}{l}0.0229 \\
(0.132)\end{array}$ & & & & & \\
\hline 1996 & $\begin{array}{l}0.0175 \\
(0.133)\end{array}$ & & $\begin{array}{c}-0.0118 \\
(0.132)\end{array}$ & & & & & \\
\hline 1997 & $\begin{array}{l}0.1564 \\
(0.138)\end{array}$ & & $\begin{array}{l}0.1646 \\
(0.137)\end{array}$ & & & & & \\
\hline 1998 & $\begin{array}{l}0.3200 \\
(0.145)\end{array}$ & $* *$ & $\begin{array}{l}0.3797 \\
(0.147)\end{array}$ & $* * *$ & & & & \\
\hline 1999 & $\begin{array}{l}0.4899 \\
(0.148)\end{array}$ & $* * *$ & $\begin{array}{l}0.5305 \\
(0.150)\end{array}$ & $* * *$ & & & & \\
\hline 2000 & $\begin{array}{l}0.3343 \\
(0.154)\end{array}$ & $* *$ & $\begin{array}{l}0.4031 \\
(0.156)\end{array}$ & $* * *$ & & & & \\
\hline 2001 & $\begin{array}{l}0.5965 \\
(0.154)\end{array}$ & $* * *$ & $\begin{array}{l}0.6431 \\
(0.158)\end{array}$ & $* * *$ & & & & \\
\hline 2002 & $\begin{array}{l}0.4436 \\
(0.158)\end{array}$ & $* * *$ & $\begin{array}{l}0.4844 \\
(0.159)\end{array}$ & $* * *$ & & & & \\
\hline 2003 & $\begin{array}{l}0.6567 \\
(0.167)\end{array}$ & $* * *$ & $\begin{array}{l}0.6686 \\
(0.168)\end{array}$ & $* * *$ & & & & \\
\hline 2004 & $\begin{array}{l}0.3518 \\
(0.167)\end{array}$ & $* *$ & $\begin{array}{l}0.4243 \\
(0.167)\end{array}$ & $* *$ & & & & \\
\hline 2005 & $\begin{array}{l}0.4397 \\
(0.162)\end{array}$ & $* * *$ & $\begin{array}{l}0.4841 \\
(0.164)\end{array}$ & $* * *$ & & & & \\
\hline
\end{tabular}


Table 7. Dynamic random effects probit models of the probability of receipt of SA at year $t$ survey interview (Heckman estimator), with interactions between lagged benefit receipt status, survey year, and lone parent status

\begin{tabular}{|c|c|c|c|c|c|c|c|c|}
\hline & \multirow{2}{*}{$\begin{array}{c}\text { Survey year } \\
\text { interactions } \\
\text { (1) }\end{array}$} & \multicolumn{7}{|c|}{ Survey year and lone parent interactions } \\
\hline & & & (2) & & (3) & & (4) & \\
\hline Received SA at $t-1$ and survey year is $1998-2005$ & & & & & $\begin{array}{l}0.4942 \\
(0.057)\end{array}$ & $* * *$ & $\begin{array}{l}0.4789 \\
(0.056)\end{array}$ & $* * *$ \\
\hline Received SA at $t-1$ and BU is lone parent at $t$ & & & $\begin{array}{l}0.4838 \\
(0.090)\end{array}$ & $* * *$ & $\begin{array}{l}0.4882 \\
(0.089)\end{array}$ & $* * *$ & $\begin{array}{l}0.4827 \\
(0.088)\end{array}$ & $* * *$ \\
\hline $\begin{array}{l}\text { Received SA at } t-1, \mathrm{BU} \text { is lone parent at } t \text {, and survey } \\
\text { year is } 1998-2005\end{array}$ & & & $\begin{array}{c}-0.3742 \\
(0.114)\end{array}$ & $* * *$ & $\begin{array}{c}-0.3735 \\
(0.112)\end{array}$ & $* * *$ & $\begin{array}{c}-0.3717 \\
(0.111)\end{array}$ & $* * *$ \\
\hline Age (years) & $\begin{array}{c}-0.0033 \\
(0.002)\end{array}$ & & $\begin{array}{r}-0.0027 \\
(0.002)\end{array}$ & & $\begin{array}{l}-0.0027 \\
(0.002)\end{array}$ & & $\begin{array}{l}-0.0025 \\
(0.002)\end{array}$ & \\
\hline Female & $\begin{array}{c}-0.1037 \\
(0.037)\end{array}$ & $* * *$ & $\begin{array}{c}-0.0987 \\
(0.037)\end{array}$ & $* * *$ & $\begin{array}{c}-0.0983 \\
(0.037)\end{array}$ & $* * *$ & $\begin{array}{c}-0.0963 \\
(0.037)\end{array}$ & $* * *$ \\
\hline Has health problem(s) & $\begin{array}{l}0.0551 \\
(0.037)\end{array}$ & & $\begin{array}{l}0.0569 \\
(0.037)\end{array}$ & & $\begin{array}{l}0.0585 \\
(0.037)\end{array}$ & & $\begin{array}{l}0.0592 \\
(0.037)\end{array}$ & \\
\hline Educational qualifications & & & & & & & & \\
\hline O-level(s), CSE, etc. & $\begin{array}{l}-0.2980 \\
(0.046)\end{array}$ & $* * *$ & $\begin{array}{c}-0.3006 \\
(0.046)\end{array}$ & $* * *$ & $\begin{array}{c}-0.2971 \\
(0.046)\end{array}$ & $* * *$ & $\begin{array}{c}-0.2966 \\
(0.046)\end{array}$ & $* * *$ \\
\hline A-level(s) or higher & $\begin{array}{c}-0.5093 \\
(0.045)\end{array}$ & $* * *$ & $\begin{array}{c}-0.5133 \\
(0.045)\end{array}$ & $* * *$ & $\begin{array}{c}-0.5116 \\
(0.045)\end{array}$ & $* * *$ & $\begin{array}{c}-0.5081 \\
(0.044)\end{array}$ & $* * *$ \\
\hline Missing & $\begin{array}{c}-1.1960 \\
(0.068)\end{array}$ & $* * *$ & $\begin{array}{c}-1.2034 \\
(0.069)\end{array}$ & $* * *$ & $\begin{array}{c}-1.1970 \\
(0.068)\end{array}$ & $* * *$ & $\begin{array}{c}-1.1902 \\
(0.068)\end{array}$ & $* * *$ \\
\hline Spouse's age (years) & $\begin{array}{l}0.0033 \\
(0.003)\end{array}$ & & $\begin{array}{l}0.0023 \\
(0.003)\end{array}$ & & $\begin{array}{l}0.0022 \\
(0.003)\end{array}$ & & $\begin{array}{l}0.0023 \\
(0.003)\end{array}$ & \\
\hline Spouse: no educational qualifications & $\begin{array}{l}0.6637 \\
(0.130)\end{array}$ & $* * *$ & $\begin{array}{c}0.6701 \\
(0.131)\end{array}$ & $* * *$ & $\begin{array}{l}0.6611 \\
(0.130)\end{array}$ & $* * *$ & $\begin{array}{l}0.6495 \\
(0.130)\end{array}$ & $* * *$ \\
\hline Spouse has O-level(s), CSE, etc. & $\begin{array}{l}0.6391 \\
(0.121)\end{array}$ & $* * *$ & $\begin{array}{l}0.6440 \\
(0.122)\end{array}$ & $* * *$ & $\begin{array}{l}0.6348 \\
(0.121)\end{array}$ & $* * *$ & $\begin{array}{l}0.6245 \\
(0.121)\end{array}$ & $* * *$ \\
\hline Spouse has A-level(s) or higher & $\begin{array}{l}0.4767 \\
(0.122)\end{array}$ & $* * *$ & $\begin{array}{l}0.4706 \\
(0.122)\end{array}$ & $* * *$ & $\begin{array}{l}0.4560 \\
(0.121)\end{array}$ & $* * *$ & $\begin{array}{l}0.4511 \\
(0.121)\end{array}$ & $* * *$ \\
\hline Spouse's missing educational qualifications & $\begin{array}{l}0.0490 \\
(0.154)\end{array}$ & & $\begin{array}{l}0.0540 \\
(0.155)\end{array}$ & & $\begin{array}{l}0.0314 \\
(0.155)\end{array}$ & & $\begin{array}{l}0.0328 \\
(0.154)\end{array}$ & \\
\hline
\end{tabular}


Table 7. Dynamic random effects probit models of the probability of receipt of SA at year $t$ survey interview (Heckman estimator), with interactions between lagged benefit receipt status, survey year, and lone parent status

\begin{tabular}{|c|c|c|c|c|c|c|c|c|}
\hline & \multirow{2}{*}{$\begin{array}{c}\text { Survey year } \\
\text { interactions } \\
\text { (1) }\end{array}$} & \multicolumn{7}{|c|}{ Survey year and lone parent interactions } \\
\hline & & & $(2)$ & & (3) & & (4) & \\
\hline Number of children in $B U=1$ & $\begin{array}{l}0.0070 \\
(0.058)\end{array}$ & & $\begin{array}{l}0.0106 \\
(0.058)\end{array}$ & & $\begin{array}{l}0.0110 \\
(0.058)\end{array}$ & & $\begin{array}{l}0.0079 \\
(0.057)\end{array}$ & \\
\hline Number of children in $\mathrm{BU}=2$ & $\begin{array}{l}0.0388 \\
(0.066)\end{array}$ & & $\begin{array}{l}0.0375 \\
(0.066)\end{array}$ & & $\begin{array}{l}0.0344 \\
(0.065)\end{array}$ & & $\begin{array}{l}0.0286 \\
(0.064)\end{array}$ & \\
\hline Number of children in $\mathrm{BU}=3$ or more & $\begin{array}{l}0.1018 \\
(0.084)\end{array}$ & & $\begin{array}{l}0.1178 \\
(0.085)\end{array}$ & & $\begin{array}{l}0.1180 \\
(0.083)\end{array}$ & & $\begin{array}{l}0.1072 \\
(0.082)\end{array}$ & \\
\hline Age of youngest child $<5$ & $\begin{array}{l}0.3035 \\
(0.045)\end{array}$ & $* * *$ & $\begin{array}{l}0.3021 \\
(0.045)\end{array}$ & $* * *$ & $\begin{array}{l}0.3049 \\
(0.045)\end{array}$ & $* * *$ & $\begin{array}{l}0.2962 \\
(0.044)\end{array}$ & $* * *$ \\
\hline BU type: lone parent & $\begin{array}{l}0.7356 \\
(0.083)\end{array}$ & $* * *$ & $\begin{array}{l}0.6024 \\
(0.092)\end{array}$ & $* * *$ & $\begin{array}{l}0.5917 \\
(0.091)\end{array}$ & $* * *$ & $\begin{array}{l}0.6006 \\
(0.091)\end{array}$ & $* * *$ \\
\hline BU type: couple & $\begin{array}{c}-0.7755 \\
(0.179)\end{array}$ & $* * *$ & $\begin{array}{c}-0.7485 \\
(0.179)\end{array}$ & $* * *$ & $\begin{array}{c}-0.7349 \\
(0.178)\end{array}$ & $* * *$ & $\begin{array}{c}-0.7251 \\
(0.177)\end{array}$ & $* * *$ \\
\hline House tenure: owned & $\begin{array}{c}-0.1978 \\
(0.055)\end{array}$ & $* * *$ & $\begin{array}{c}-0.2013 \\
(0.055)\end{array}$ & $* * *$ & $\begin{array}{c}-0.2014 \\
(0.055)\end{array}$ & $* * *$ & $\begin{array}{c}-0.1972 \\
(0.055)\end{array}$ & $* * *$ \\
\hline Lives in London (inner or outer) & $\begin{array}{l}0.3166 \\
(0.137)\end{array}$ & $* *$ & $\begin{array}{l}0.3153 \\
(0.138)\end{array}$ & $* *$ & $\begin{array}{l}0.3216 \\
(0.137)\end{array}$ & $* *$ & $\begin{array}{l}0.3173 \\
(0.136)\end{array}$ & $* *$ \\
\hline Unemployment rate in TTWA (\%) & $\begin{array}{l}0.0412 \\
(0.011)\end{array}$ & $* * *$ & $\begin{array}{l}0.0417 \\
(0.011)\end{array}$ & $* * *$ & $\begin{array}{l}0.0411 \\
(0.011)\end{array}$ & $* * *$ & $\begin{array}{l}0.0353 \\
(0.007)\end{array}$ & $* * *$ \\
\hline \multicolumn{9}{|l|}{ Survey year } \\
\hline 1993 & $\begin{array}{c}0.0343 \\
(0.058)\end{array}$ & & $\begin{array}{l}0.0371 \\
(0.058)\end{array}$ & & $\begin{array}{l}0.0399 \\
(0.051)\end{array}$ & & & \\
\hline 1994 & $\begin{array}{l}0.0221 \\
(0.062)\end{array}$ & & $\begin{array}{l}0.0305 \\
(0.062)\end{array}$ & & $\begin{array}{c}-0.0060 \\
(0.054)\end{array}$ & & & \\
\hline 1995 & $\begin{array}{l}0.0060 \\
(0.064)\end{array}$ & & $\begin{array}{l}0.0048 \\
(0.064)\end{array}$ & & $\begin{array}{l}0.0133 \\
(0.057)\end{array}$ & & & \\
\hline 1996 & $\begin{array}{l}0.0493 \\
(0.075)\end{array}$ & & $\begin{array}{l}0.0635 \\
(0.075)\end{array}$ & & $\begin{array}{l}0.0595 \\
(0.067)\end{array}$ & & & \\
\hline 1997 & $\begin{array}{l}0.0027 \\
(0.086)\end{array}$ & & $\begin{array}{l}0.0133 \\
(0.086)\end{array}$ & & $\begin{array}{l}0.0635 \\
(0.079)\end{array}$ & & & \\
\hline
\end{tabular}


Table 7. Dynamic random effects probit models of the probability of receipt of SA at year $t$ survey interview (Heckman estimator), with interactions between lagged benefit receipt status, survey year, and lone parent status

\begin{tabular}{|c|c|c|c|c|c|c|c|c|}
\hline & \multirow{2}{*}{$\begin{array}{c}\text { Survey year } \\
\text { interactions } \\
\text { (1) }\end{array}$} & \multicolumn{7}{|c|}{ Survey year and lone parent interactions } \\
\hline & & & $(2)$ & & (3) & & (4) & \\
\hline 1998 & $\begin{array}{c}-0.1200 \\
(0.091)\end{array}$ & & $\begin{array}{c}-0.1105 \\
(0.091)\end{array}$ & & $\begin{array}{c}-0.1501 \\
(0.084)\end{array}$ & $*$ & & \\
\hline 1999 & $\begin{array}{c}-0.1830 \\
(0.098)\end{array}$ & * & $\begin{array}{c}-0.1687 \\
(0.098)\end{array}$ & $*$ & $\begin{array}{c}-0.1661 \\
(0.089)\end{array}$ & $*$ & & \\
\hline 2000 & $\begin{array}{c}-0.0325 \\
(0.096)\end{array}$ & & $\begin{array}{c}-0.0264 \\
(0.096)\end{array}$ & & $\begin{array}{c}-0.0617 \\
(0.090)\end{array}$ & & & \\
\hline 2001 & $\begin{array}{c}-0.2239 \\
(0.103)\end{array}$ & $* *$ & $\begin{array}{c}-0.2176 \\
(0.104)\end{array}$ & $* *$ & $\begin{array}{c}-0.1659 \\
(0.096)\end{array}$ & $*$ & & \\
\hline 2002 & $\begin{array}{c}-0.1783 \\
(0.103)\end{array}$ & * & $\begin{array}{c}-0.1630 \\
(0.103)\end{array}$ & & $\begin{array}{c}-0.1671 \\
(0.095)\end{array}$ & $*$ & & \\
\hline 2003 & $\begin{array}{c}-0.0869 \\
(0.101)\end{array}$ & & $\begin{array}{c}-0.0595 \\
(0.101)\end{array}$ & & $\begin{array}{c}-0.0163 \\
(0.095)\end{array}$ & & & \\
\hline 2004 & $\begin{array}{c}-0.1424 \\
(0.109)\end{array}$ & & $\begin{array}{c}-0.1281 \\
(0.109)\end{array}$ & & $\begin{array}{c}-0.1610 \\
(0.102)\end{array}$ & & & \\
\hline 2005 & $\begin{array}{c}-0.0138 \\
(0.101)\end{array}$ & & $\begin{array}{l}0.0036 \\
(0.101)\end{array}$ & & $\begin{array}{c}-0.0045 \\
(0.095)\end{array}$ & & & \\
\hline $1998-2005$ & & & & & & & $\begin{array}{c}-0.1693 \\
(0.041)\end{array}$ & $* * *$ \\
\hline \multicolumn{9}{|l|}{ Time-averaged characteristics } \\
\hline Has health problem(s) & $\begin{array}{l}0.3066 \\
(0.060)\end{array}$ & $* * *$ & $\begin{array}{l}0.3080 \\
(0.061)\end{array}$ & $* * *$ & $\begin{array}{l}0.3068 \\
(0.061)\end{array}$ & $* * *$ & $\begin{array}{l}0.3062 \\
(0.060)\end{array}$ & $* * *$ \\
\hline Spouse: no educational qualifications & $\begin{array}{c}-0.1544 \\
(0.199)\end{array}$ & & $\begin{array}{c}-0.1624 \\
(0.201)\end{array}$ & & $\begin{array}{c}-0.1598 \\
(0.200)\end{array}$ & & $\begin{array}{c}-0.1510 \\
(0.199)\end{array}$ & \\
\hline Spouse has O-level(s), CSE, etc & $\begin{array}{c}-0.3948 \\
(0.193)\end{array}$ & $* *$ & $\begin{array}{c}-0.4115 \\
(0.194)\end{array}$ & $* *$ & $\begin{array}{c}-0.4078 \\
(0.194)\end{array}$ & $* *$ & $\begin{array}{c}-0.3996 \\
(0.192)\end{array}$ & $* *$ \\
\hline Spouse has A-level(s) or higher & $\begin{array}{c}-0.3200 \\
(0.192)\end{array}$ & * & $\begin{array}{c}-0.3323 \\
(0.194)\end{array}$ & $*$ & $\begin{array}{c}-0.3267 \\
(0.193)\end{array}$ & $*$ & $\begin{array}{c}-0.3228 \\
(0.191)\end{array}$ & $*$ \\
\hline Spouse's missing educational qualifications & $\begin{array}{c}-0.3250 \\
(0.257)\end{array}$ & & $\begin{array}{c}-0.3319 \\
(0.259)\end{array}$ & & $\begin{array}{c}-0.3083 \\
(0.259)\end{array}$ & & $\begin{array}{c}-0.3167 \\
(0.257)\end{array}$ & \\
\hline
\end{tabular}


Table 7. Dynamic random effects probit models of the probability of receipt of SA at year $t$ survey interview (Heckman estimator), with interactions between lagged benefit receipt status, survey year, and lone parent status

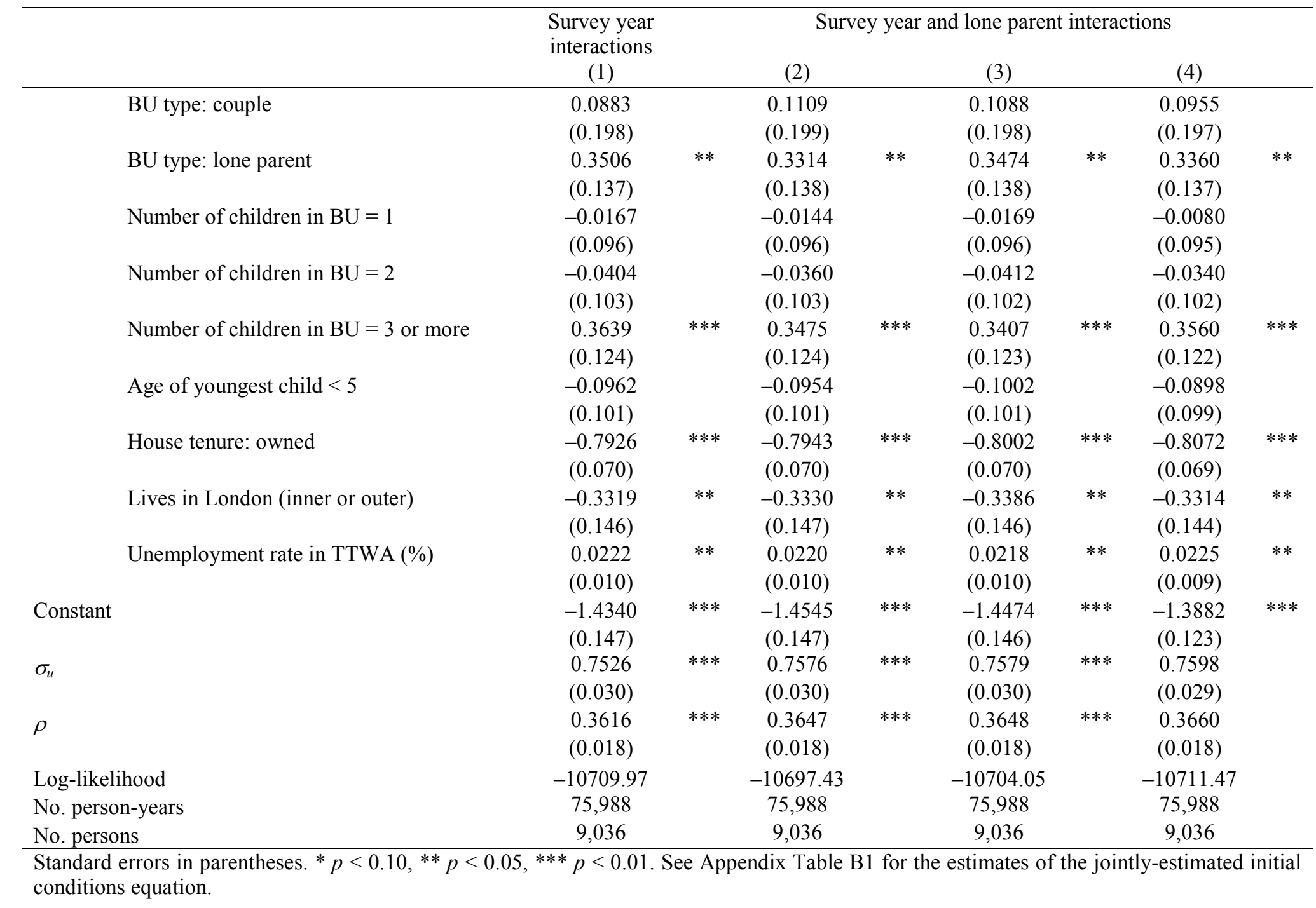




\section{Implications of the parameter estimates}

137. We now consider the 'Boskin and Nold' predictions of SA entry and persistence rates, and related statistics such as spell lengths that are implied by our preferred specification (model (4) reported in Table 7). The predictions are based on the formulae shown in equations (17) and (18). We should stress that these are 'steady state' predictions - what would apply were SA entry and exit rates to each remain constant over the indefinite future. This is a fictional scenario, of course, as we have already shown how SA transition probabilities have varied over time. Thus, the predictions should be considered as transformations of the model parameters that help illuminate their interpretation in terms of concepts that are more familiar. The derivation of the predictions also requires specification of each of series of 'person types' characterized by a particular configuration of characteristics. Some characteristics (such as age) change over time and that is not taken into account when deriving the predictions. All explanatory variables are set at fixed constant values. Hence a year-specific variables and its time-averaged counterpart have the same value: the effect of the variable is the sum of the coefficients on the two variables.

138. The statistics that we calculate from the model estimates are the steady state SA entry rate $\left(e_{i}\right)$, the SA persistence rate $\left(s_{i}\right)$ i.e. one minus the exit rate, the median duration of SA receipt for someone beginning an SA spell, and the median duration of SA non-receipt for someone ending an SA spell. We supplement these with the calculation of the unconditional probability of being found in SA receipt at any interview (which might also be interpreted as the predicted proportion of total time spent in SA receipt), and also the expected turnover rate. ${ }^{30} \mathrm{We}$ also calculated mean spell lengths but do not report them for brevity (they are larger than the corresponding medians, since the spell length distributions are skewed). The difference between the mean and median is a reminder that there is dispersion in spell lengths even among individuals sharing the same characteristics.

139. We begin by specifying the characteristics of a reference person type, and then explore the implications of varying characteristics relative to this baseline case. The reference person is a 40 year old woman, living outside London in an area with unemployment rate of $9 \%$, with one child aged under 5 years, married (spouse aged 40), no health problems, no educational qualifications (self and spouse), owner-occupier, survey year is before 1998. Table 8 shows the transition rates and spell lengths predicted by the model estimates.

140. For the base case the annual probability of remaining in SA receipt is 0.648 , and the annual probability of SA entry is 0.341 . This corresponds to a median spell length of SA receipt of 1.6 years for someone beginning a spell of SA receipt, and a median spell length of SA non-receipt of 1.7 years for someone ending a spell of SA receipt. The unconditional probability of SA receipt is just under one half (0.49) and the expected turnover rate is 0.17 .

141. Subsequent rows of Table 8 show the corresponding predictions for different person types. For example, if the respondent has A-levels or higher educational qualifications rather no qualifications (row 4), her SA persistence rate falls substantially (to 0.490 ) and her SA entry rate also falls. The median SA spell length falls to less than a year (0.97 years) and the median non-receipt spell length increases to 3 years. The unconditional probability of SA receipt falls to 0.289 (from 0.492). If the respondent's spouse also has A-levels or higher educational qualifications rather no qualifications (row 5), the median SA spell length falls even further to just over half a year (0.52) and the unconditional probability of receipt falls to less than one tenth $(0.09)$.

142. The steady state predictions corresponding to survey years 1998 and afterwards yield to lower entry rates and higher persistence rates (lower exit rates). But at the same time, we know that unemployment rates fell over the 1990s - a factor associated with lower persistence rates and lower entry rates. The net effect (row 12) is a slightly lower persistence rate relative to the base case $(0.64$

30. Standard errors for the predictions are derived using the delta method, and are non-linear functions of the variance covariance matrix of the coefficient estimates. The fixed values of the covariates used to characterize each person type are treated as non-stochastic. 
rather than 0.65$)$, and an entry rate about one third smaller $(0.21$ rather than 0.34$)$. The median SA spell length is only slightly smaller than the base case, but the median time spell in non receipt increases substantially (it is 3.0 years rather than 1.7), and the unconditional probability of receipt falls to 0.36 from 0.49 .

143. Table 8 underlines the disadvantage in SA receipt terms that is associated with being a lone parent (row 13) and living in non-owned accommodation (row 8) or the combination of these factors (row 14). A lone mother living in social housing is predicted to have an SA persistence rate of almost one (0.99) and a very high entry rate as well (0.88), which correspond to a predicted median SA spell length of 71 years. (This is of course virtually impossible, which is a reminder that all these predictions are extrapolations made on the assumption that characteristics do not change. Note too that the standard errors associated with the predicted medians are relatively large.)

144. At the bottom of the table (row 17), we contrast this high-receipt probability case with the case of someone with 'favourable characteristics'. She has the same characteristics as Base Case, except that she and her partner have educational qualifications to A-level or higher, the local unemployment rate is $3 \%$, and her youngest child is aged over 5 years. Compared to the base case, the SA persistence rate is about one third as large (0.22 compared to 0.65$)$ and the entry rate is less than one fifth as large (0.06 rather than 0.34), implying a median SA spell length of less than a year and median non-receipt spell length of 11 years. The unconditional probability of SA receipt is one seventh that of the base case: 0.07 rather than 0.29 . Observe that the expected turnover rate for this person is relatively small (0.06), which happens to be the rate for a lone mother as well. But the low turnover arises in very different ways - from remaining off SA in the former case, and remaining in receipt in the latter case.

145. Overall, it appears from Table 8 that there is greater individual heterogeneity in SA entry rates than in SA persistence rates. Probabilities of SA entry range from 0.061 to 0.878 , compared with variation in persistence probabilities from 0.224 to 0.990 . The relative importance of heterogeneity in entry rates was also remarked on by Cappellari and Jenkins (2004) in their BHPS-based study of differences in poverty entry and exit rates. 
Table 8. Predicted 'Boskin-Nold' steady-state SA transition probabilities and related statistics for different types of person

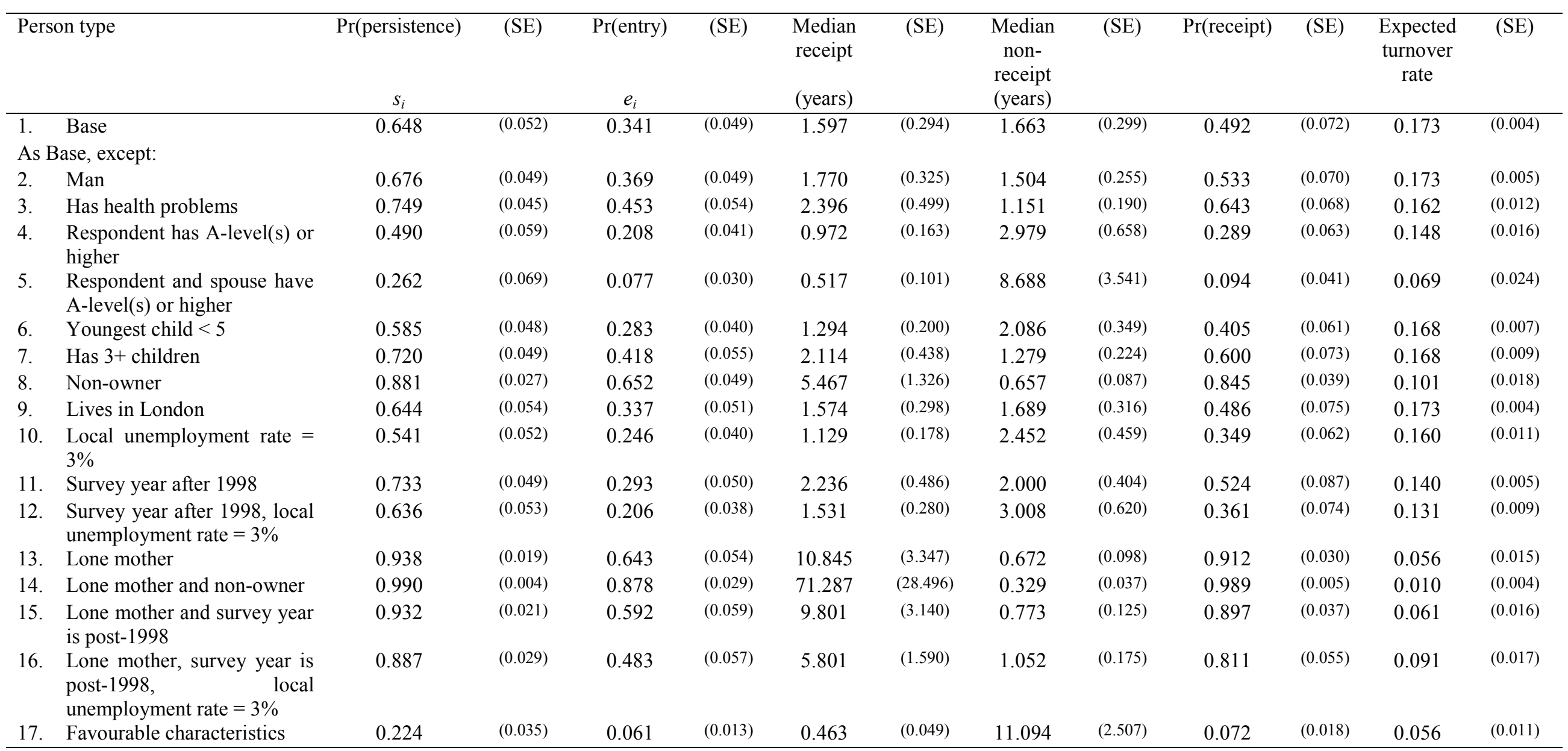

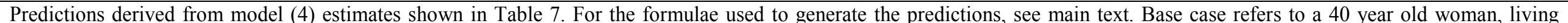

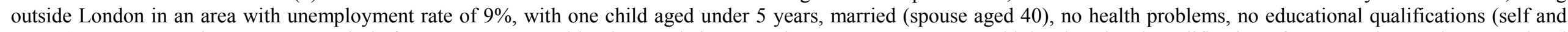

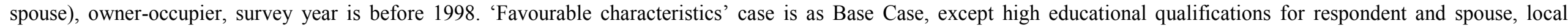
unemployment rate is $3 \%$, and age of youngest child is over 5 years. 
146. We have modelled the dynamics of social assistance benefit receipt in Britain using data from the British Household Panel Survey, waves 1-15 (survey years 1991-2005), and have fitted a series of dynamic random effects probit models.

\section{Substantive findings}

147. There are clear associations between the probability of SA receipt and a number of characteristics. Probabilities of receipt are slightly higher for men than women - unless the women are lone parents in which case the probabilities are very much higher. Living in non-owned housing is also associated with relatively high probabilities of receipt. Probabilities are also higher for individuals with young children, or with relatively low educational qualifications. Having a spouse with low educational qualifications raises the chances of SA receipt further. Receipt probabilities are lower for those living outside London, or in a travel-to-work area with a low unemployment rate. Differences in age, or having health problems, have no statistically significant association with the probability of SA receipt.

148. The risk of receiving SA in one year is noticeably higher if SA was also received in the previous year, even after controlling for observed and unobserved differences in characteristics. According to the basic model specification, the risk is about 14 percentage points higher (19\% rather than 5\%). This might be interpreted as a state dependence or scarring effect of SA receipt, but such an interpretation requires caution particularly because it suggests that there is a single effect for all individuals. By contrast, we have demonstrated that there are marked differences between groups of individuals. SA persistence rates are much higher for those with continuing spells compared to those with non-receipt in the period between annual interviews, and also much higher for lone parents compared to other groups.

149. These substantive findings about the impact of different characteristics and of past benefit receipt are broadly in line with the small number of existing studies of SA receipt for Sweden and Canada. They are also, unsurprisingly, broadly consistent with previous studies of related topics such as unemployment dynamics and poverty dynamics. It would be surprising if they were not given the close links between unemployment, low income and receipt of SA.

150. Unlike previous studies, we have given substantial attention to trends over time in SA receipt and transition rates. We have shown that there was a clear decline over the last 15 years in the average SA annual entry rate (from above $4 \%$ to below $2 \%$ ), and there was also rise in the average SA annual persistence rate from around $60 \%$ to nearly $75 \%$ (corresponding to a decline in the annual exit rate from around $40 \%$ to nearly $25 \%$ ). It was the decline in entry rates that was principally responsible for the decline in the cross-sectional rates of SA receipt, rather than changes in SA exit rates. According to the model estimates, the key distinction in pure calendar time effects was between the period before 1998 and the period thereafter, which is somewhat of a puzzle since the timing does not closely correspond with the introduction of one of New Labour's major policy reforms to the social security system. We have also pointed out how changes in the characteristics of the populations at risk of entering and of remaining in SA receipt affected the overall SA entry and persistence rates. Factors such as the secular rise in educational qualifications and the decline in local unemployment rates would have reduced the entry rate. The growing concentration of individuals living in social housing among SA recipients was associated with the declining SA exit rates.

\section{Lessons for studies of other countries and methodological issues}

151. We have discussed at length the definitions of SA itself and its component income sources, the unit of SA receipt, and the reference period over which receipt is measured. We have argued that there are a number of important choices to be made concerning each of these and, importantly, the 
choices that are feasible in the context of empirical analysis will depend on the specific country and on the data sources that are available. Changes to the social security system, as in Britain over the last two decades, have made derivation of a consistent cross-time definition of SA more difficult. Moreover, we have shown that analysis possibilities may differ depending on whether one has access to panel data derived from a household panel survey or from administrative registers. Related, the between-interview histories of benefit receipt in household panel surveys are subject to seam problems that make consistent continuous benefit histories difficult to derive - a key reason for focusing on a dynamic probit models rather than a survival analysis approach to analysis of individuals' benefit receipt over time. Differences across countries in definitions and data sources reduce the comparability of estimates derived from country specific studies.

152. The nature of the issues that are most pertinent or possible to analyse may also be countryspecific. For example, we have drawn attention to the trends over time in Britain in cross-sectional rates of SA receipt and in annual SA transition probabilities. During the same period, there were also major changes to social assistance and other benefits, including the introduction of tax credits. Using multivariate analysis to study trends in rates and policy impacts requires data that span a long period of time. The BHPS meets this criterion, but the other studies of SA dynamics to date have used data spanning shorter periods. Instead their focus has been on different issues, such as differences in state dependence across regions, or between non-immigrant citizens and immigrants - topics that the BHPS is ill-suited to address.

153. We have been cautious about attributing the observed changes over time to policy and to policy reforms. Although we have pointed to some explanations, a full-blown analysis of policy effects and causation needs a less broad study than this one, one that focuses on particular policies and particular groups 'at risk'.

154. We have added to the small but growing literature that finds that the Heckman, Wooldridge and Orme estimators of dynamic random effects probit models produce similar estimates. This is useful for analysts because the latter two estimators can be applied using readily available software rather than requiring specially-written program modules that are either not widely available or, if available, require infeasibly long amounts of computer time. Specialist modules continue to be required to fit models such as those allowing for unobserved heterogeneity in state dependence - an interesting topic for future research given our findings about observed heterogeneity in these effects. Another aspect worthy of attention in future research on SA receipt is the effects of a 'history' of receipt beyond the previous year - examination of second- or higher order Markov specifications. Another major issue to be addressed, and which requires specialist software, is the modelling of potential feedback effects. Not only may a number of demographic and other characteristics such as housing tenure determine outcomes such as SA receipt, but past receipt may also contribute to the determination of those characteristics. 


\section{REFERENCES}

Andrén, Thomas (2007), 'The persistence of welfare participation', Working Papers in Economics No 266, School of Business, Economics and Law, Göteborg University, Göteborg. http://hdl.handle.net/2077/7366

Arellano, Manuel and Steven Bond (1991), 'Some tests of specification for panel data: Monte Carlo evidence and an application to employment equations', Review of Economic Studies, 58: 277297.

Arulampalam, Wiji, and Mark B. Stewart (2007), 'Simplified implementation of the Heckman estimator of the dynamic probit model and a comparison with alternative estimators', IZA Discussion Paper No. 3039, Institute for the Study of Labour (IZA), Bonn. ftp://repec.iza.org/RePEc/Discussionpaper/dp3039.pdf

Arulampalam, Wiji, Alison L. Booth, and Mark P. Taylor (2000), 'Unemployment persistence', Oxford Economic Papers, 52: 24-50.

Arulampalam, Wiji, Paul Gregg, and Mary Gregory (2001), 'Introduction: unemployment scarring', Economic Journal, 111: F577-F584.

Biewen, Martin (2004), 'Measuring state dependence in individual poverty status: are there feedback effects to employment decisions and household composition?', IZA Discussion Paper 1138, Institute for the Study of Labour (IZA), Bonn.

ftp://repec.iza.org/RePEc/Discussionpaper/dp1138.pdf

Böheim, René, John F. Ermisch, and Stephen P. Jenkins (1999), 'The dynamics of lone mothers' incomes: public and private income sources compared', ISER Working Paper 1999-05, University of Essex, Colchester. http://www.iser.essex.ac.uk/pubs/workpaps/pdf/1999-05.pdf

Boskin, Michael J. and Frederick C. Nold (1975), 'A Markov model of turnover in Aid for Families with Dependent Children’, Journal of Human Resources 10: 467-481.

Brewer, Michael, and Andrew Shephard (2004), Has Labour Made Work Pay?, York Publishing Services for the Joseph Rowntree Foundation, York. http://www.jrf.org.uk/bookshop/eBooks/1859352626.pdf

Brewer, Michael, Alan Duncan, Andrew Shephard, and María José Suarez (2006), 'Did working families' tax credit work? The impact of in-work support on labour supply in Britain', Labour Economics, 13: 699-720.

Cappellari, Lorenzo, and Stephen P. Jenkins (2004), 'Modelling low income transitions', Journal of Applied Econometrics, 19: 593-610.

Cappellari, Lorenzo, and Stephen P. Jenkins (2008), 'Estimating low pay transition probabilities accounting for endogenous selection mechanisms', Journal of the Royal Statistical Society, Series C (Applied Statistics), 57: 165-186.

Chamberlain, Gary (1984), 'Panel data', in Zvi Griliches and Michael Intrilligator (eds), Handbook of Econometrics, North-Holland: Amsterdam. 
Enberg, John, Peter Gottschalk, and Douglas Wolf (1990), 'A random-effects logit model of workwelfare transitions', Journal of Econometrics, 43: 63-75.

Francesconi, Marco and Wilbert van der Klaauw (2007), 'The socioeconomic consequences of inwork benefit reform for British lone mothers', Journal of Human Resources, 42: 1-31.

Gregg, Paul, Susan Harkness, and Sarah Smith (2007), 'Welfare reform and lone parents in the UK', CEMPO Working Paper 07/182, Centre for Market and Public Organisation, University of Bristol, Bristol.

Hansen, Jörgen, and Magnus Lofstrom (2003), 'Immigrant assimilation and welfare participation: do immigrants assimilate into or out of welfare?' Journal of Human Resources, 38: 74-98.

Hansen, Jörgen, and Magnus Lofstrom (2006), 'Immigrant-native differences in welfare participation: the role of entry and exit rates', IZA Discussion Paper No. 2261, Institute for the Study of Labour (IZA), Bonn. ftp://repec.iza.org/RePEc/Discussionpaper/dp2261.pdf

Hansen, Jörgen, Magnus Lofstrom, and Xuelin Zhang (2006), 'State dependence in Canadian welfare participation', IZA Discussion Paper No. 2266, Institute for the Study of Labour (IZA), Bonn. ftp://repec.iza.org/RePEc/Discussionpaper/dp2266.pdf

Heckman, James J. (1979). 'Sample selection bias as a specification error', Econometrica, 47: 153161.

Heckman, James J. (1981), 'The incidental parameters problem and the problem of initial conditions in estimating a discrete time-discrete data stochastic process', in Charles F. Manski and Daniel McFadden (eds), Structural Analysis of Discrete Data with Econometric Applications, MIT Press, Cambridge, MA.

Jenkins, Stephen P. (2000), 'Modelling household income dynamics', Journal of Population Economics, 13: 529-567.

Mundlak, Yair (1978), 'On the pooling of time series and cross section data', Econometrica, 46: 6985.

Orme, Christopher D. (1997). 'The initial conditions problem and two-step estimation in discrete panel data models', Discussion Paper No. 9633, School of Social Sciences, University of Manchester. Revised version, June 2001, retitled as: 'Two-Step inference in dynamic non-linear panel data models', http://personalpages.manchester.ac.uk/staff/chris.orme/documents/Research\%20Papers/initcond $\underline{\text { last.pdf }}$

Petrongolo, Barbara. (2007) 'What are the long-term effects of UI? Evidence from the UK JSA reform', Discussion Paper No 841, Centre for Economic Performance, London School of Economics, $\underline{\text { http://cep.lse.ac.uk/pubs/download/dp0841.pdf }}$

Stewart, Mark B. (2006), 'Maximum simulated likelihood estimation of random effects dynamic probit models with autocorrelated errors', Stata Journal, 6: 256-272.

Stewart, Mark B. (2007), 'The interrelated dynamics of unemployment and low pay', Journal of Applied Econometrics, 22: 511-531.

Stewart, Mark B. and Joanna K. Swaffield (1999), 'Low pay dynamics and transition probabilities', Economica, 66: 23-42. 
Taylor, Marcia F. (ed.) with John Brice, Nick Buck, and Elaine Prentice-Lane (2007), British Household Panel Survey User Manual Volume A: Introduction, Technical Report and Appendices, Institute for Social and Economic Research, University of Essex, Colchester. http://www.iser.essex.ac.uk/ulsc/bhps/doc/pdf versions/volumes/bhpsvola.pdf

Wooldridge, Jeffery M. (2005), 'Simple solutions to the initial conditions problem in dynamic, nonlinear panel data models with unobserved heterogeneity', Journal of Applied Econometrics, 20: $39-54$. 


\section{APPENDIX A. SOFTWARE AND ESTIMATION DETAILS}

155. All data management, graphics, model estimation and post-estimation computational tasks were undertaken using Stata version 10MP2. The main difficulty confronting us was how to estimate dynamic random effects probit models accurately and in a timely fashion.

156. The main estimates reported use the Heckman approximation to estimation of the initial conditions equation (see section 2). The estimates reported were derived with Alfonso Miranda's program module dupr, which uses maximum simulated likelihood methods with Halton draws. (This module is not yet in the public domain.) All estimates were derived using 1000 Halton draws. Increasing the number of draws from 500 to 1000 made little difference to the estimates derived. The principal reason for choosing dupr was computational speed: estimates were derived for the basic model specification within approximately one hour. We also re-estimated models using Mark Stewart's program module redprob, which uses Gauss-Hermite quadrature. (The module is downloadable from his web page http://www2.warwick.ac.uk/fac/soc/economics/staff/faculty/stewart/stata.) Estimation of the basic specification took about 15 hours. Reassuringly, dupr and redprob produced parameter estimates that were very similar.

157. We also investigated three other program modules for the Heckman estimator, each of which uses maximum simulated likelihood methods: Mark Stewart's redpace (downloadable from the Stata Journal code archive) which optionally allows for first order autocorrelation in the white noise error term; our own specially-written code utilising a 'plugin' for calculation of multivariate normal probabilities (see our article in the Stata Journal, 2006, 6(2)); and code using LIMDEP/NLOGIT version 4 rather than Stata. We abandoned all three modules when it became clear that computational speed was infeasibly slow for the sample sizes and number of explanatory variables that we were considering (convergence time was counted in terms of days).

158. Estimates of the dynamic random effects probit models using the Orme and Wooldridge approaches were derived with the random effects probit module xtprobit that is built-in to Stata. It uses adaptive Gauss-Hermite quadrature by default. Estimates of the basic specification took approximately one hour to derive with 25 integration points. Increasing the number of integration points from the default (8) changed the estimates little. 


\section{APPENDIX B. INITIAL CONDITIONS ESTIMATES}

Table B1. The probability of SA receipt at $t=1$ (initial conditions): basic specification

\begin{tabular}{|c|c|c|c|c|c|c|}
\hline \multirow[b]{2}{*}{ Age (years) } & \multicolumn{2}{|c|}{$\begin{array}{l}\text { Unbalanced } \\
\text { panel, all } \\
\text { sequences start at } \\
\text { wave } 1 \\
\quad \text { (1) }\end{array}$} & \multicolumn{2}{|c|}{$\begin{array}{l}\text { Fifteen-wave } \\
\text { balanced panel }\end{array}$} & \multicolumn{2}{|c|}{\begin{tabular}{l} 
Unbalanced panel, \\
excluding sequences \\
with continuous \\
receipt \\
\multicolumn{1}{c}{ (3) }
\end{tabular}} \\
\hline & $\begin{array}{c}-0.0026 \\
(0.005)\end{array}$ & & $\begin{array}{c}-0.0209 \\
(0.016)\end{array}$ & & $\begin{array}{l}0.0012 \\
(0.004)\end{array}$ & \\
\hline Female & $\begin{array}{l}0.0205 \\
(0.078)\end{array}$ & & $\begin{array}{c}-0.0122 \\
(0.166)\end{array}$ & & $\begin{array}{c}-0.0066 \\
(0.057)\end{array}$ & \\
\hline Has health problem(s) & $\begin{array}{l}0.0968 \\
(0.072)\end{array}$ & & $\begin{array}{c}-0.0186 \\
(0.131)\end{array}$ & & $\begin{array}{l}0.1755 \\
(0.053)\end{array}$ & $* * *$ \\
\hline Educational qualifications & & & & & & \\
\hline O-level(s), CSE, etc. & $\begin{array}{c}-0.1588 \\
(0.090)\end{array}$ & * & $\begin{array}{c}-0.4687 \\
(0.172)\end{array}$ & $* * *$ & $\begin{array}{c}-0.2067 \\
(0.069)\end{array}$ & $* * *$ \\
\hline A-level(s) or higher & $\begin{array}{c}-0.4909 \\
(0.101)\end{array}$ & $* * *$ & $\begin{array}{c}-0.8168 \\
(0.207)\end{array}$ & $* * *$ & $\begin{array}{c}-0.4981 \\
(0.078)\end{array}$ & $* * *$ \\
\hline Missing & $\begin{array}{c}-0.7866 \\
(0.189)\end{array}$ & $* * *$ & $\begin{array}{c}-0.7464 \\
(0.425)\end{array}$ & $*$ & $\begin{array}{c}-0.9422 \\
(0.128)\end{array}$ & $* * *$ \\
\hline Spouse's age (years) & $\begin{array}{c}-0.0011 \\
(0.006)\end{array}$ & & $\begin{array}{l}0.0016 \\
(0.019)\end{array}$ & & $\begin{array}{c}-0.0020 \\
(0.005)\end{array}$ & \\
\hline Spouse: no educational qualifications & $\begin{array}{l}0.1182 \\
(0.231)\end{array}$ & & $\begin{array}{l}0.6346 \\
(0.560)\end{array}$ & & $\begin{array}{l}0.3156 \\
(0.184)\end{array}$ & $*$ \\
\hline Spouse has O-level(s), CSE, etc. & $\begin{array}{c}-0.0770 \\
(0.231)\end{array}$ & & $\begin{array}{l}0.2415 \\
(0.565)\end{array}$ & & $\begin{array}{l}0.0917 \\
(0.182)\end{array}$ & \\
\hline Spouse has A-level(s) or higher & $\begin{array}{c}-0.2911 \\
(0.234)\end{array}$ & & $\begin{array}{l}0.1016 \\
(0.546)\end{array}$ & & $\begin{array}{c}-0.0222 \\
(0.182)\end{array}$ & \\
\hline Spouse's missing educational qualifications & $\begin{array}{c}-0.4654 \\
(0.335)\end{array}$ & & $\begin{array}{l}0.1343 \\
(0.733)\end{array}$ & & $\begin{array}{c}-0.2487 \\
(0.261)\end{array}$ & \\
\hline Number of children in $\mathrm{BU}=1$ & $\begin{array}{l}0.1907 \\
(0.109)\end{array}$ & $*$ & $\begin{array}{c}-0.0528 \\
(0.220)\end{array}$ & & $\begin{array}{l}0.1549 \\
(0.083)\end{array}$ & * \\
\hline Number of children in $\mathrm{BU}=2$ & $\begin{array}{l}0.1282 \\
(0.112)\end{array}$ & & $\begin{array}{c}-0.0964 \\
(0.217)\end{array}$ & & $\begin{array}{l}0.1431 \\
(0.087)\end{array}$ & \\
\hline Number of children in $\mathrm{BU}=3$ or more & $\begin{array}{l}0.3175 \\
(0.145)\end{array}$ & $* *$ & $\begin{array}{c}-0.0362 \\
(0.283)\end{array}$ & & $\begin{array}{l}0.4526 \\
(0.109)\end{array}$ & $* * *$ \\
\hline Age of youngest child $<5$ & $\begin{array}{l}0.4290 \\
(0.102)\end{array}$ & $* * *$ & $\begin{array}{l}0.2258 \\
(0.200)\end{array}$ & & $\begin{array}{l}0.2280 \\
(0.078)\end{array}$ & $* * *$ \\
\hline BU type: lone parent & $\begin{array}{l}1.1871 \\
(0.171)\end{array}$ & $* * *$ & $\begin{array}{l}1.8468 \\
(0.367)\end{array}$ & $* * *$ & $\begin{array}{l}1.1054 \\
(0.127)\end{array}$ & $* * *$ \\
\hline BU type: couple & $\begin{array}{c}-0.1685 \\
(0.342)\end{array}$ & & $\begin{array}{c}-0.0625 \\
(0.856)\end{array}$ & & $\begin{array}{c}-0.2816 \\
(0.253)\end{array}$ & \\
\hline House tenure: owned & $\begin{array}{c}-0.7847 \\
(0.079)\end{array}$ & $* * *$ & $\begin{array}{c}-1.0562 \\
(0.165)\end{array}$ & $* * *$ & $\begin{array}{c}-0.6618 \\
(0.059)\end{array}$ & $* * *$ \\
\hline Lives in London (inner or outer) & $\begin{array}{c}-0.0489 \\
(0.111)\end{array}$ & & $\begin{array}{c}-0.4867 \\
(0.296)\end{array}$ & & $\begin{array}{c}-0.0854 \\
(0.084)\end{array}$ & \\
\hline
\end{tabular}


Table B1. The probability of SA receipt at $t=1$ (initial conditions): basic specification

\begin{tabular}{|c|c|c|c|c|c|c|}
\hline \multirow[b]{2}{*}{ Unemployment rate in TTWA (\%) } & \multicolumn{2}{|c|}{$\begin{array}{l}\text { Unbalanced } \\
\text { panel, all } \\
\text { sequences start at } \\
\text { wave } 1 \\
\quad(1)\end{array}$} & \multicolumn{2}{|c|}{$\begin{array}{l}\text { Fifteen-wave } \\
\text { balanced panel } \\
\text { (2) } \\
\end{array}$} & \multicolumn{2}{|c|}{\begin{tabular}{l} 
Unbalanced panel, \\
excluding sequences \\
with continuous \\
receipt \\
\multicolumn{1}{c}{ (3) } \\
\end{tabular}} \\
\hline & $\begin{array}{c}0.0543 \\
(0.018)\end{array}$ & $* * *$ & $\begin{array}{c}0.0368 \\
(0.034)\end{array}$ & & $\begin{array}{l}0.0445 \\
(0.013)\end{array}$ & $* * *$ \\
\hline \multicolumn{7}{|l|}{ Instruments for SA receipt status at $t=1$} \\
\hline Mother's employment status missing & $\begin{array}{c}-0.1552 \\
(0.258)\end{array}$ & & $\begin{array}{c}-0.2481 \\
(0.535)\end{array}$ & & $\begin{array}{c}-0.3149 \\
(0.200)\end{array}$ & \\
\hline Mother not employed & $\begin{array}{l}0.1579 \\
(0.075)\end{array}$ & $* *$ & $\begin{array}{l}0.0373 \\
(0.142)\end{array}$ & & $\begin{array}{l}0.0958 \\
(0.055)\end{array}$ & * \\
\hline Mother not alive & $\begin{array}{l}0.2094 \\
(0.214)\end{array}$ & & $\begin{array}{c}-0.4777 \\
(1.086)\end{array}$ & & $\begin{array}{l}0.2393 \\
(0.177)\end{array}$ & \\
\hline Father's employment status missing & $\begin{array}{l}0.1420 \\
(0.193)\end{array}$ & & $\begin{array}{l}0.2038 \\
(0.371)\end{array}$ & & $\begin{array}{l}0.1288 \\
(0.136)\end{array}$ & \\
\hline Father not employed & $\begin{array}{l}0.0890 \\
(0.191)\end{array}$ & & $\begin{array}{c}-0.1189 \\
(0.372)\end{array}$ & & $\begin{array}{l}0.0274 \\
(0.135)\end{array}$ & \\
\hline Father not alive & $\begin{array}{c}-0.0689 \\
(0.167)\end{array}$ & & $\begin{array}{c}-0.2387 \\
(0.302)\end{array}$ & & $\begin{array}{c}-0.0845 \\
(0.127)\end{array}$ & \\
\hline Had job when first left full-time education & $\begin{array}{c}-0.1574 \\
(0.099)\end{array}$ & & $\begin{array}{c}-0.0518 \\
(0.206)\end{array}$ & & $\begin{array}{c}-0.0931 \\
(0.071)\end{array}$ & \\
\hline SEG $1^{\text {st }}$ job: manager or professional & $\begin{array}{c}-0.1119 \\
(0.234)\end{array}$ & & $\begin{array}{c}0.6394 \\
(0.384)\end{array}$ & * & $\begin{array}{c}0.0155 \\
(0.175)\end{array}$ & \\
\hline SEG $1^{\text {st }}$ job: non-manual & $\begin{array}{c}-0.2903 \\
(0.099)\end{array}$ & $* * *$ & $\begin{array}{l}0.1019 \\
(0.250)\end{array}$ & & $\begin{array}{c}-0.0924 \\
(0.077)\end{array}$ & \\
\hline SEG $1^{\text {st }}$ job: manual & $\begin{array}{c}-0.1136 \\
(0.092)\end{array}$ & & $\begin{array}{l}0.0717 \\
(0.244)\end{array}$ & & $\begin{array}{l}0.0221 \\
(0.072)\end{array}$ & \\
\hline SEG $1^{\text {st }}$ job: other & $\begin{array}{l}0.0206 \\
(0.191)\end{array}$ & & $\begin{array}{l}0.1347 \\
(0.440)\end{array}$ & & $\begin{array}{l}0.2292 \\
(0.137)\end{array}$ & $*$ \\
\hline \multicolumn{7}{|l|}{ Survey year } \\
\hline 1993 & & & & & $\begin{array}{l}0.0544 \\
(0.117)\end{array}$ & \\
\hline 1994 & & & & & $\begin{array}{l}0.0246 \\
(0.131)\end{array}$ & \\
\hline 1995 & & & & & $\begin{array}{l}0.1334 \\
(0.141)\end{array}$ & \\
\hline 1996 & & & & & $\begin{array}{l}0.1868 \\
(0.143)\end{array}$ & \\
\hline 1997 & & & & & $\begin{array}{l}0.1627 \\
(0.162)\end{array}$ & \\
\hline 1998 & & & & & $\begin{array}{l}0.0375 \\
(0.163)\end{array}$ & \\
\hline 1999 & & & & & $\begin{array}{l}0.0859 \\
(0.179)\end{array}$ & \\
\hline 2000 & & & & & $\begin{array}{c}-0.1013 \\
(0.199)\end{array}$ & \\
\hline 2001 & & & & & $\begin{array}{l}0.1501 \\
(0.179)\end{array}$ & \\
\hline 2002 & & & & & $\begin{array}{c}-0.4039 \\
(0.232)\end{array}$ & * \\
\hline 2003 & & & & & $\begin{array}{c}-0.1627 \\
(0.225)\end{array}$ & \\
\hline
\end{tabular}


DELSA/ELSA/WD/SEM(2008)4

Table B1. The probability of SA receipt at $t=1$ (initial conditions): basic specification

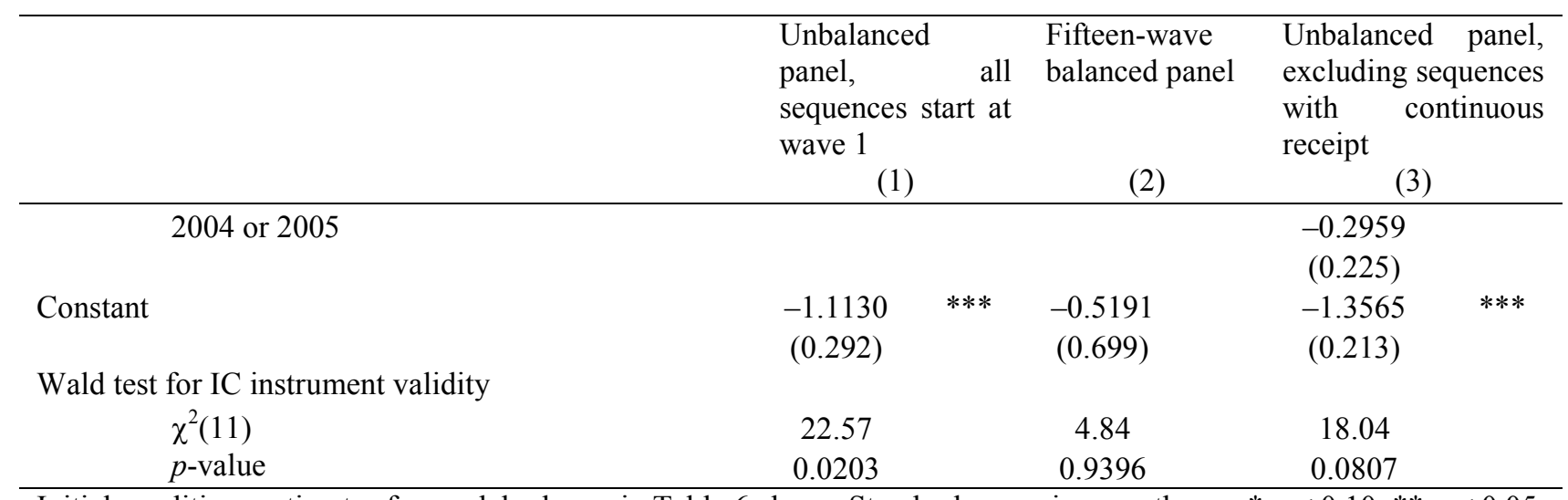

Initial conditions estimates for models shown in Table 6 above. Standard errors in parentheses. $* p<0.10, * * p<0.05$, $* * * p<0.01$. Test for instrument validity is a test that coefficients on all instruments are jointly zero. 
Table B2. The probability of SA receipt at $t=1$ (initial conditions): specifications including with interactions between lagged receipt, survey year, and lone parent status

\begin{tabular}{|c|c|c|c|c|c|c|c|c|}
\hline & \multirow{2}{*}{$\begin{array}{l}\text { Survey year } \\
\text { interactions } \\
\text { (1) }\end{array}$} & & \multicolumn{6}{|c|}{ Survey year and lone parent interactions } \\
\hline & & & (2) & & (3) & & (4) & \\
\hline Age (years) & $\begin{array}{c}-0.0016 \\
(0.004)\end{array}$ & & $\begin{array}{c}-0.0014 \\
(0.004)\end{array}$ & & $\begin{array}{c}-0.0013 \\
(0.004)\end{array}$ & & $\begin{array}{l}-0.0011 \\
(0.004)\end{array}$ & \\
\hline Female & $\begin{array}{c}-0.0352 \\
(0.058)\end{array}$ & & $\begin{array}{c}-0.0321 \\
(0.058)\end{array}$ & & $\begin{array}{c}-0.0310 \\
(0.058)\end{array}$ & & $\begin{array}{c}-0.0313 \\
(0.058)\end{array}$ & \\
\hline Has health problem(s) & $\begin{array}{l}0.2659 \\
(0.053)\end{array}$ & $* * *$ & $\begin{array}{l}0.2604 \\
(0.054)\end{array}$ & $* * *$ & $\begin{array}{l}0.2595 \\
(0.053)\end{array}$ & $* * *$ & $\begin{array}{l}0.2597 \\
(0.053)\end{array}$ & $* * *$ \\
\hline Educational qualifications & & & & & & & & \\
\hline O-level(s), CSE, etc. & $\begin{array}{c}-0.2650 \\
(0.071)\end{array}$ & $* * *$ & $\begin{array}{c}-0.2693 \\
(0.071)\end{array}$ & $* * *$ & $\begin{array}{c}-0.2668 \\
(0.071)\end{array}$ & $* * *$ & $\begin{array}{c}-0.2650 \\
(0.071)\end{array}$ & $* * *$ \\
\hline A-level(s) or higher & $\begin{array}{c}-0.6033 \\
(0.078)\end{array}$ & $* * *$ & $\begin{array}{c}-0.6100 \\
(0.078)\end{array}$ & $* * *$ & $\begin{array}{c}-0.6086 \\
(0.078)\end{array}$ & $* * *$ & $\begin{array}{c}-0.6036 \\
(0.078)\end{array}$ & $* * *$ \\
\hline Missing & $\begin{array}{c}-0.9621 \\
(0.119)\end{array}$ & $* * *$ & $\begin{array}{c}-0.9665 \\
(0.120)\end{array}$ & $* * *$ & $\begin{array}{r}-0.9707 \\
(0.119)\end{array}$ & $* * *$ & $\begin{array}{l}-0.9777 \\
(0.119)\end{array}$ & $* * *$ \\
\hline Spouse's age (years) & $\begin{array}{c}-0.0034 \\
(0.005)\end{array}$ & & $\begin{array}{c}-0.0042 \\
(0.005)\end{array}$ & & $\begin{array}{c}-0.0045 \\
(0.005)\end{array}$ & & $\begin{array}{c}-0.0046 \\
(0.005)\end{array}$ & \\
\hline Spouse: no educational qualifications & $\begin{array}{l}0.2662 \\
(0.179)\end{array}$ & & $\begin{array}{l}0.2654 \\
(0.180)\end{array}$ & & $\begin{array}{l}0.2745 \\
(0.179)\end{array}$ & & $\begin{array}{l}0.2803 \\
(0.179)\end{array}$ & \\
\hline Spouse has O-level(s), CSE, etc & $\begin{array}{c}-0.0090 \\
(0.176)\end{array}$ & & $\begin{array}{c}-0.0100 \\
(0.178)\end{array}$ & & $\begin{array}{l}0.0019 \\
(0.176)\end{array}$ & & $\begin{array}{l}0.0053 \\
(0.176)\end{array}$ & \\
\hline Spouse has A-level(s) or higher & $\begin{array}{c}-0.1373 \\
(0.176)\end{array}$ & & $\begin{array}{c}-0.1478 \\
(0.177)\end{array}$ & & $\begin{array}{c}-0.1385 \\
(0.176)\end{array}$ & & $\begin{array}{c}-0.1298 \\
(0.176)\end{array}$ & \\
\hline Spouse's missing educational qualifications & $\begin{array}{c}-0.4471 \\
(0.261)\end{array}$ & $*$ & $\begin{array}{c}-0.4529 \\
(0.262)\end{array}$ & $*$ & $\begin{array}{c}-0.4442 \\
(0.261)\end{array}$ & * & $\begin{array}{c}-0.4439 \\
(0.261)\end{array}$ & $*$ \\
\hline Number of children in $\mathrm{BU}=1$ & $\begin{array}{l}0.2318 \\
(0.083)\end{array}$ & $* * *$ & $\begin{array}{l}0.2321 \\
(0.084)\end{array}$ & $* * *$ & $\begin{array}{l}0.2293 \\
(0.083)\end{array}$ & $* * *$ & $\begin{array}{l}0.2282 \\
(0.083)\end{array}$ & $* * *$ \\
\hline Number of children in $\mathrm{BU}=2$ & $\begin{array}{l}0.2928 \\
(0.086)\end{array}$ & $* * *$ & $\begin{array}{l}0.2864 \\
(0.087)\end{array}$ & $* * *$ & $\begin{array}{l}0.2863 \\
(0.086)\end{array}$ & $* * *$ & $\begin{array}{l}0.2830 \\
(0.086)\end{array}$ & $* * *$ \\
\hline Number of children in $\mathrm{BU}=3$ or more & $\begin{array}{l}0.5540 \\
(0.112)\end{array}$ & $* * *$ & $\begin{array}{l}0.5294 \\
(0.113)\end{array}$ & $* * *$ & $\begin{array}{l}0.5319 \\
(0.111)\end{array}$ & $* * *$ & $\begin{array}{l}0.5333 \\
(0.111)\end{array}$ & $* * *$ \\
\hline
\end{tabular}


DELSA/ELSA/WD/SEM(2008)4

Table B2. The probability of SA receipt at $t=1$ (initial conditions): specifications including with interactions between lagged receipt, survey year, and lone parent status

\begin{tabular}{|c|c|c|c|c|c|c|c|c|}
\hline & \multirow{2}{*}{$\begin{array}{c}\text { Survey year } \\
\text { interactions } \\
\text { (1) }\end{array}$} & \multicolumn{6}{|c|}{ Survey year and lone parent interactions } & \\
\hline & & & $(2)$ & & (3) & & (4) & \\
\hline Age of youngest child $<5$ & $\begin{array}{l}0.2446 \\
(0.079)\end{array}$ & $* * *$ & $\begin{array}{l}0.2490 \\
(0.079)\end{array}$ & $* * *$ & $\begin{array}{l}0.2479 \\
(0.078)\end{array}$ & $* * *$ & $\begin{array}{l}0.2481 \\
(0.078)\end{array}$ & $* * *$ \\
\hline BU type: lone parent & $\begin{array}{l}1.2527 \\
(0.129)\end{array}$ & $* * *$ & $\begin{array}{l}1.2635 \\
(0.129)\end{array}$ & $* * *$ & $\begin{array}{l}1.2573 \\
(0.129)\end{array}$ & $* * *$ & $\begin{array}{l}1.2608 \\
(0.129)\end{array}$ & $* * *$ \\
\hline BU type: couple & $\begin{array}{c}-0.1632 \\
(0.244)\end{array}$ & & $\begin{array}{c}-0.1219 \\
(0.245)\end{array}$ & & $\begin{array}{c}-0.1163 \\
(0.244)\end{array}$ & & $\begin{array}{c}-0.1145 \\
(0.244)\end{array}$ & \\
\hline House tenure: owned & $\begin{array}{c}-0.7886 \\
(0.058)\end{array}$ & $* * *$ & $\begin{array}{c}-0.7856 \\
(0.058)\end{array}$ & $* * *$ & $\begin{array}{r}-0.7770 \\
(0.058)\end{array}$ & $* * *$ & $\begin{array}{c}-0.7786 \\
(0.058)\end{array}$ & $* * *$ \\
\hline Lives in London (inner or outer) & $\begin{array}{c}-0.0976 \\
(0.087)\end{array}$ & & $\begin{array}{c}-0.0992 \\
(0.087)\end{array}$ & & $\begin{array}{c}-0.0917 \\
(0.087)\end{array}$ & & $\begin{array}{c}-0.0932 \\
(0.087)\end{array}$ & \\
\hline Unemployment rate in TTWA $(\%)$ & $\begin{array}{l}0.0629 \\
(0.014)\end{array}$ & $* * *$ & $\begin{array}{l}0.0641 \\
(0.014)\end{array}$ & $* * *$ & $\begin{array}{l}0.0634 \\
(0.014)\end{array}$ & $* * *$ & $\begin{array}{l}0.0624 \\
(0.014)\end{array}$ & $* * *$ \\
\hline \multicolumn{9}{|l|}{ Survey year } \\
\hline 1993 & $\begin{array}{l}0.2671 \\
(0.120)\end{array}$ & $* *$ & $\begin{array}{l}0.2612 \\
(0.121)\end{array}$ & $* *$ & $\begin{array}{l}0.2621 \\
(0.120)\end{array}$ & $* *$ & $\begin{array}{l}0.2570 \\
(0.119)\end{array}$ & $* *$ \\
\hline 1994 & $\begin{array}{l}0.1387 \\
(0.134)\end{array}$ & & $\begin{array}{l}0.1341 \\
(0.135)\end{array}$ & & $\begin{array}{l}0.1269 \\
(0.134)\end{array}$ & & $\begin{array}{l}0.1188 \\
(0.133)\end{array}$ & \\
\hline 1995 & $\begin{array}{l}0.3035 \\
(0.138)\end{array}$ & $* *$ & $\begin{array}{l}0.3236 \\
(0.139)\end{array}$ & $* *$ & $\begin{array}{l}0.3196 \\
(0.139)\end{array}$ & $* *$ & $\begin{array}{l}0.3076 \\
(0.138)\end{array}$ & $* *$ \\
\hline 1996 & $\begin{array}{l}0.3533 \\
(0.148)\end{array}$ & $* *$ & $\begin{array}{l}0.3566 \\
(0.148)\end{array}$ & $* *$ & $\begin{array}{l}0.3502 \\
(0.148)\end{array}$ & $* *$ & $\begin{array}{l}0.3472 \\
(0.148)\end{array}$ & $* *$ \\
\hline 1997 & $\begin{array}{l}0.4934 \\
(0.163)\end{array}$ & $* * *$ & $\begin{array}{l}0.5065 \\
(0.164)\end{array}$ & $* * *$ & $\begin{array}{l}0.5000 \\
(0.162)\end{array}$ & $* * *$ & $\begin{array}{l}0.5004 \\
(0.162)\end{array}$ & $* * *$ \\
\hline 1998 & $\begin{array}{l}0.2640 \\
(0.172)\end{array}$ & & $\begin{array}{l}0.2821 \\
(0.173)\end{array}$ & & $\begin{array}{l}0.2738 \\
(0.173)\end{array}$ & & $\begin{array}{l}0.2598 \\
(0.172)\end{array}$ & \\
\hline 1999 & $\begin{array}{l}0.3738 \\
(0.174)\end{array}$ & $* *$ & $\begin{array}{l}0.3957 \\
(0.175)\end{array}$ & $* *$ & $\begin{array}{l}0.3932 \\
(0.173)\end{array}$ & $* *$ & $\begin{array}{l}0.3846 \\
(0.173)\end{array}$ & $* *$ \\
\hline 2000 & $\begin{array}{l}0.3110 \\
(0.202)\end{array}$ & & $\begin{array}{l}0.3043 \\
(0.203)\end{array}$ & & $\begin{array}{l}0.2939 \\
(0.202)\end{array}$ & & $\begin{array}{l}0.2844 \\
(0.202)\end{array}$ & \\
\hline
\end{tabular}


Table B2. The probability of SA receipt at $t=1$ (initial conditions): specifications including with interactions between lagged receipt, survey year, and lone parent status

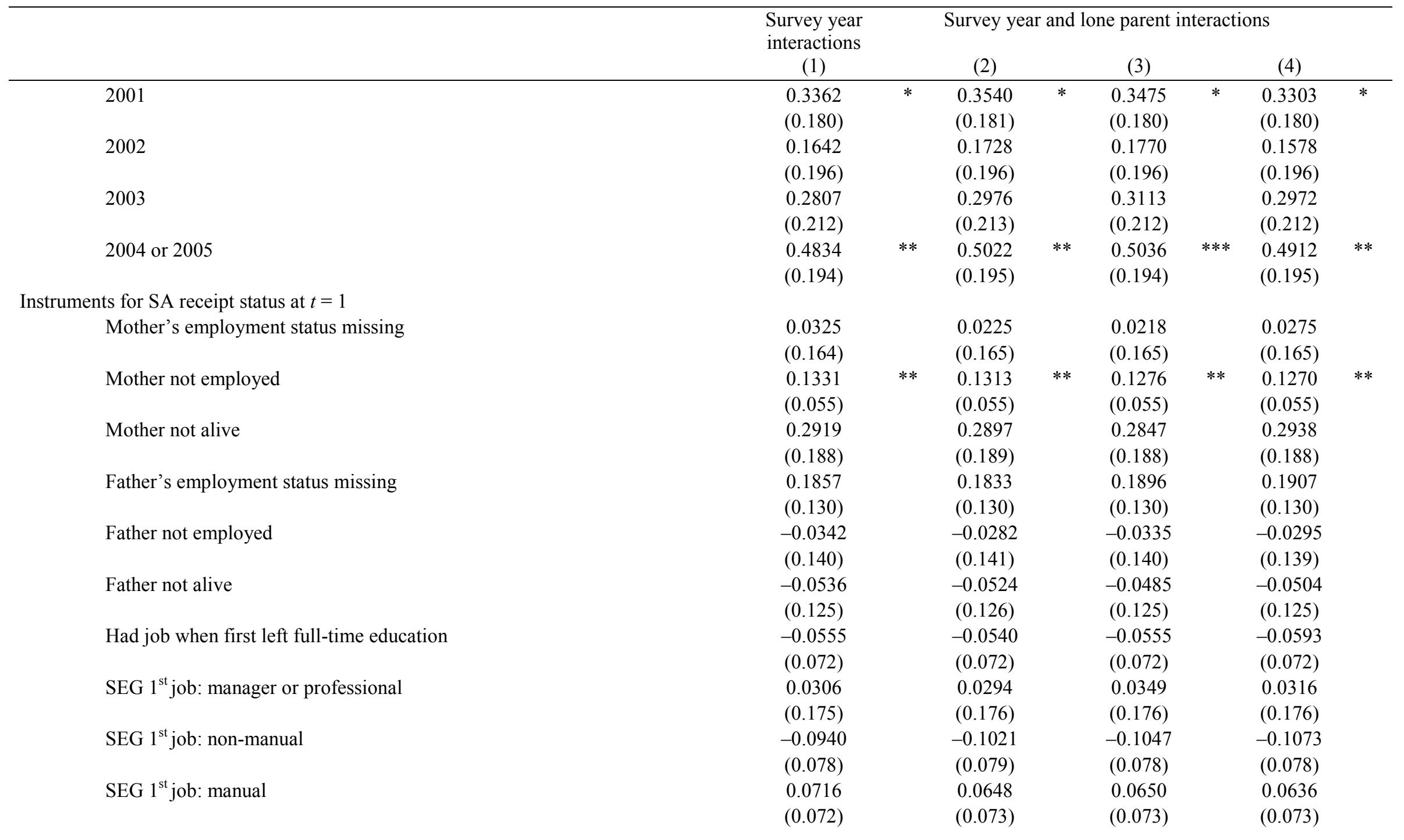


DELSA/ELSA/WD/SEM(2008)4

Table B2. The probability of SA receipt at $t=1$ (initial conditions): specifications including with interactions between lagged receipt, survey year, and lone parent status

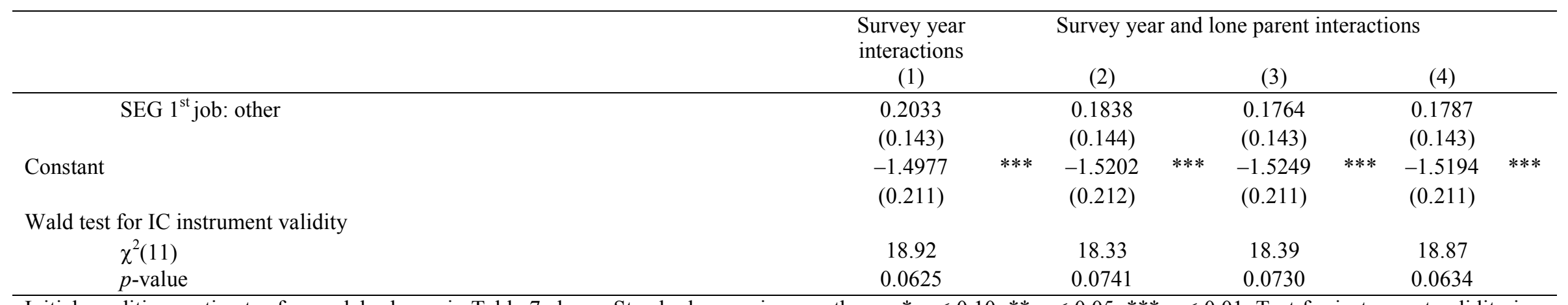

Initial conditions estimates for models shown in Table 7 above. Standard errors in parentheses. $* p<0.10, * * p<0.05$, *** $p<0.01$. Test for instrument validity is a test that coefficients on all instruments are jointly zero. 


\section{OECD SOCIAL, EMPLOYMENT AND MIGRATION WORKING PAPERS}

Most recent releases are:

No. 66 REFORMING RETIREMENT-INCOME SYSTEMS: LESSONS FROM THE RECENT EXPERIENCES OF OECD COUNTRIES

John P. Martin and Edward Whitehouse (2008)

No. 65 THE JOINT DISTRIBUTION OF HOUSEHOLD INCOME AND WEALTH: EVIDENCE FROM THE LUXEMBOURG WEALTH STUDY

Markus Jantti, Eva Sierminska and Tim Smeeding (2008)

No. 64 A REVIEW OF STUDIES ON THE DISTRIBUTIONAL IMPACT OF CONSUMPTION TAXES IN OECD COUNTRIES

Neil Warren (2008)(Forthcoming)

No. 63 GLOBALISATION AND LABOUR MARKETS: POLICY ISUES ARISING FROM THE EMERGENCE OF CHINA AND INDIA

David T. Coe (2007)

No. 62 MIGRANT WOMEN INTO WORK - WHAT IS WORKING?

Alexandra Heron (2008) Forthcoming

No. 61 ADDRESSING LABOUR MARKET DUALITY IN KOREA

David Grubb, Jae-Kap Lee and Peter Tergeist (2007)

No. 60 LIFE-EXPECTANCY RISK AND PENSIONS: WHO BEARS THE BURDEN?

Edward Whitehouse (2007)

No. 59 AUDIT DU SERVICE PUBLIC DE L'EMPLOI AU LUXEMBOURG

David Grubb (2007)

No. 58 TRENDS IN INTERNATIONAL MIGRATION FLOWS AND STOCKS, 1975-2005

B. Lindsay Lowell (2007)

No.57 UNAUTHORIZED MIGRANTS IN THE UNITED STATES: ESTIMATES, METHODS, AND

CHARACTERISTICS (2007)

Jeffrey Passel

No. 56 LA POLITIQUE MIGRATOIRE FRANÇAISE À UN TOURNANT (2007)

Martine Durand et Georges Lemaître

No. 55 THE UNIFICATION OF THE SOCIAL INSURANCE CONTRIBUTION COLLECTION SYSTEM IN KOREA (2007)

Sinchul Jang

No. 54 ASSESSING THE IMPACT OF LABOUR MARKET POLICIES ON PRODUCTIVITY: A DIFFERENCE-IN-DIFFERENCES APPROACH (2007)

Andrea Bassanini and Danielle Venn

No. 53 PENSION REFORM IN CHINA: PROGRESS AND PROSPECTS (2007)

Felix Salditt, Peter Whiteford and Willem Adema

No. 52 INTERGENERATIONAL TRANSMISSION OF DISADVANTAGE: MOBILITY OR IMMOBILITY ACROSS GENERATIONS? A REVIEW OF THE EVIDENCE FOR OECD COUNTRIES (2007)

Anna Christina d'Addio

No. 51 WHAT WORKS BEST IN REDUCING CHILD POVERTY: A BENEFIT OR WORK STRATEGY? (2007)

Peter Whiteford and Willem Adema

Other series of working papers available from the OECD include: OECD HEALTH WORKING PAPERS 


\section{RECENT RELATED OECD PUBLICATIONS:}

JOBS FOR YOUTH: CANADA (2008)

JOBS FOR YOUTH: NETHERLANDS (2008)

JOBS FOR YOUTH: NEW ZEALAND (2008)

JOBS FOR YOUTH: NORWAY (2008)

JOBS FOR YOUTH: UNITED KINGDOM (2008)

A PROFILE OF IMMIGRANT POPULATIONS IN THE $21^{\text {ST }}$ CENTURY (2008)

OECD EMPLOYMENT OUTLOOK (2008)

INTERNATIONAL MIGRATION OUTLOOK - 2008 Edition

MODERNISING SOCIAL POLICY FOR THE NEW LIFE COURSE (2007)

BABIES AND BOSSES - Reconciling Work and Family Life: A Synthesis of Findings for OECD Countries (2007)

BENEFITS AND WAGES - OECD Indicators (2007)

JOBS FOR IMMIGRANTS (VOL. 1): LABOUR MARKET INTEGRATION IN AUSTRALIA, DENMARK, GERMANY AND SWEDEN (2007)

FACING THE FUTURE: KOREA'S FAMILY, PENSION AND HEALTH POLICY CHALLENGES (2007)

PENSIONS AT A GLANCE: Public policies across OECD countries (2007)

JOBS FOR YOUTH: KOREA (2007)

JOBS FOR YOUTH: BELGIUM (2007)

JOBS FOR YOUTH: SPAIN (2007)

JOBS FOR YOUTH: SLOVAK REPUBLIC (2007)

SICKNESS, DISABILITY AND WORK: BREAKING THE BARRIERS (VOL. 2) - AUSTRALIA, LUXEMBOURG, SPAIN AND THE UNITED KINGDOM (2007)

WOMEN AND MEN IN OECD COUNTRIES (2006)

SOCIETY AT A GLANCE: OECD Social Indicators (2006)

PENSIONS PANORAMA: RETIREMENT INCOME SYSTEMS IN 53 COUNTRIES

(joint publication with the World Bank) (2006)

SICKNESS, DISABILITY AND WORK: BREAKING THE BARRIERS (VOL. 1) - NORWAY, POLAND AND SWITZERLAND (2006)

AGEING AND EMPLOYMENT POLICIES: LIVE LONGER, WORK LONGER (2006)

For a full list, consult the OECD On-Line Bookstore at www.oecd.org 